A Statistical Analysis of Satellite-Observed Trade Wind Cloud Clusters in the Western North Pacific

\author{
By \\ Knox T. Williams \\ Project Leader: \\ William M. Gray
}

Department of Atmospheric Science

Colorado State University

Fort Collins, Colorado

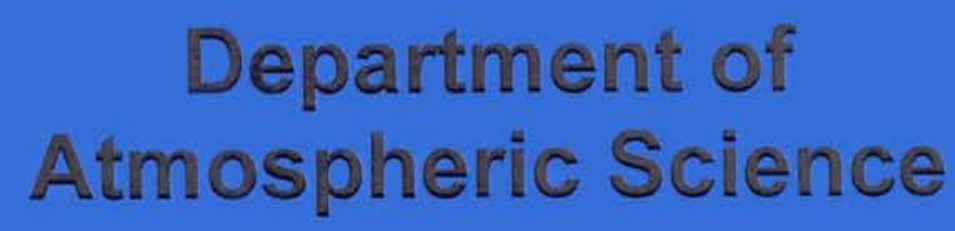

Paper No. 161 


\title{
A STATISTICAL ANALYSIS OF SATELLITE-OBSERVED TRADE WIND CLOUD CLUSTERS IN THE WESTERN NORTH PACIFIC
}

\author{
by \\ Knox T. Williams \\ Preparation of this report \\ has been supported by \\ ESSA E - $233-68(\mathrm{G})$ \\ Department of Atmospheric Science \\ Colorado State University \\ Fort Collins, Colorado

$$
\text { June, } 1970
$$

Atmospheric Science Paper No. 161 


\section{ABSTRACT}

Composite upper-air soundings have been constructed relative to 1257 individual satellite-observed mesoscale $\left(3-6^{\circ}\right.$ latitude) trade wind cloud clusters in the western tropical North Pacific. Clusters have been stratified into five categories: pre-storm clusters (166 cases treated), developing clusters (211), conservative clusters (537), non-conservative clusters (135), and dying clusters (208). A sixth category has been specified for clear areas (553). Rawinsonde observations from 14 island stations for the two-year period of October 1966 to October 1968 provide composited data for 16 pressure levels from the surface to $30 \mathrm{mb}$. Approximately 12, 000 observations make up the data sample. Computerized composited summaries for each group of clusters have been made from Northern Hemisphere Data Tabulations (NHDT) tapes for wind, vorticity, divergence, kinetic energy, temperature, moisture, stability, and isobaric heights. Mass and thermal balances are very well satisfied by the composited data.

Significant differences in the low-level horizontal wind shears exist among the six categories. The pre-storm and developing clusters exhibit large low-level cyclonic shears, whereas the remaining cloud categories show weaker cyclonic shears. The clear areas show a marked anticyclonic low-level wind shear. The relative vorticities are mostly determined by shears of the zonal wind. East-west shears of the meridional wind are of secondary importance. These cloud clusters may be viewed as typical of the usual easterly trade wave only if the latter is primarily interpreted as a shearing phenomena of the zonal trade wind.

These observations support the contention of Charney (1958), Charney and Eliassen (1964), and Gray (1968) that low-level frictionally forced convergence (i. e., conditional instability of the second kind, or CISK) in the zonal shearing environment north of the equatorial trough is the mechanism for producing and maintaining these clusters (some of which later develop into typhoons). 
TABLE OF CONTENTS

$\underline{\text { Page }}$

Abstract ......................... iii

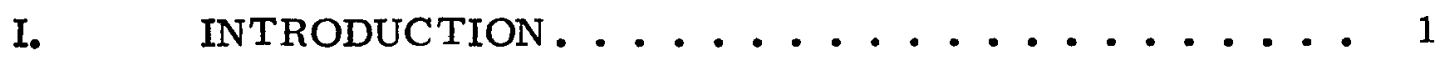

A. Background ................ 1

B. Purpose................. 3

II. TECHNIQUE................. 4

A. Area of Study and Data Sources ........ 4

B. Classification of Clusters ......... 12

C. Compositing Procedure........... 13

III. DESCRIPTION OF TROPICAL CLOUD CLUSTERS. . . 21

A. Dynamic Properties ............ 21

1. Wind Field at Cloud Center ........ 21

2. Horizontal Shears and Relative Vorticity . . . 21

3. Observed and Interpreted Divergence Profiles 33

4. Moisture Convergence.......... 46

5. Vertical Velocity. ........... 48

6. Vertical Wind Shear........... 52

7. Kinetic Energy Budget. . . . . . . . 53

8. Absolute Vorticity Budget ........ 59

9. Contrast with Clear Areas. . . . . . . 63

B. Thermodynamic Properties ........ 63

1. Temperature and Moisture ....... 63

2. Stability ............... 64

3. Temperature and Thickness Considerations . 66

4. Comparison of Cluster Categories .... 68

IV. SUMMARY DISCUSSION................ 69

Acknowledgements. ............. 72

Appendix........................ 73

References ................. 77 


\section{INTRODUCTION}

\section{Background}

In the pre-satellite era, daily observations of the tropical atmosphere were limited to widely spaced conventional rawinsonde observations. With the launching of the daily ESSA weather satellites in 1966, a new observational tool became available to meteorologists. In particular, weather satellites have allowed the observation and documentation of the trade wind mesoscale (typically $3-6^{\circ}$ latitude) cloud clusters ${ }^{1}$ (see Figs. 9-12) forming, moving and dying over the tropical oceans. These clusters have recently attracted attention because of their hypothesized important role in the general circulation and as spawners of tropical storms. Sadler (1962), Fett (1964), and Fritz et al. (1966) were the first to investigate extensively satellite-observed trade wind clusters and discuss their later development intotropical cyclones. Recent satellite studies of wave disturbances in the Atlantic trades have been accomplished by Frank (1969, 1970), Frank and Johnson (1969), and Simpson et al. $(1968,1969)$. Recent satellite studies in the Pacific trades have been made by Wallace and Chang (1969), Chang et al. (1970), and Chang (1970). In general these studies have not had available or have not extensively considered the conventional

${ }^{1}$ This name was adopted in the GARP Report (1968). 
rawinsonde information associated with the satellite cloud pictures. In 1969 , the later phases of Project $\mathrm{BOMEX}^{1}$ investigated trade wind cloud clusters, and in the $1970^{\prime}$ 's the GARP Tropical Cloud Cluster Experiment will be implemented. It is important that we learn as much as we can about the dynamics of these clusters now. This study was accomplished with this in mind.

A cloud cluster appears in a satellite photograph as a solid white mass, an appearance due to the large cirrus canopies typically associated with them. These cirrus canopies are produced by outflow from and remnants of the cumulonimbi. In general, developing and conservative clusters maintain their cumulonimbi from a steady low-level mass convergence; clusters gradually die when their low-level mass convergence is eliminated ${ }^{2}$. Clusters sometimes lose a large part of their cloudiness due to temporary stabilizing buoyancy changes from cumulus downdrafts as proposed by Riehl and Malkus (1958) and documented by Zipser (1969).

${ }^{1}$ Barbados Oceanographic and Meteorological Experiment. During this project, the author participated in several flight missions into cloud clusters.

2 The 1969 BOMEX project well documented the 3 to 9 hour or more time lag between the satellite-viewed cirrus canopies of dying clusters and the active cumulonimbus clouds which produced them. Flying under the satellite-observed cirrus, one often ob-. served very few cumulonimbi. 
Purpose

The purpose of this study is to describe the dynamic and thermodynamic features of the typical satellite-observed mesoscale trade wind cloud cluster as revealed by rawinsonde data composited relative to the cluster center. Clusters have been stratified into several categories based on their daily life cycles. For contrast, trade wind clear areas have also been composited. These are representative of the clear environment surrounding the clusters.

Most previous tropical cloud cluster investigations have been accomplished on individual cases or have used only conventional or only satellite information by itself [for example, Chang (1970) and Fujita et al. (1969)]. The present study represents a new approach: the use of both conventional rawinsonde data and satellite data simultaneously in a large statistical survey of individual cluster types. 


\section{TECHNIQUE}

\section{Area of Study and Data Sources}

The western tropical North Pacific Ocean from latitude $0^{\circ}$ to $30^{\circ} \mathrm{N}$ and longitude $120^{\circ} \mathrm{E}$ to $170^{\circ} \mathrm{W}$ was chosen as the study area because of the high incidence of clusters (and tropical storms) and also because here exists the world's best broad-scale tropical upper-air network. Fig. 1 shows the study area and the 14 island stations making up the data network.

Composite upper-air soundings have been constructed relative to 1257 individual satellite-observed trade wind clusters in this area. Five categories of clusters were established: pre-storm clusters (166 cases treated), developing clusters (211), conservative clusters (537), non-conservative or developing-dying clusters (135), and dying clusters (208). Clear areas (553) make up a sixth category. Figs. 2-7 show the positions of all the clusters making up each category. Rawinsonde data from the 14 stations for the twoyear period of October 1966 to October 1968 provide composited data for 16 pressure levels from the surface to $30 \mathrm{mb}$. Approximately 12,000 radiosonde observations make up the data sample. Computerized composited summaries for each group of clusters have been made from Northern Hemisphere Data Tabulations (NHDT) tapes for wind, vorticity, divergence, kinetic energy, temperature, moisture, stability, and isobaric heights. The $00 \mathrm{Z}$ data were 


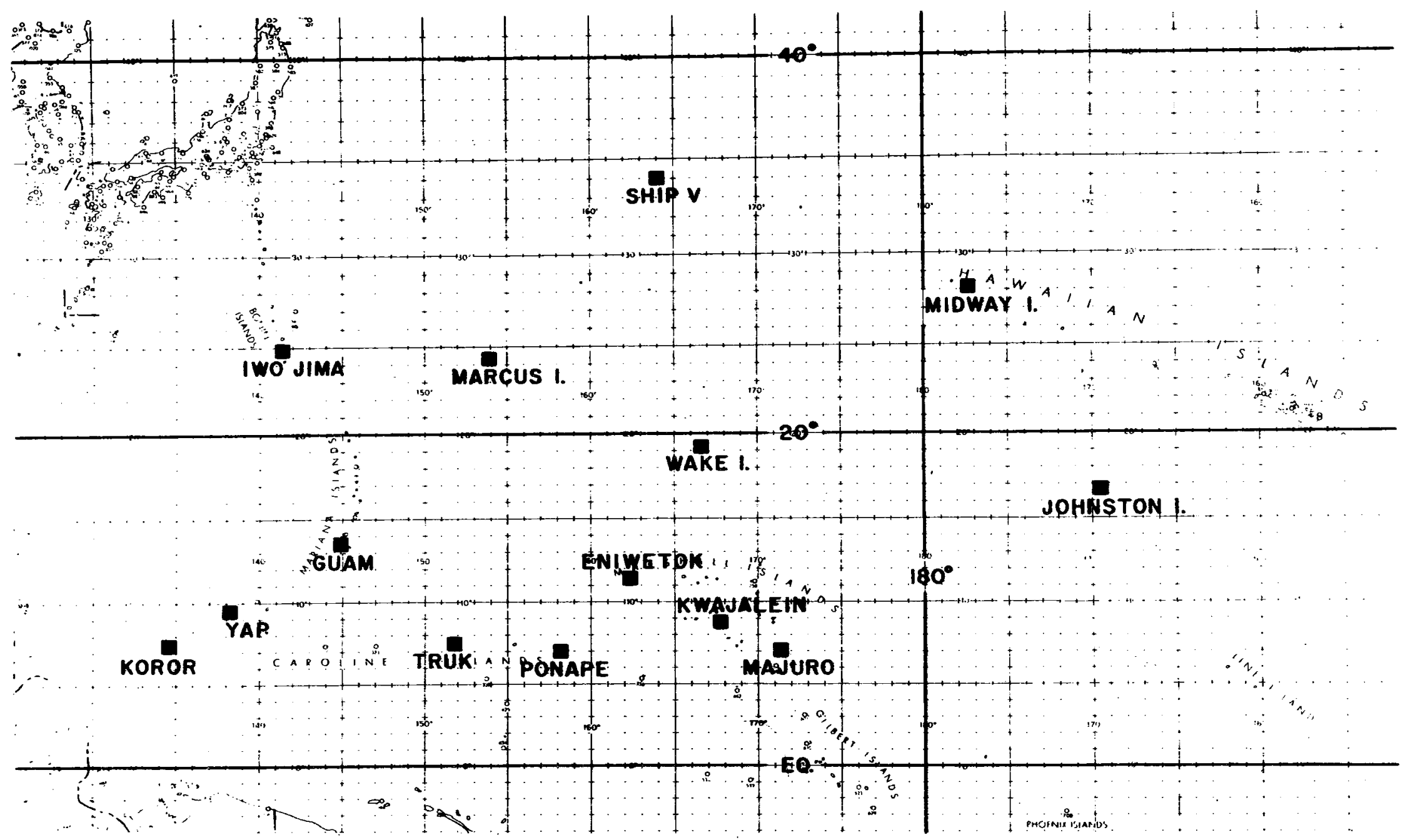

Fig. 1. Upper air stations within the study area. 


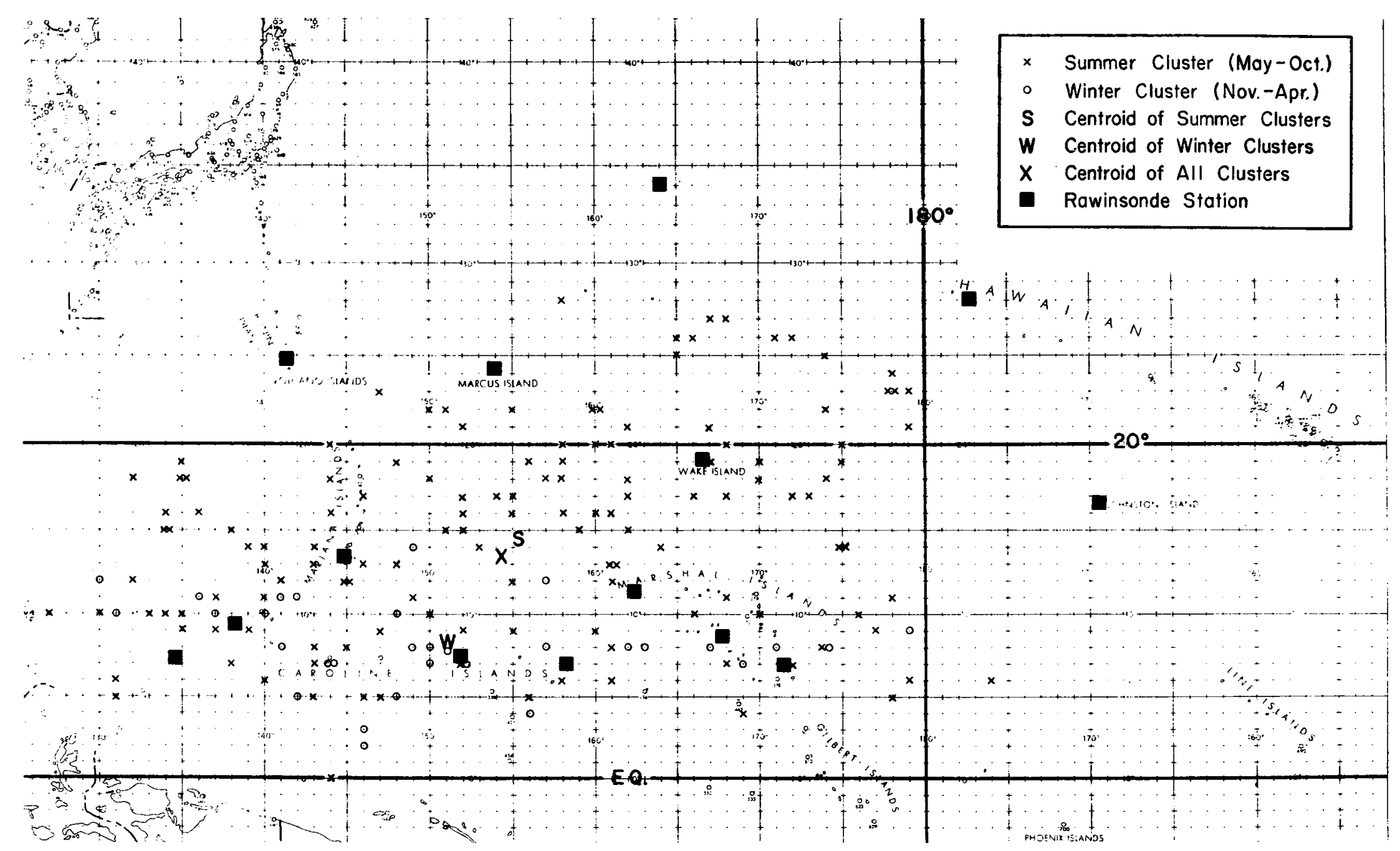

Fig. 2. Positions ( $x^{\prime} s$ and o's) of all (166) pre-storm clusters in data sample. 


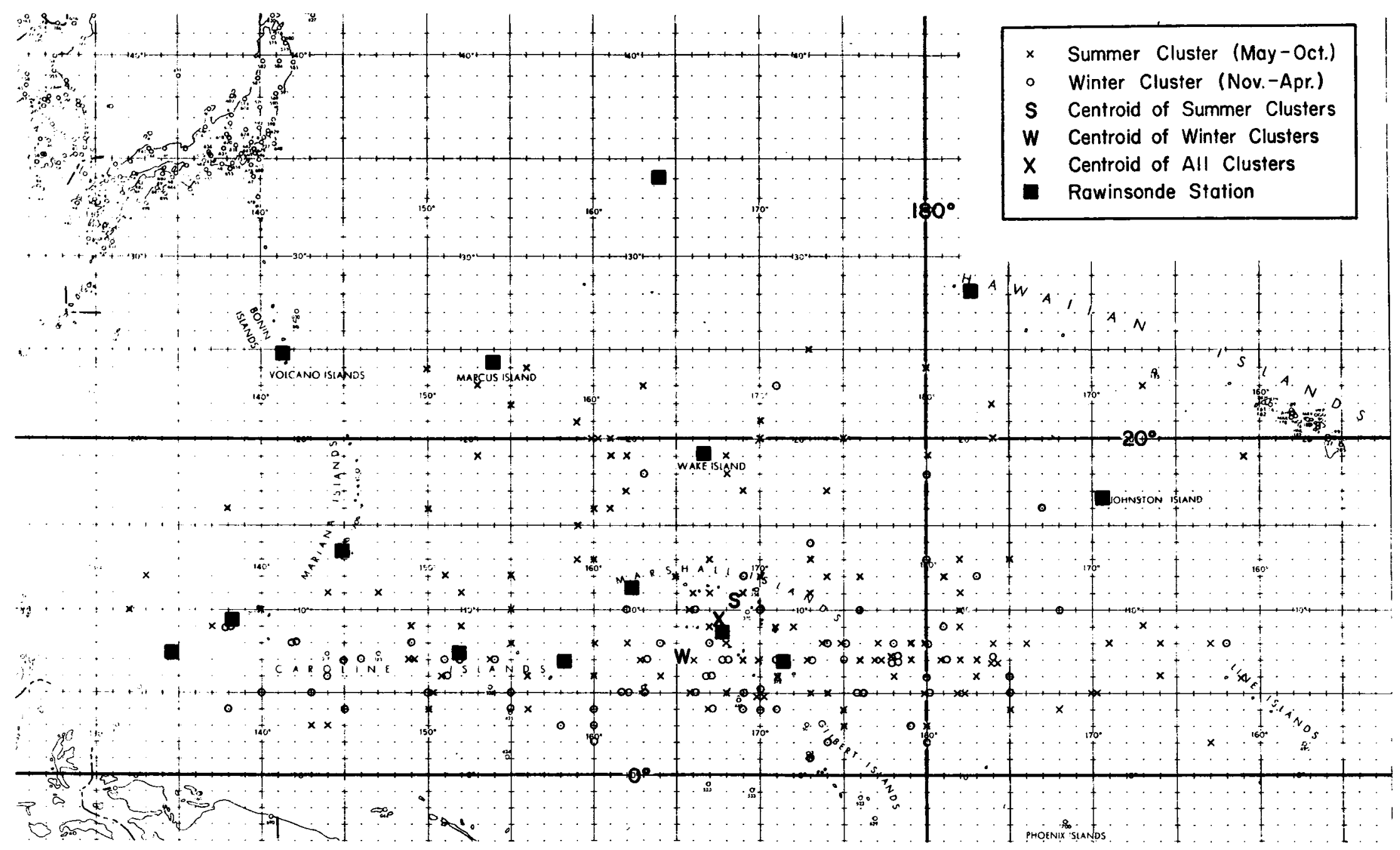

Fig. 3. Positions ( $x^{\prime} s$ and $o^{\prime} s$ ) of all (211) developing clusters in data sample. 


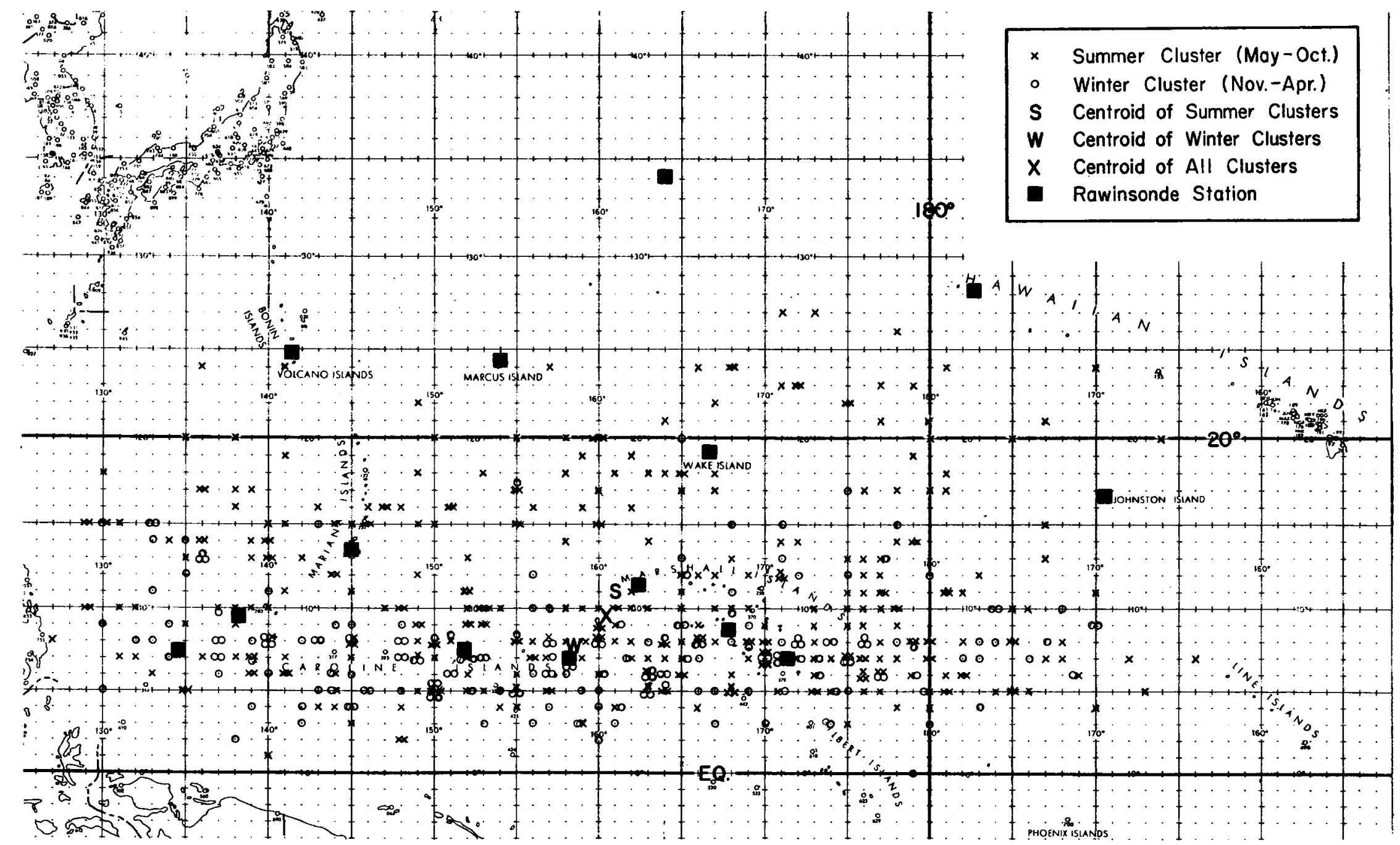

Fig. 4. Positions (x's and o's) of all (537) conservative clusters in data sample. 


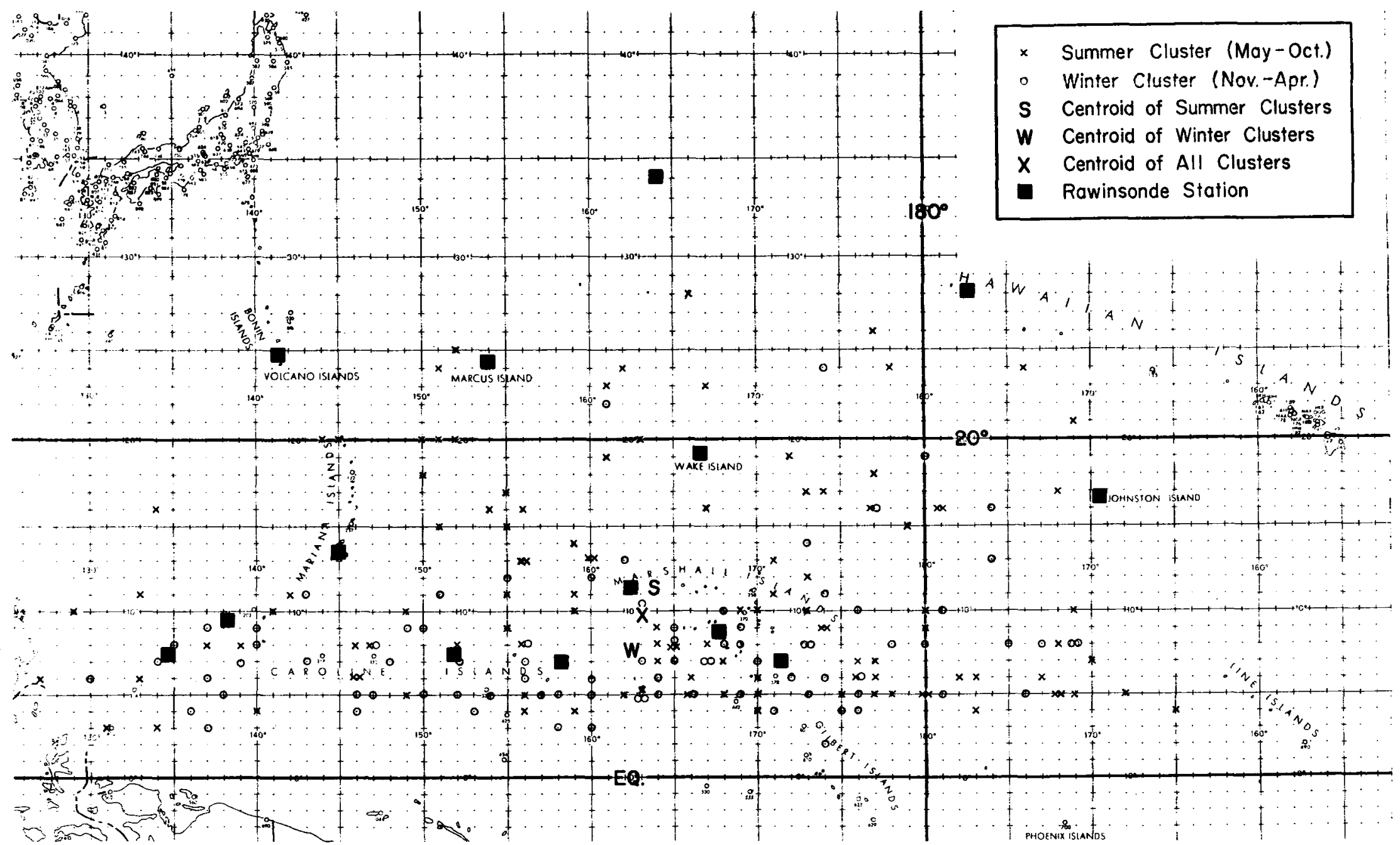

Fig. 5. Positions ( $x^{\prime} s$ and o's) of all (208) dying clusters in data sample. 


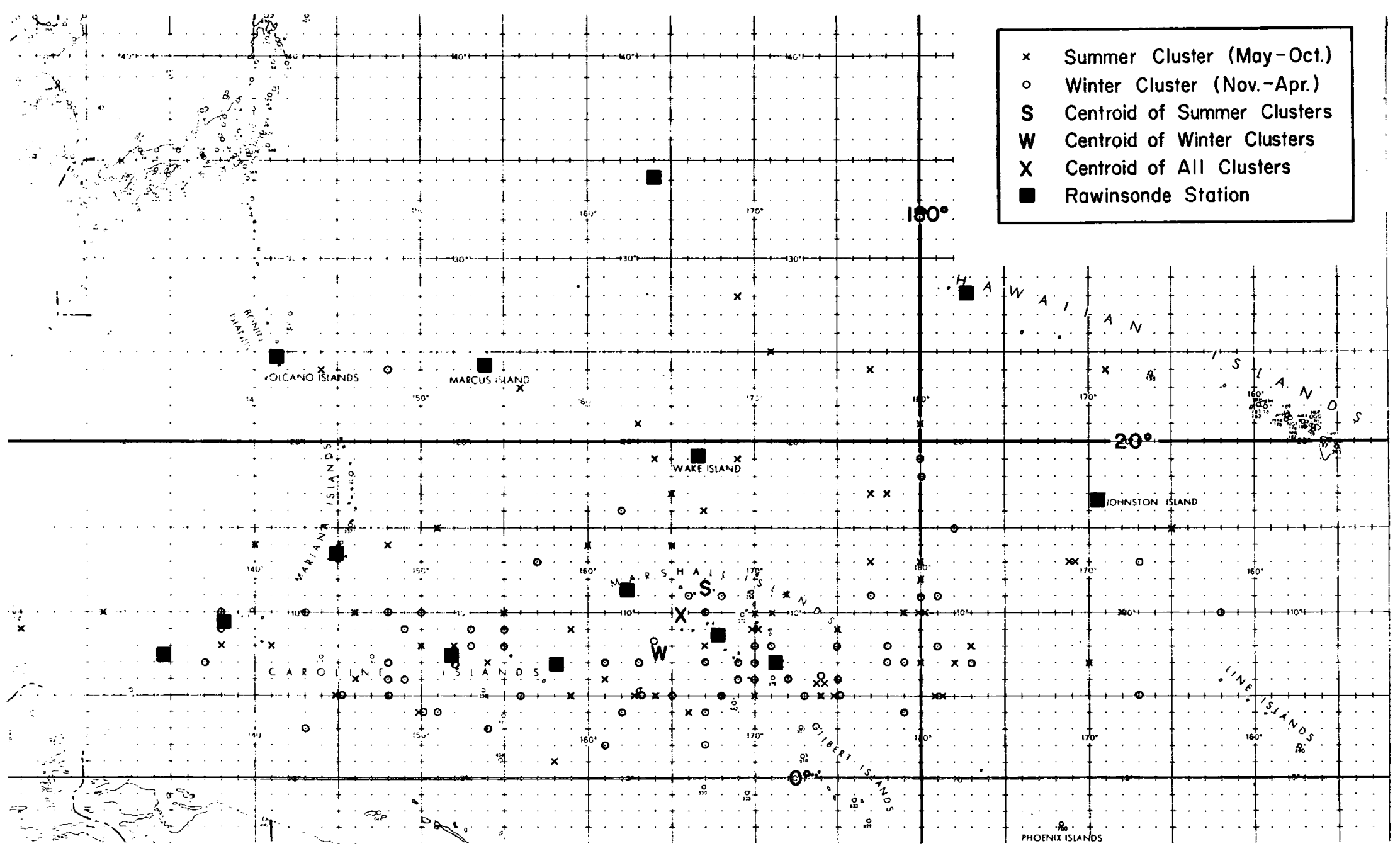

Fig. 6. Positions ( $x^{\prime}$ s and o's) of all (135) developing-dying clusters in data sample. 


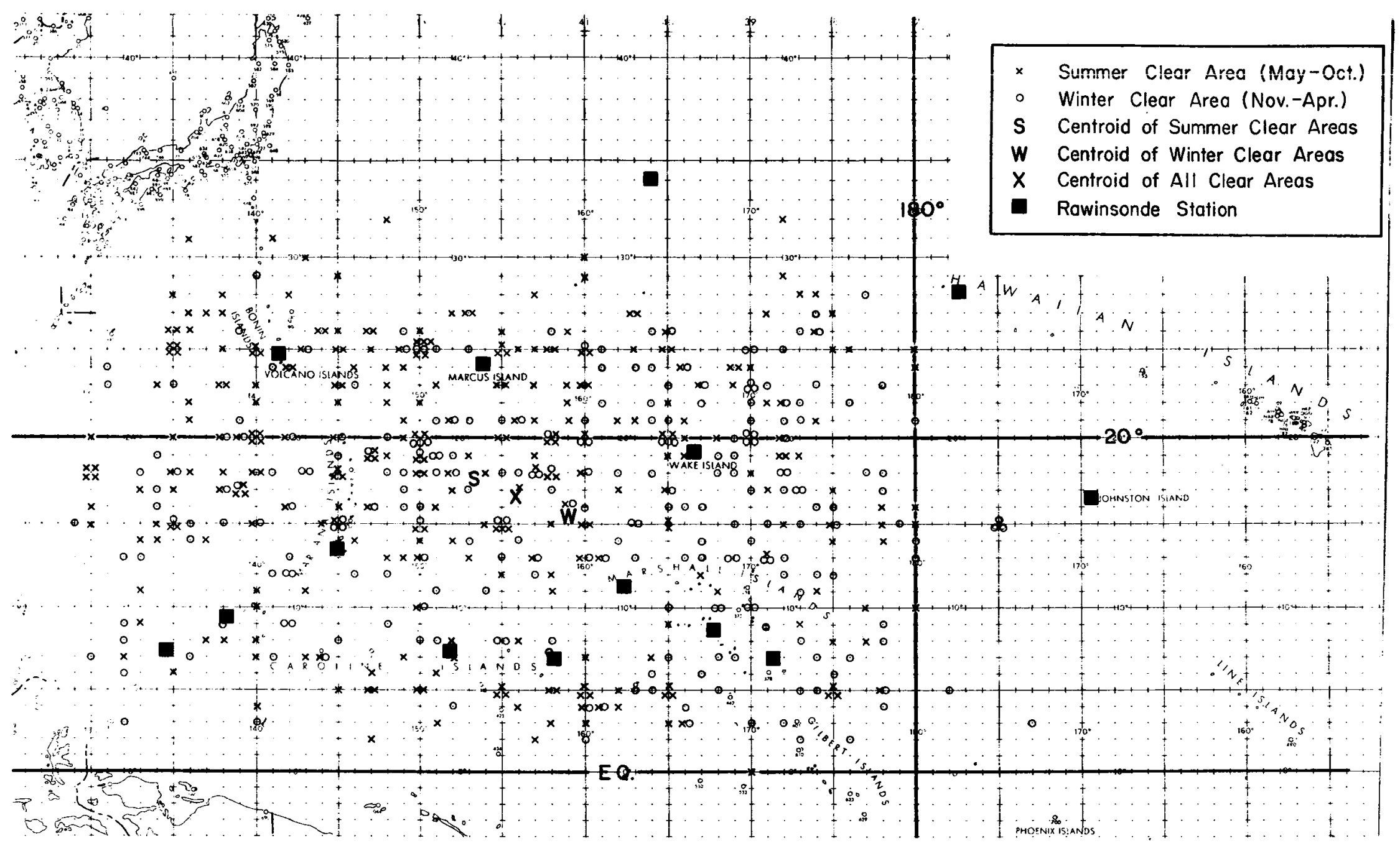

Fig. 7. Positions ( $x^{\prime}$ s and o's) of all (553) clear areas in data sample. 


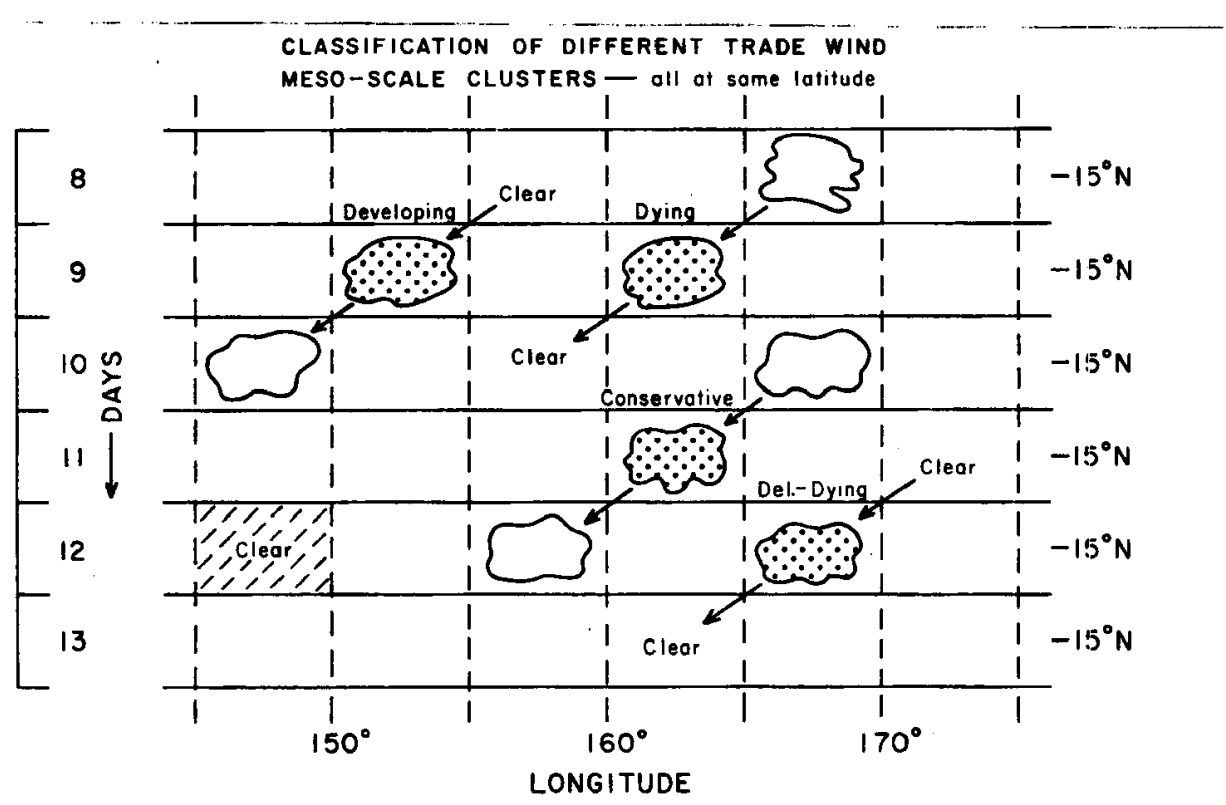

Fig. 8. Illustration of cluster classification scheme.

extensively analyzed as this time period was very close to the time of the daily ESSA satellite photographs. In addition, data 12 and 24 hours before and after this time were also utilized to obtain tendency changes.

\section{Classification of Clusters}

Fig. 8 pictorially shows how the clusters were classified, and Figs. 9-12 show sequences for developing, conservative, dying and non-conservative clusters, respectively. Only trade wind clusters have been considered. Developing clusters were ones which could not be traced backward 4 to $6^{\circ}$ longitude in the trade current the day before their observation but were observed the day after 4 to $6^{\circ}$ to the west. Conservative clusters could be traced both backward and forward on the previous and following days, respectively. 
Dying clusters could be traced backward the day before, but were not detectable the day after. Non-conservative or developing-dying clusters had a life cycle of less than one day, not being detectable on either the previous or the following day. Pre-storm clusters were those that eventually formed tropical storms or typhoons. Clusters were placed in this category from the day they developed until the first indication of an organized circulation as seen in the satellite photograph. Clear areas were picked where at least a $10^{\circ}$-latitude-square area was free of cloud cover. The final category, All Clouds, is simply the sum of the five classes of clusters. An individual cluster will develop, often be conservative for one or more days, and then dissipate. This cluster would fall into three of the cluster categories. Because of natural satellite picture uncertainties, some subjectivity was encountered in applying the above classification scheme. Nonetheless, it was established and found to be a very workable method for specifying physical differences between the statistical summaries.

\section{Compositing Procedure}

Because of the sub-synoptic size of these clusters, no present trade wind data network can adequately describe individual cluster dynamics. However, data for many individual clusters composited together make a detailed broad-scale analysis possible. Various dynamic and thermodynamic relationships can then be determined. 

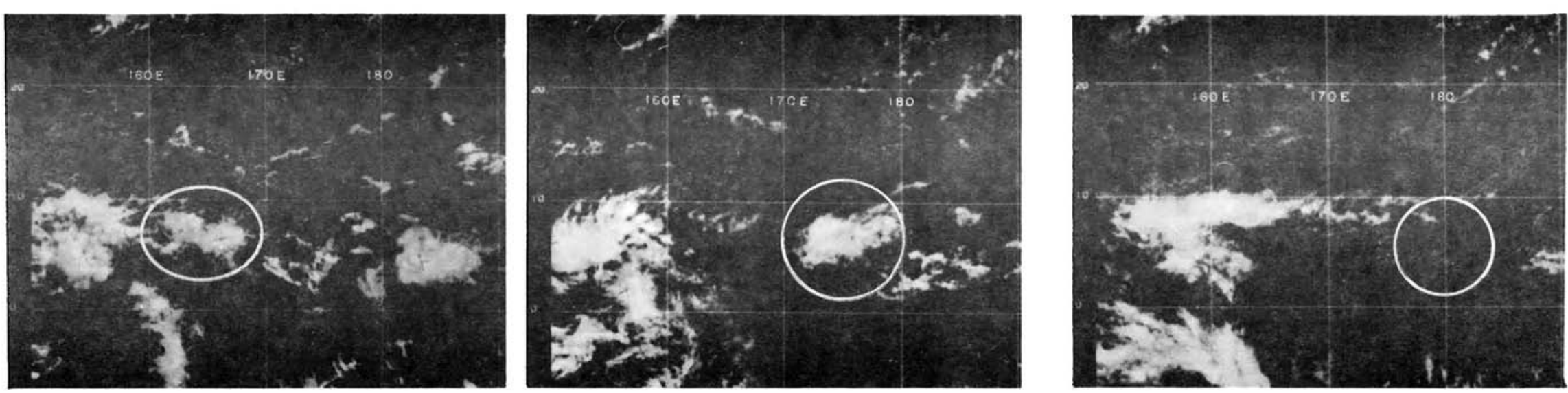

March 30

Fig. 9. 3-day sequence (March 28-30, 1967) of ESSA satellite pictures showing a developing cluster (circled) on March 29. No cluster is detectable on March 28 in the circled region upwind. On the day after development, the cluster is observed about $8^{\circ}$ longitude to the west. A trade wind clear area is evident on March 29 at $15^{\circ} \mathrm{N}, 175^{\circ} \mathrm{E}$, just north of the developing cluster. 

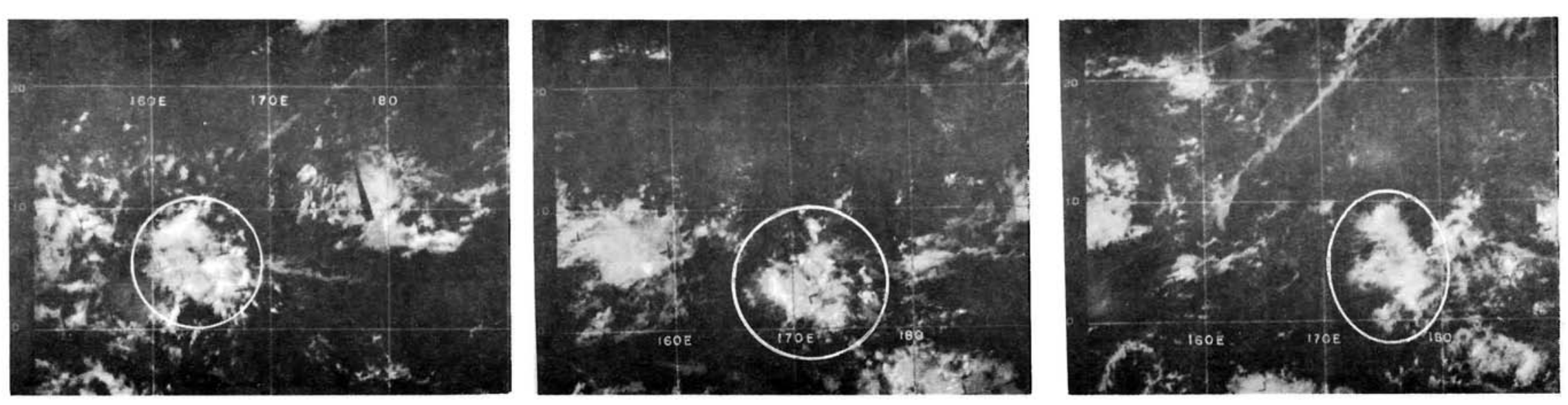

August 7

August 6

August 5

Fig. 10. 3-day sequence (August 5-7, 1967) of ESSA satellite pictures showing a conservative cluster. This cluster (circled) is evident on all three days and is progressing in the trade flow at a rate of $6^{\circ}$ longitude per day. Sun glint is visible on August 5 at $14^{\circ} \mathrm{N}, 174^{\circ} \mathrm{E}$ in the center of a clear area. 

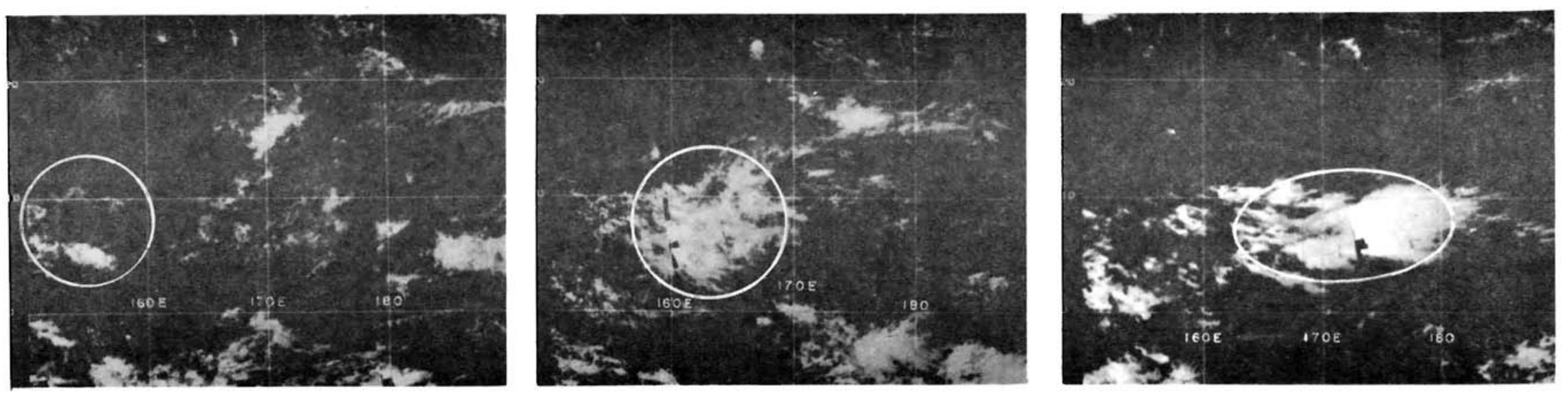

May 19

May 18

May 17

Fig. 11. 3-day sequence (May 17-19, 1967) of ESSA satellite pictures showing a dying cluster (circled) on May 18. This cluster is easily traced backward the day before, $\overline{\mathrm{May}} 17$, but is barely detectable on the day after, May 19, in the circled region. 

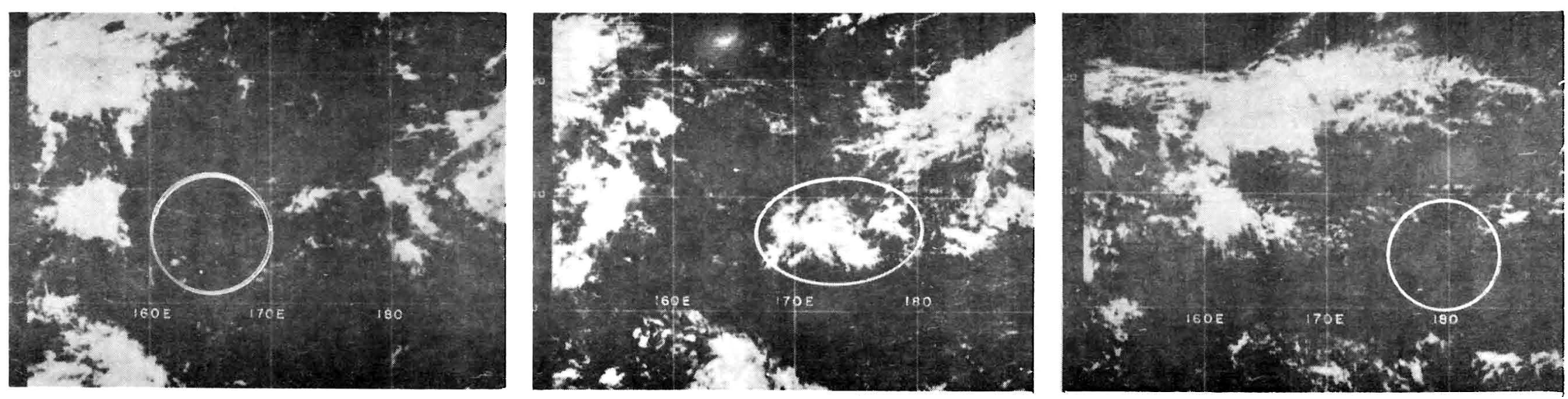

March 19

March 18

March 17

Fig. 12. 3-day sequence (March 17-19, 1967) of ESSA satellite pictures showing a developing-dying cluster (circled) on March 18. No cluster is detectable in the circled regions on either the day before or the day after. Note the clear areas centered at $15^{\circ} \mathrm{N}, 165^{\circ} \mathrm{E}$ on both March 18 and March 19. 


\section{COMPOSITING OF DATA RELATIVE}

TO MESO-SCALE CLUSTER

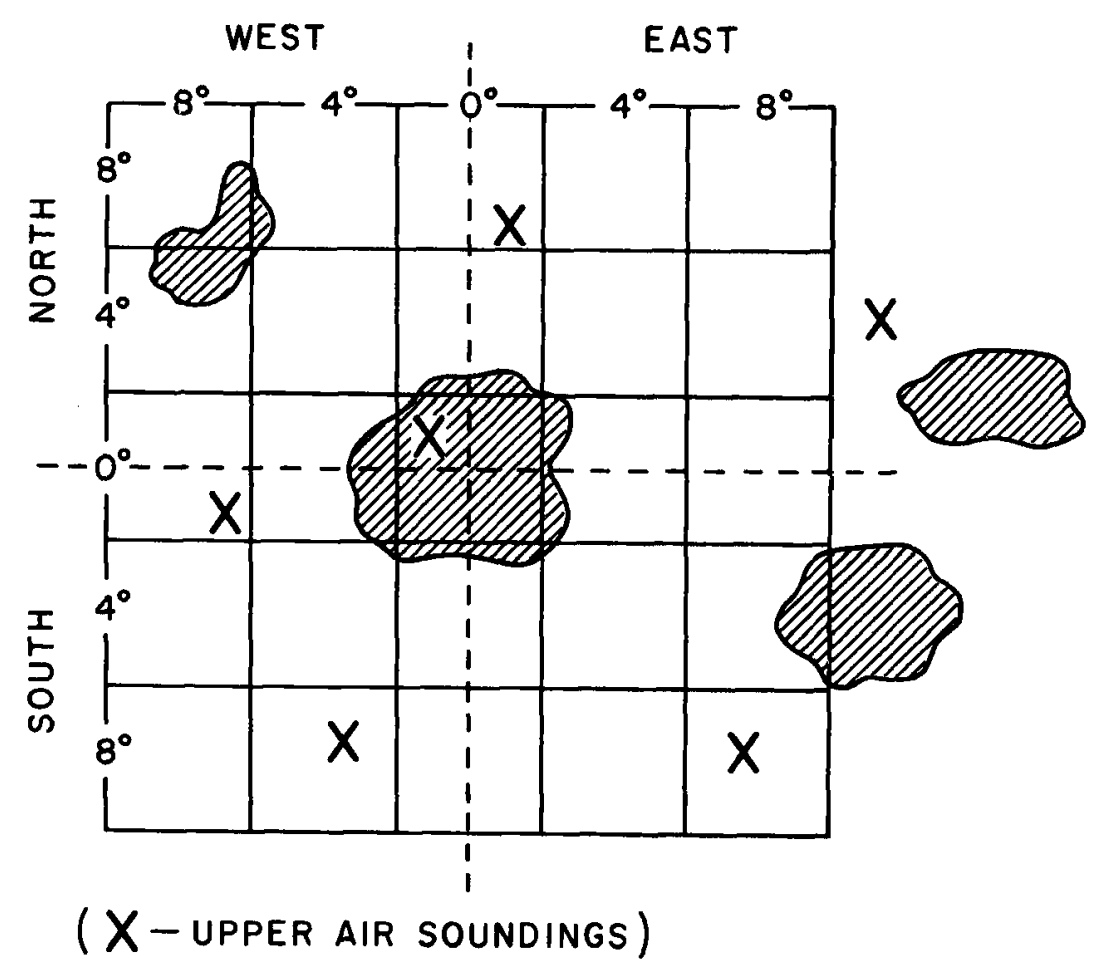

Fig. 13. Illustration of compositing scheme and rectangular grid centered on cloud cluster.

Fig. 13 shows the compositing scheme. A rectangular grid consisting of $4^{\circ}$-latitude squares and extending out $12^{\circ}$ latitude was centered on each satellite-observed cluster. Surrounding each individual cluster, there existed a pattern of upper-air stations falling into the various $4^{\circ}$-squares. Each cluster within a given category had a different array of stations surrounding it. The data from all observations falling within each square were then averaged to provide mean conditions around the composited cluster. Fig. 14 shows a sample printout of one of the computerized data composites. 


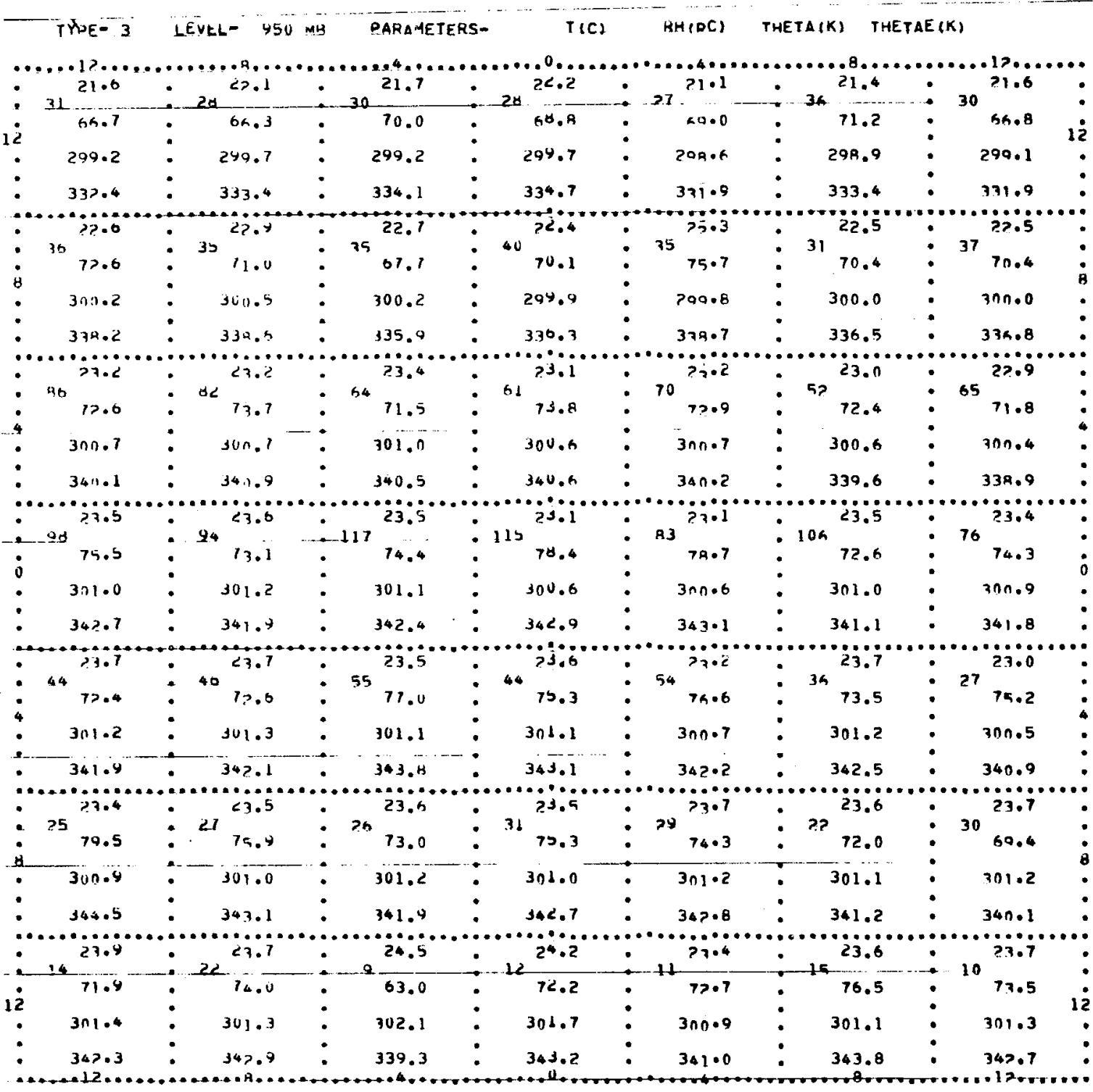

Fig. 14. Sample computer printout of the composited data at the $950 \mathrm{mb}$ level for the conservative clusters (type 3). For each box, the number of observations and the averaged temperature, relative humidity, $\theta$, and $\theta_{\mathrm{e}}$ are shown. The numbers along the outside border indicate the degrees of latitude north and south and of longitude east and west of the cluster center. The center is located at 0,0 . At this $4^{\circ}$-square center box, there are 115 observations which yield the following average values: $T=23.1^{\circ} \mathrm{C}$, $\mathrm{RH}=78.4 \%, \theta=300.6^{\circ} \mathrm{K}, \theta_{\mathrm{e}}=342.9^{\circ} \mathrm{K}$. 
The properties of trade wind cloud clusters presented in this study are derived from these $4^{\circ}$-square averaged composites.

A determination of the representativeness of the composited data is presented in the Appendix. A discussion of the sample sizes and standard deviations of several of the parameters treated is also given in this section. 


\section{DESCRIPTION OF TROPICAL CLOUD CLUSTERS}

\section{Dynamic Properties}

\section{Wind Field at Cloud Center}

Figs. 15-17 show profiles of the zonal wind with height for the pre-storm clusters, conservative clusters, and clear areas, respectively. The profile at the center of the conservative clusters shows that the typical trade wind cluster is embedded entirely in an easterly current which extends through the depth of the troposphere. The zonal wind is strongest in the lower layers, averaging $11 \mathrm{kts}$. At $200 \mathrm{mb}$, the zonal flow is typically easterly but considerably weaker than the low-level flow. This is primarily due to the variability of easterly and westerly winds in the upper troposphere above the lower-level steady trade winds.

Though not shown here, the meridional wind is observed to be weak, less than $3 \mathrm{kts}$, at all levels for each category. The horizontal shears of the zonal wind primarily determine the relative vorticity.

Horizontal Shears and Relative Vorticity ${ }^{1}$

In the low and middle troposphere, the trade flow is revealed to be stronger north of the cloud center than to the south (see Figs. 15

${ }^{1}$ The central $4^{\circ}$-square average vorticity and divergence values were determined from $8^{\circ}$ wind shears across the box centers. 


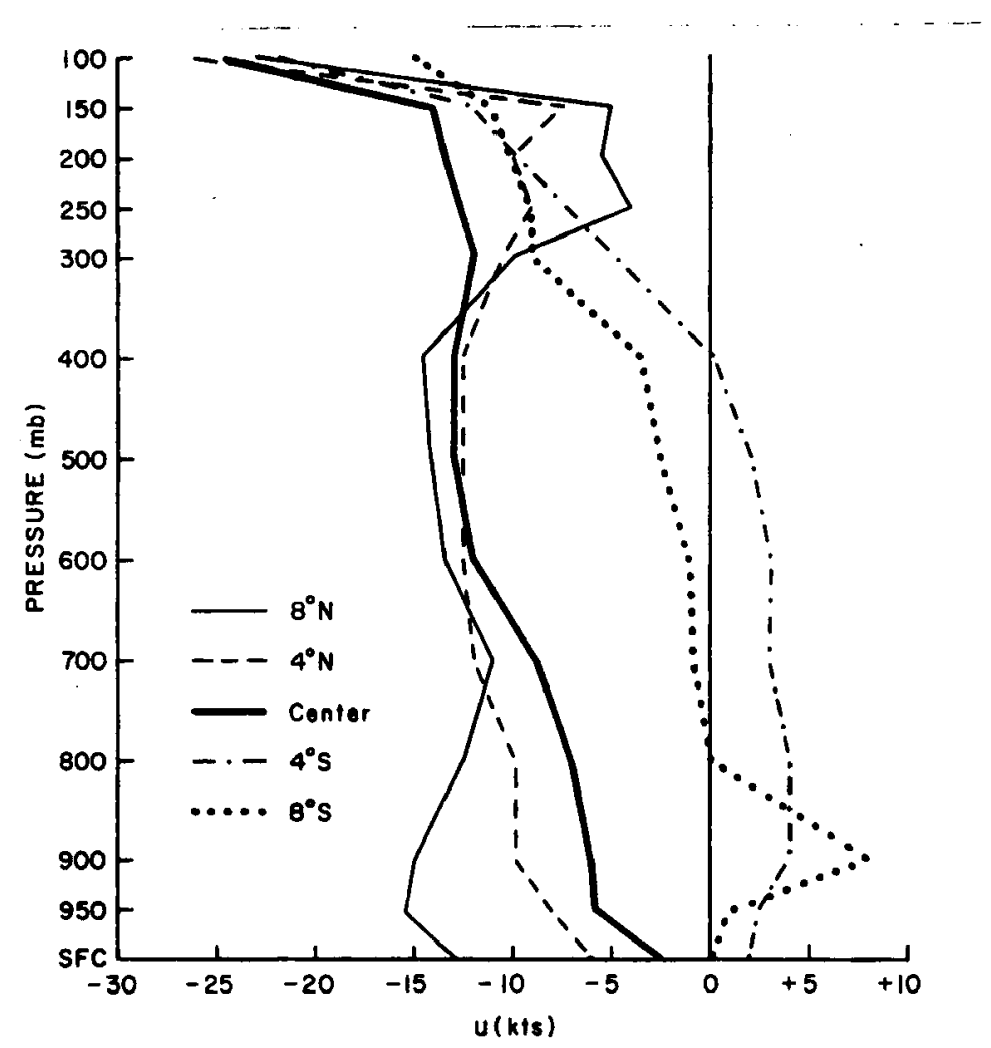

Fig. 15. Vertical profiles of the zonal wind north of center, at center, and south of center for pre-storm clusters.

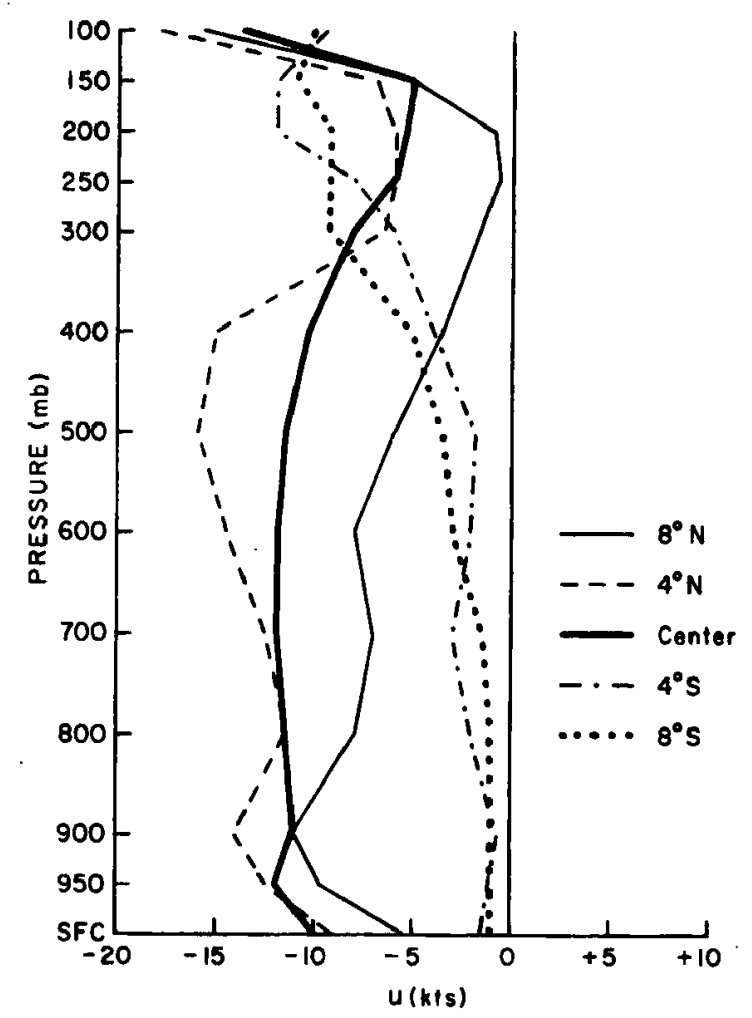

Fig. 16. Vertical profiles of the zonal wind north of center, at center, and south of center for conservative clusters. 


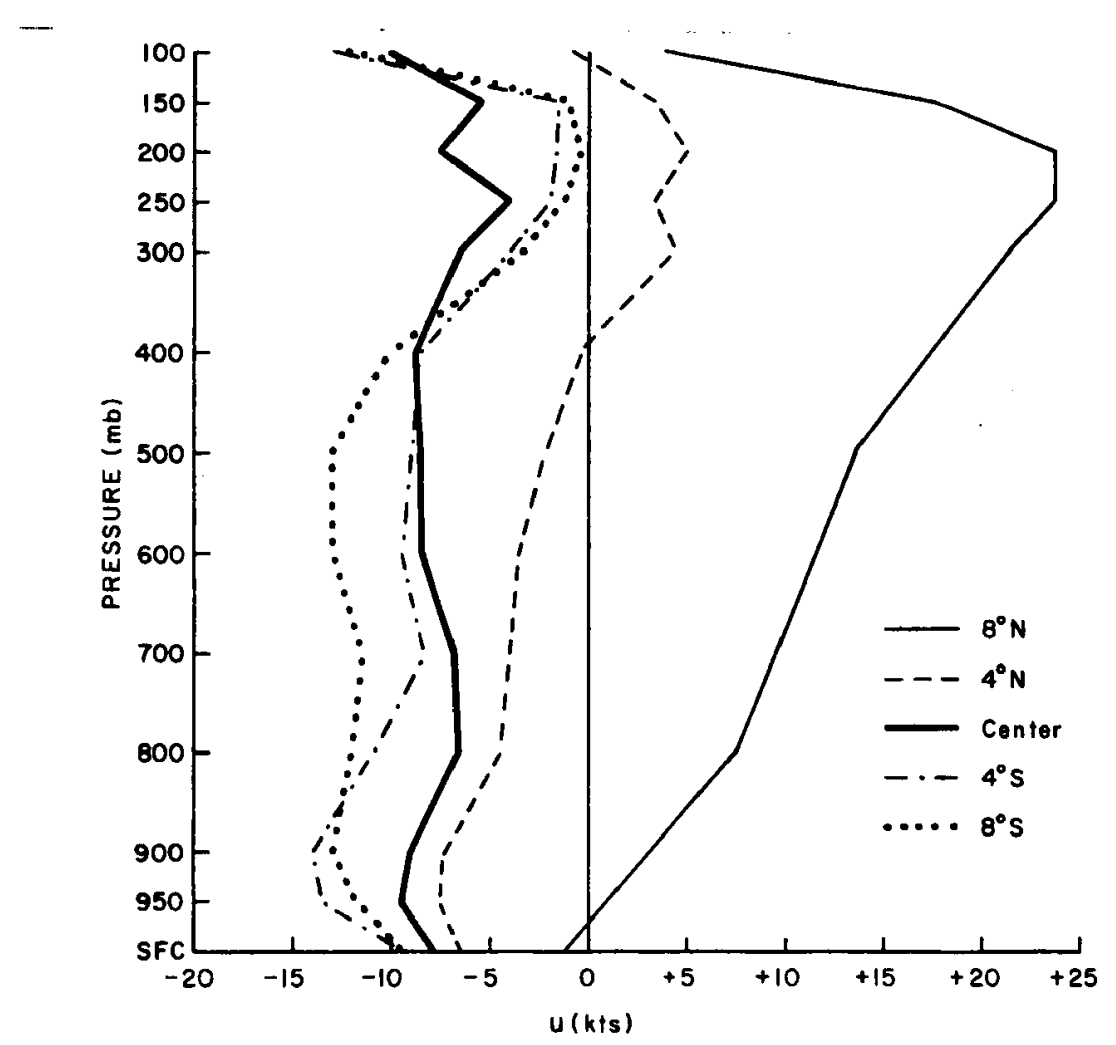

Fig. 17. Vertical profiles of the zonal wind north of center, at center, and south of center for the clear areas.

and 16). These clusters exist on the cyclonic shearing side of the trades. Table 1 shows values of $950 \mathrm{mb}$ shear of the zonal wind $(\varepsilon u / \partial y)$ from $4^{\circ}$ north of the cluster to $4^{\circ}$ south. For all the cluster types, this shear averages about $10 \mathrm{kts}$. The east-west shear of the meridional wind $(\partial \mathrm{v} / \delta \mathrm{x})$ is also cyclonic but is observed to be very much weaker.

These cyclonic shears are contrasted sharply with that for the clear areas. Both Fig. 17 and Table 1 indicate that the clear areas exist in an anticyclonic shearing environment throughout most of the troposphere. 
Table 1. $950 \mathrm{mb}$ north-south horizontal shear of the zonal wind over $8^{\circ}$ latitude and east-west horizontal shear of the meridional wind over $8^{\circ}$ longitude. Units are knots and a positive value denotes cyclonic shear.

\begin{tabular}{|c|c|c|c|c|}
\hline re & $\begin{array}{l}\text { Develop- } \\
\text { ing }\end{array}$ & $\begin{array}{l}\text { Conser- } \\
\text { vative }\end{array}$ & Dy & $\begin{array}{l}\text { Dev. - } \\
\text { Dying }\end{array}$ \\
\hline
\end{tabular}

$\begin{array}{rrrrrrrr}-\hat{\mathrm{cu}} / \partial \mathrm{y} & 17.0 & 10.4 & 9.4 & 9.6 & 3.2 & 10.4 & -6.8 \\ \partial \mathrm{v} / \hat{\mathrm{cx}} & 5.3 & 1.4 & 2.4 & 2.4 & 1.2 & 2.8 & -1.6\end{array}$

To determine whether clusters are associated with the typical easterly wave as defined by Riehl $(1945,1954)$, streamline analyses at several low tropospheric levels were made. Upwind from the clusters, the wind direction averages about $110^{\circ}$; downwind, about $85^{\circ}$. There is indeed a very weak amplitude wave in the streamline patterns, but there is littie contribution by this curvature to the computed values of relative vorticity. As shown in Fig. 18, fully $75 \%$ of the relative vorticity at all levels is contributed by shears in the zonal flow, i.e., -au/zy. These trade wind clusters appear to be associated, therefore, with a weak amplitude wave typified not so much by curvature but by a north-south cyclonic shear. Indeed, in a case study of a cluster, Simpson et al. (1967) could detect no noticeable perturbation in the lower-tropospheric wind field.

Many studies of waves in the easterlies can be found in the literature beginning with Riehl (op. cit.) and Palmer (1952) and more recently by Yanai (1961, 1963), Elsberry (1966), Frank (op. cit.), Wallace and Chang (op. cit.), Chang et al. (op. cit.), and others. 


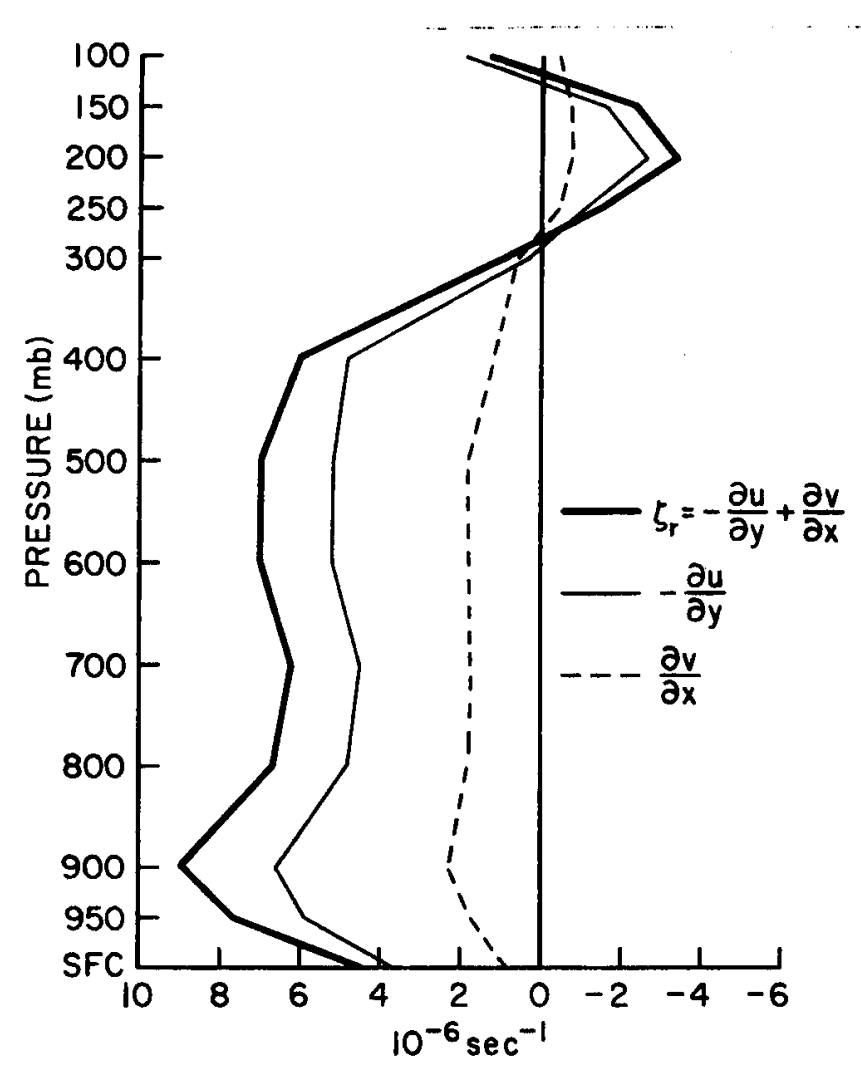

Fig. 18. Contributions to the relative vorticity by the shear of the zonal wind $(-\operatorname{tua} / \theta \mathrm{y})$ and the shear of the meridional wind $(\partial v / \partial x)$ at the $4^{\circ}$-square center box for all cloud clusters. The zonal shear accounts for fully $75 \%$ of the relative vorticity at all levels.

Some researchers as typified by Sadler (1966) have felt that the importance of the easterly wave has been overemphasized. Depending on semantics, one may choose to call these clusters waves in the easterlies or not to call them waves. Should one decide to call them

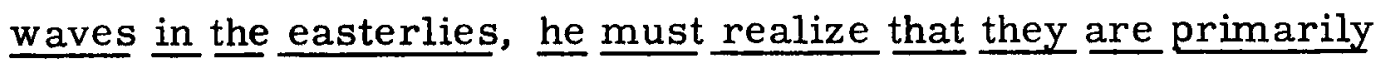
waves of north-south shear and not of curvature. (The ratio of zonal to meridional shear is 3 to 1 at nearly all tropospheric levels.) He must also realize that cloud clusters have typical lifetimes of but 1 to 3 days. 


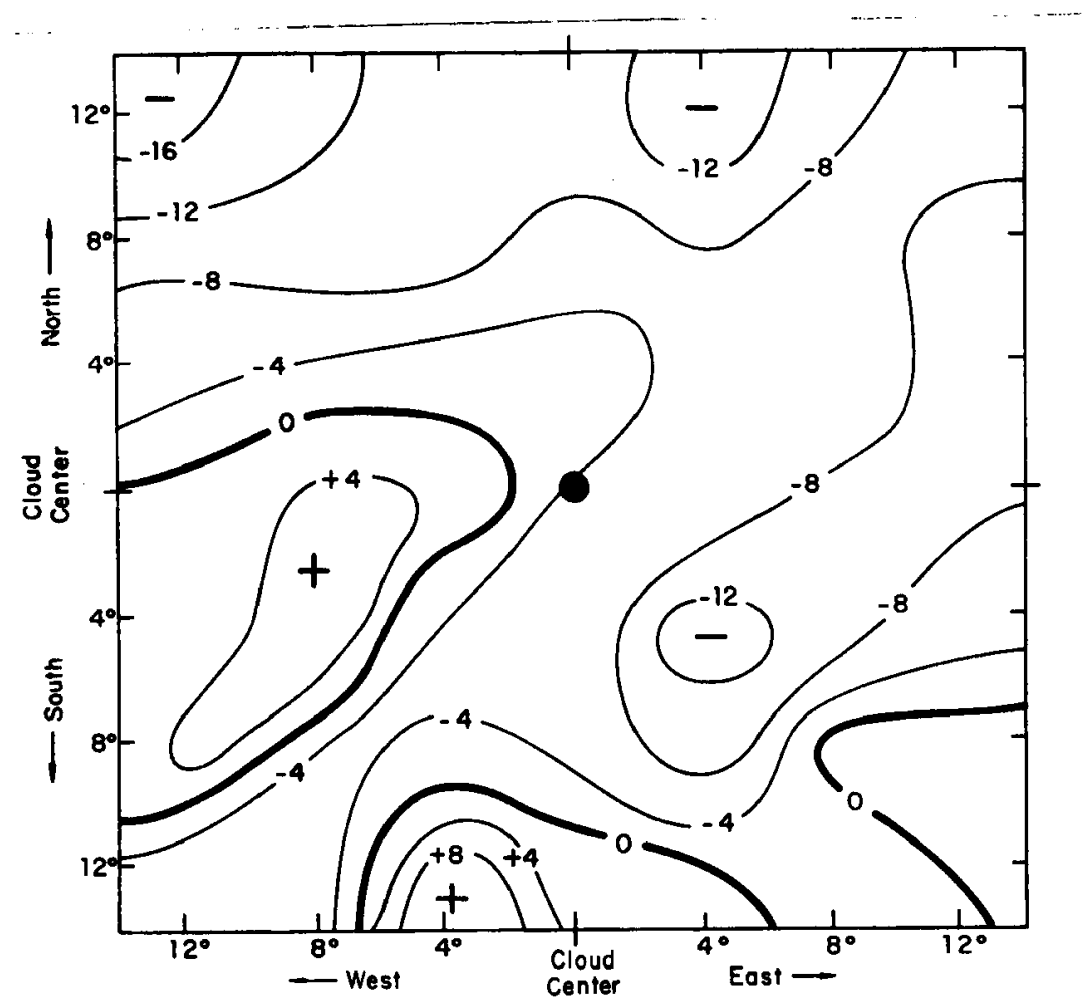

Fig. 19. $200 \mathrm{mb}$ relative vorticity map for conservative clusters. Units are $10^{-6} \mathrm{sec}^{-1}$.

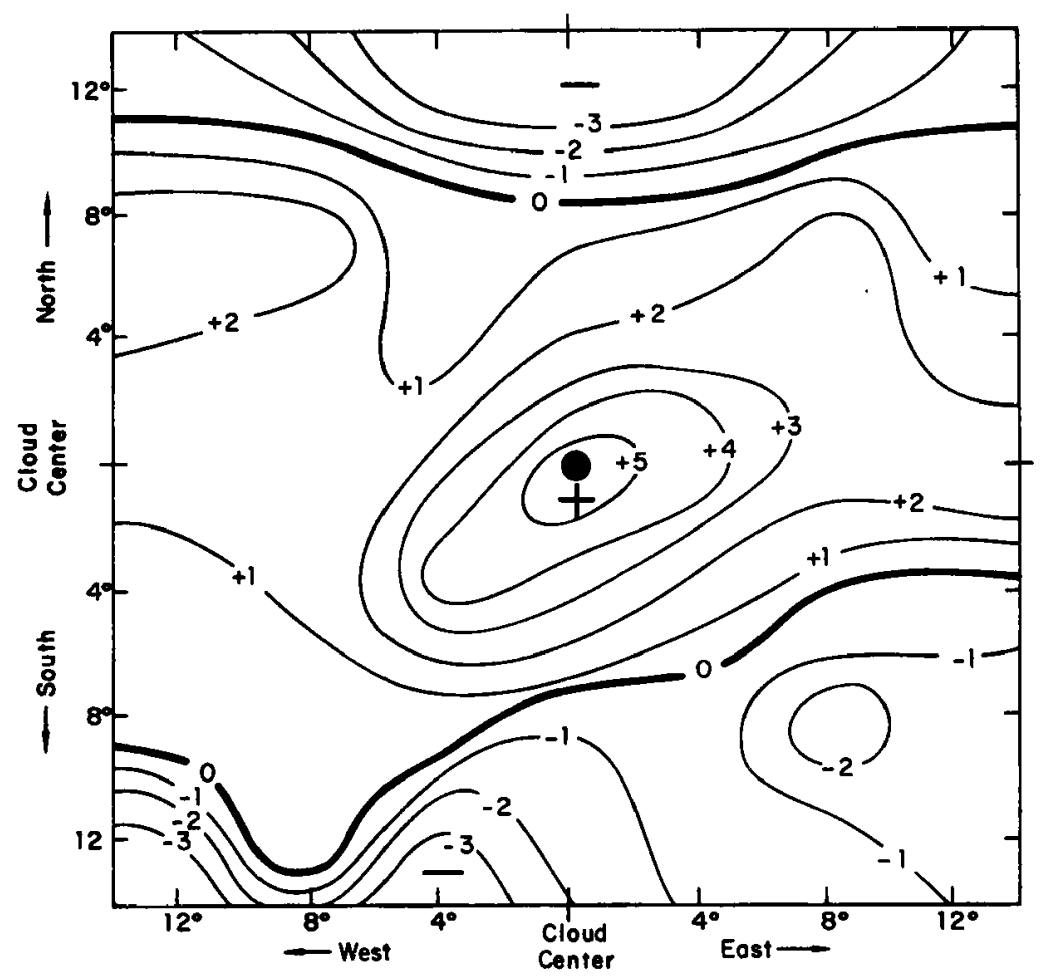

Fig. 20. Surface relative vorticity map for conservative clusters. Units are $10^{-6} \mathrm{sec}^{-1}$. 


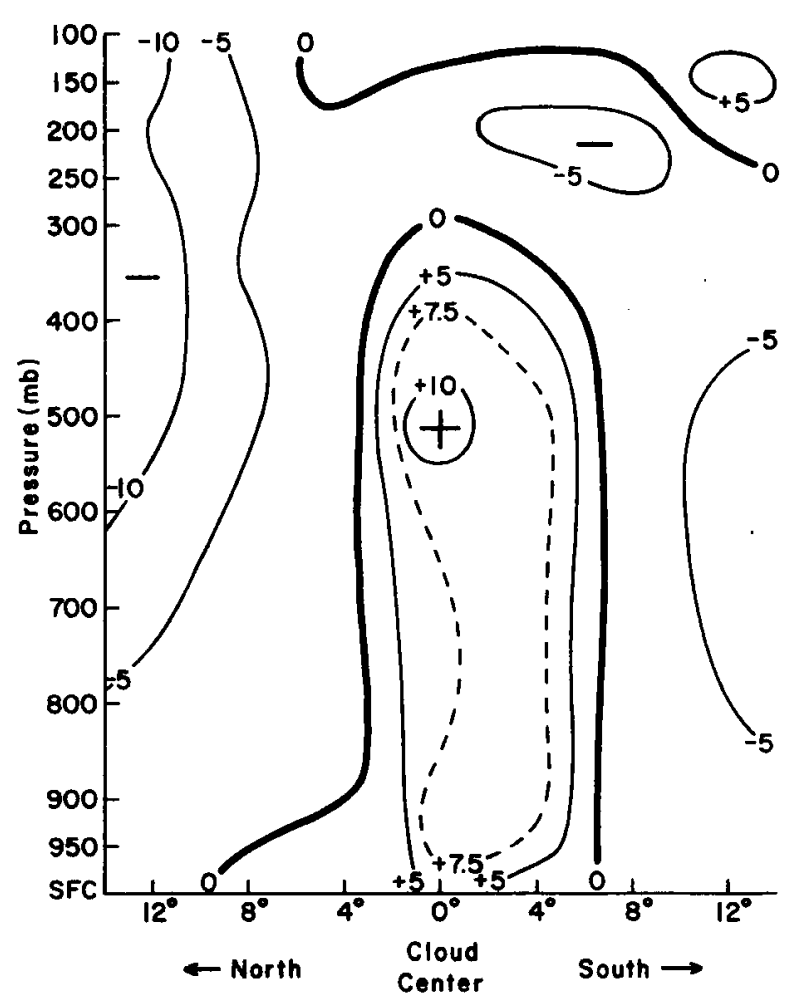

Fig. 21. Vertical north-south cross section of relative vorticity for conservative cluster's. Units are $10^{-6} \mathrm{sec}^{-1}$.

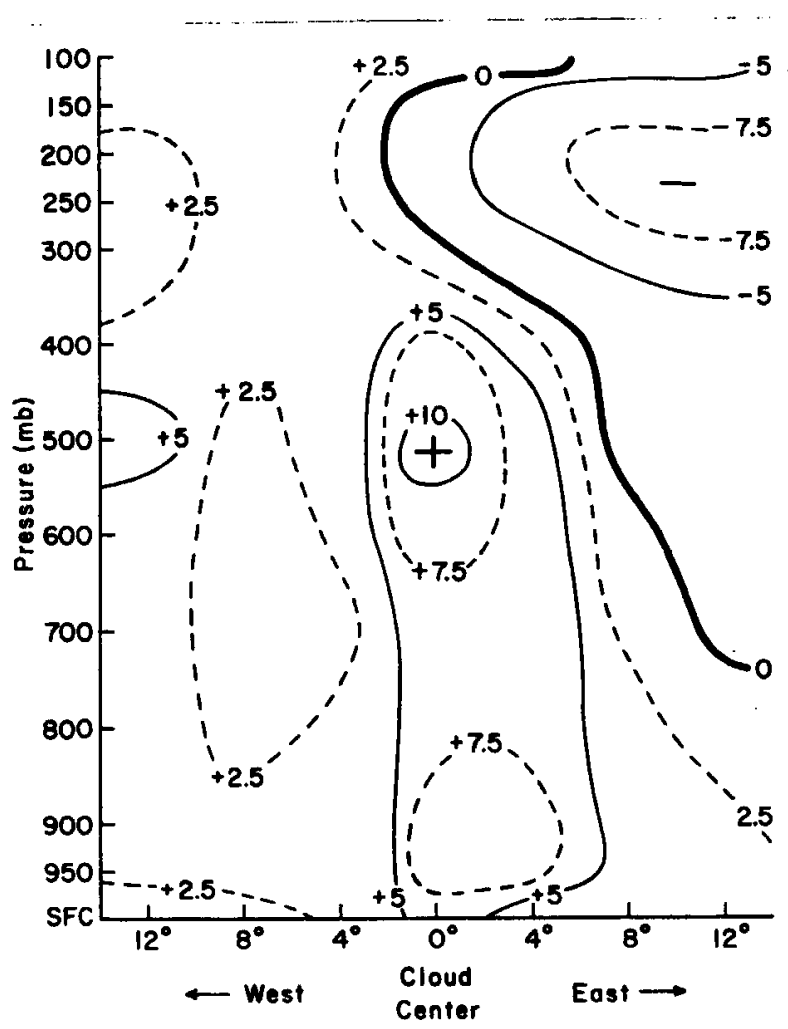

Fig. 22. Vertical east-west cross section of relative vorticity for conservative clusters. Units are $10^{-6} \mathrm{sec}^{-1}$. 


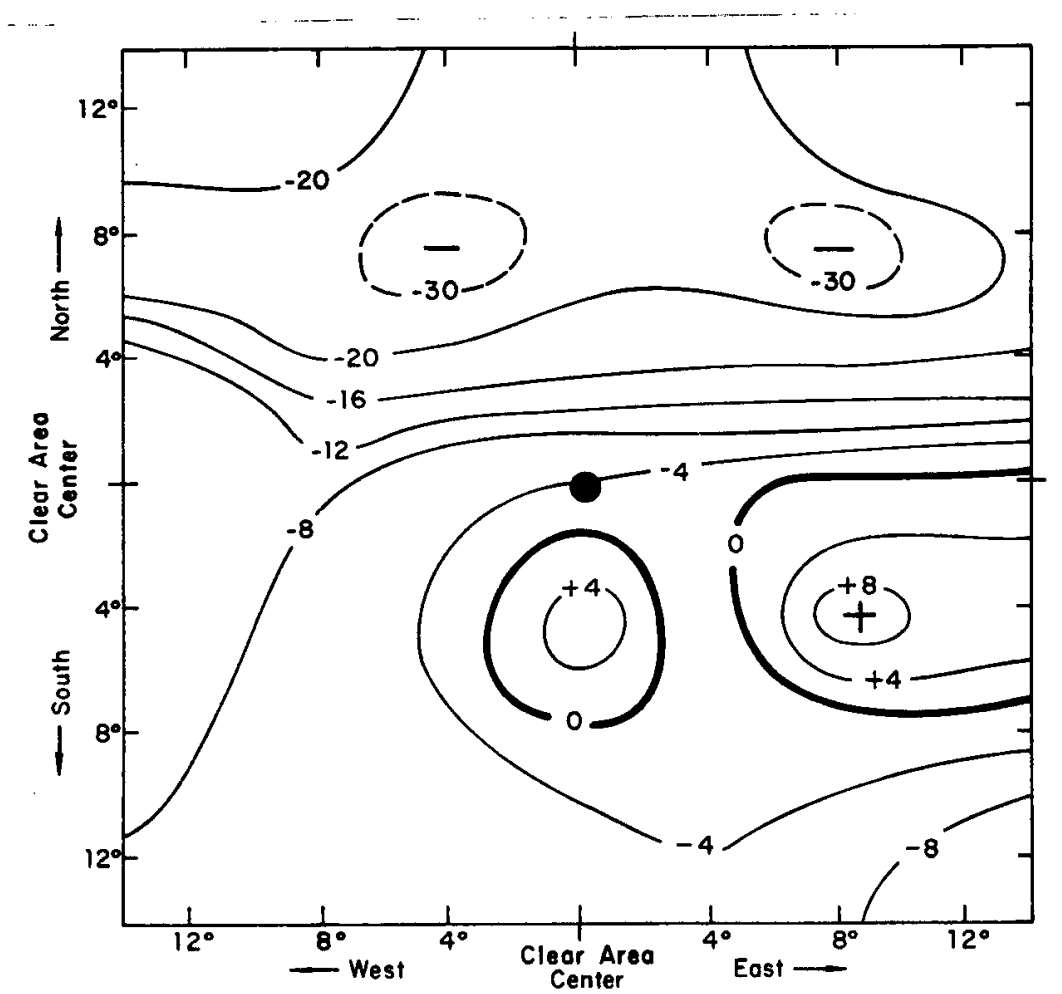

Fig. 23. $200 \mathrm{mb}$ relative vorticity map for clear areas. Units are $10^{-6} \mathrm{sec}^{-1}$.

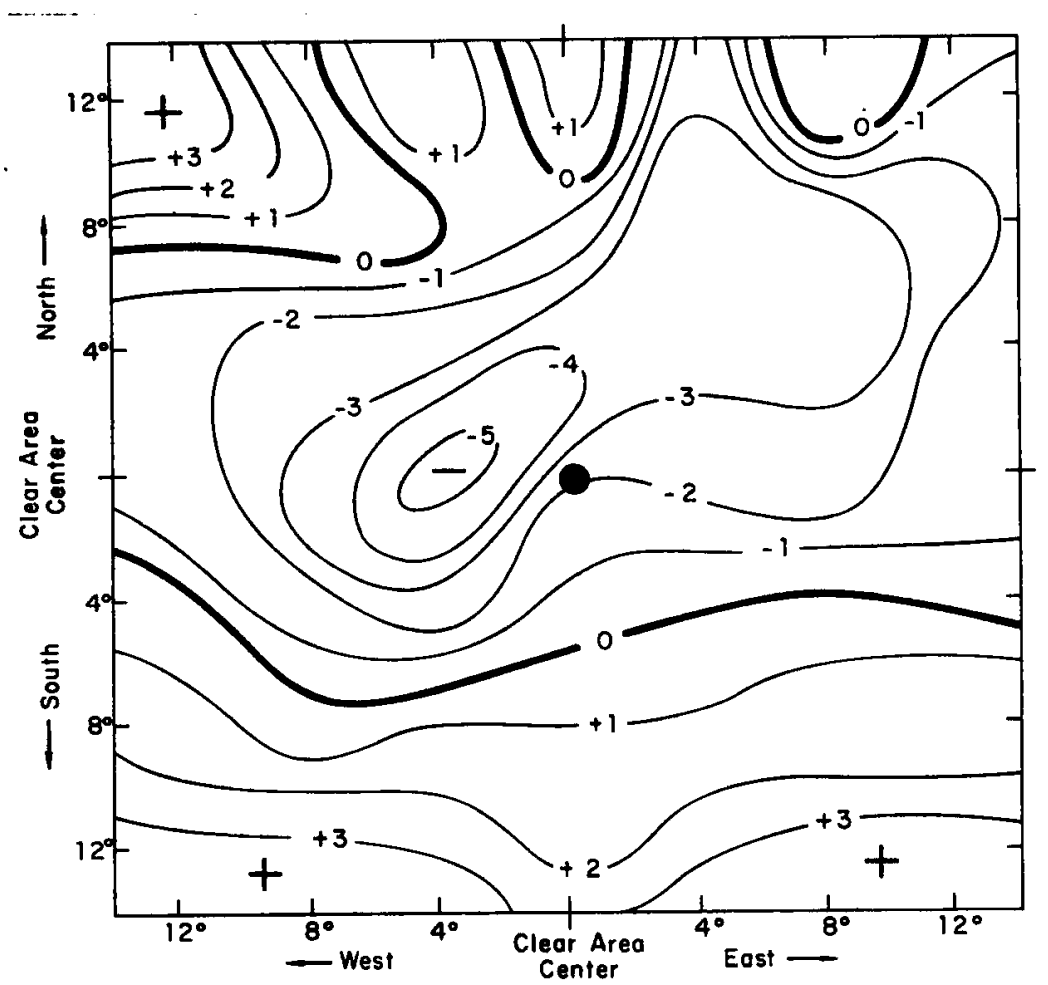

Fig. 24. Surface relative vorticity map for clear areas. Units are $10^{-6} \mathrm{sec}^{-1}$. 


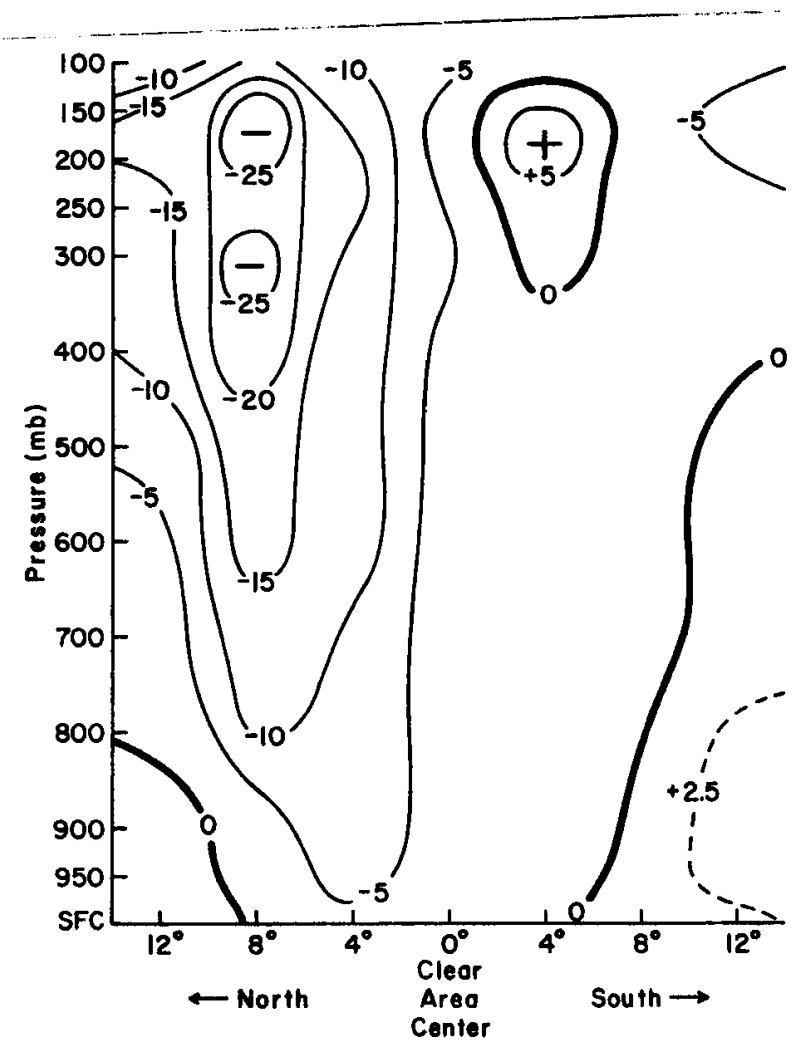

Fig. 25. Vertical north-south cross section of relative vorticity for clear areas. Units are $10^{-6} \mathrm{sec}^{-1}$.

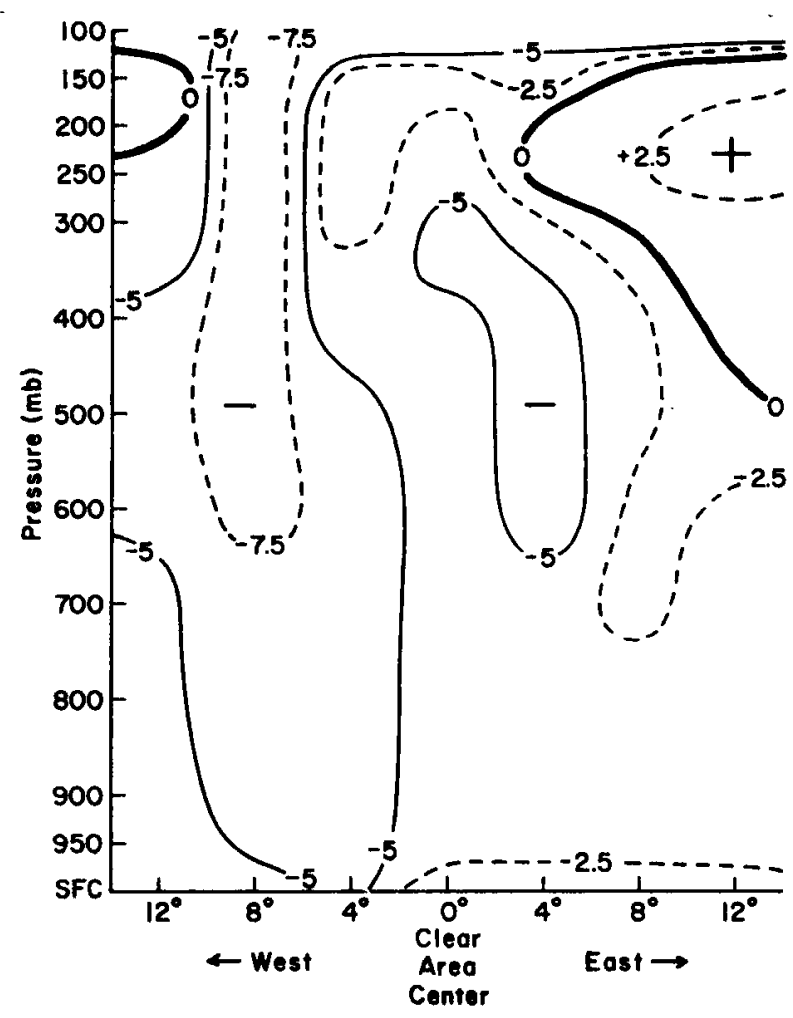

Fig. 26. Vertical east-west cross section of relative vorticity for clear areas. Units are $10^{-6} \mathrm{sec}^{-1}$. 


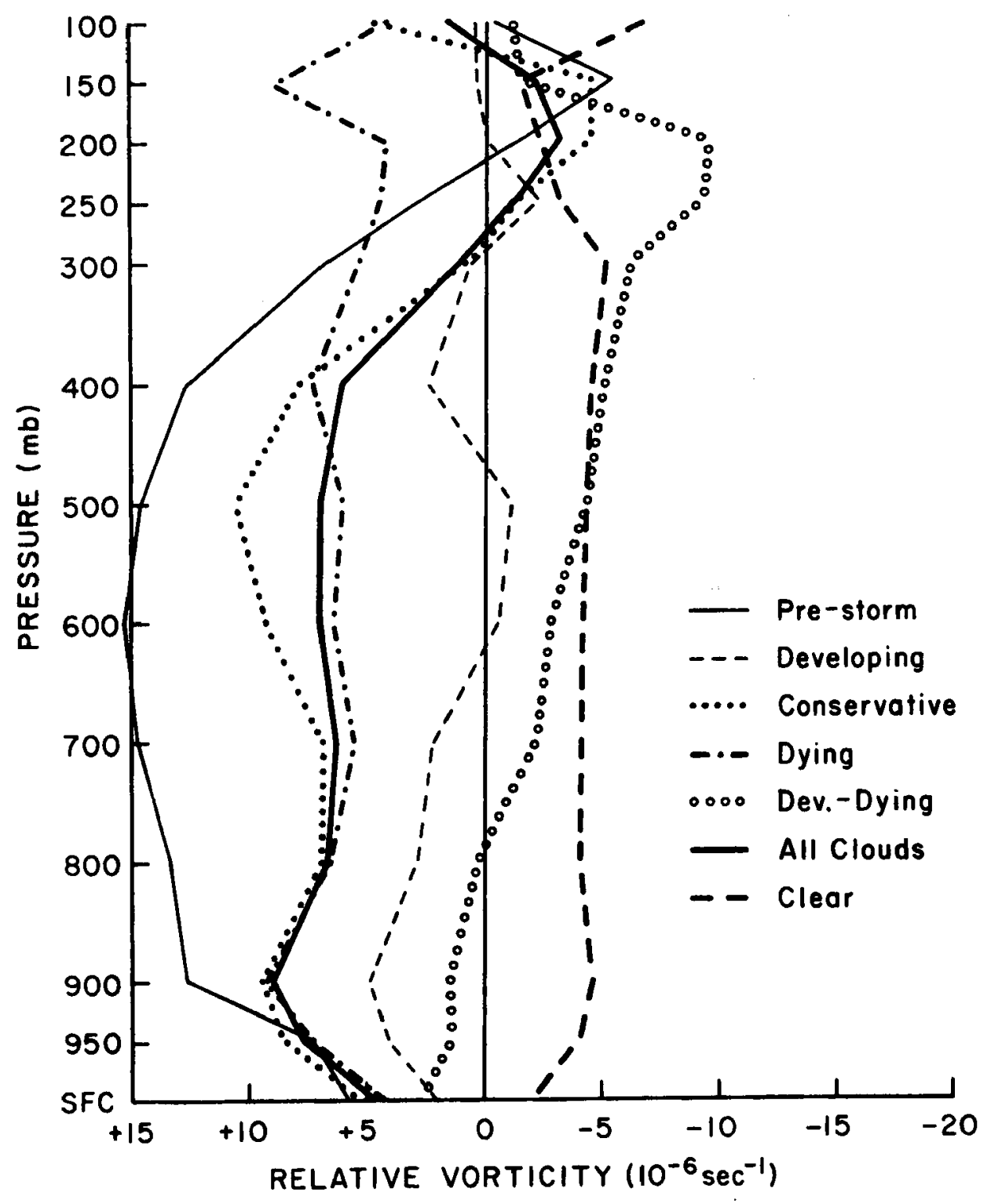

Fig. 27. Vertical profiles of $4^{\circ}$-s quare area-average relative vorticity at cluster centers. 
Surface and $200 \mathrm{mb}$ maps of relative vorticity are presented for the conservative clusters ${ }^{1}$ in Figs. 19 and 20 and for the clear areas in Figs. 23 and 24 . Vertical cross sections of relative vorticity taken north-south and east-west through the cluster center are shown in Figs. 21 and 22. Similar cross sections through the clear areas are shown in Figs. 25 and 26.

For the clusters, the surface relative vorticity is strongest at the cloud center with positive values extending more broadly eastwest than north-south. In the upper levels, negative relative vorticities exist everywhere except west of the cloud center. In contrast, the clear areas exhibit negative vorticity values at the center which extend through the depth of the troposphere.

Vertical profiles of relative vorticity taken at the center of each cluster type are presented in Fig. 27. For most clusters, the relative vorticity is positive throughout the lower and middle troposphere. The pre-storm clusters possess by far the largest vorticity values; the non-conservative or developing-dying clusters, the smallest. Note, however, that all clusters exhibit positive relative vorticity in the lowest $50 \mathrm{mb}$ - the planetary boundary layer. Cyclonic shear and positive relative vorticity in the boundary layer are

${ }^{1}$ The conservative clusters show nearly identical characteristics with the average of all clusters. The "conservative clusters" and "cloud clusters" are practically the same. 


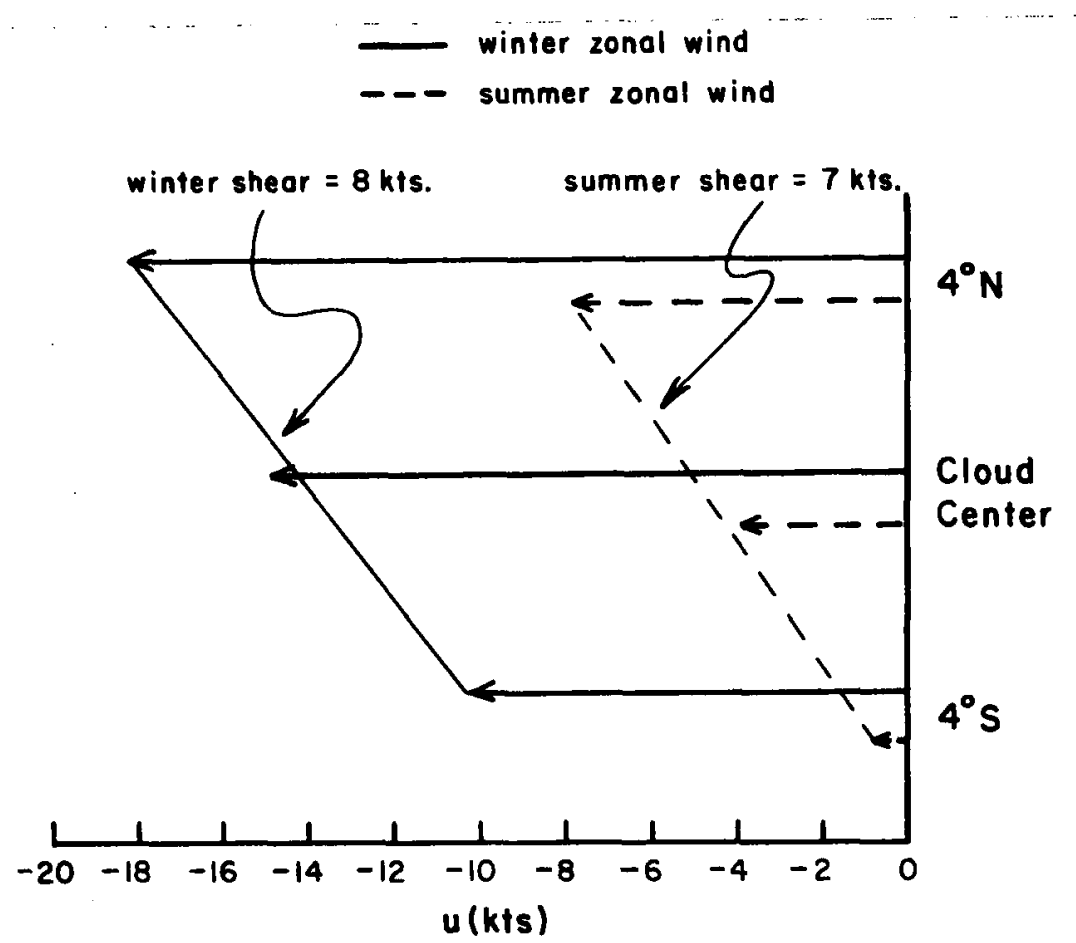

Fig. 28. $950 \mathrm{mb}$ zonal wind north of center, at center, and south of center for the summer and winter conservative clusters. Note that shears $(-\partial u / \partial y)$ are nearly equal for both seasons.

thought to be a crucial feature of cluster dynamics, as will be discussed later.

Seasonal differences in horizontal shears were also determined. Clusters were divided into summer (May to October) and winter (November to April) categories (see Figs. 2-7). Values of the $950 \mathrm{mb}$ zonal wind north and south of the summer and winter conservative clusters are presented in Fig. 28. Although the trade winds are fully twice as strong in winter than in summer, the north-south horizontal shears are nearly the same. This is consistent with the presence of easterly winds on the equator in winter and westerly winds in summer. Consequently, low-level relative vorticity is 
nearly the same in winter and summer. The higher incidence and more conservatism of trade wind cloud clusters in summer than in winter may be attributable to the larger cumulus buoyancy and much weaker vertical shears of summer compared with winter. The weaker vertical shears cause less tropospheric ventilation and allow for more concentration of cumulus-produced warming.

\section{Observed and Interpreted Divergence Profiles}

Surface and $200 \mathrm{mb}$ maps of divergence are presented for the conservative clusters in Figs. 29 and 30 and for the clear areas in Figs. 33 and 34 . Vertical cross sections of divergence taken northsouth and east-west are shown in Figs. 31 and 32 for the clusters and in Figs. 35 and 36 for the clear areas.

For the clusters, low-level convergence is concentrated in an east-west band passing through the cluster center. Above the cluster center, convergence is maintained up to $400 \mathrm{mb}$ but with strong divergence centered at $200 \mathrm{mb}$. The clear areas exhibit, on the other hand, surface divergence and upper-level convergence at the center. Practically no middle-tropospheric divergence is observed in the clear areas.

Vertical profiles of divergence at the center of each cluster type are shown in Fig. 37. For all cluster categories, convergence is typically maximum at cloud base and gradually decreases with height. A striking maximum of divergence is centered at $200 \mathrm{mb}$. 


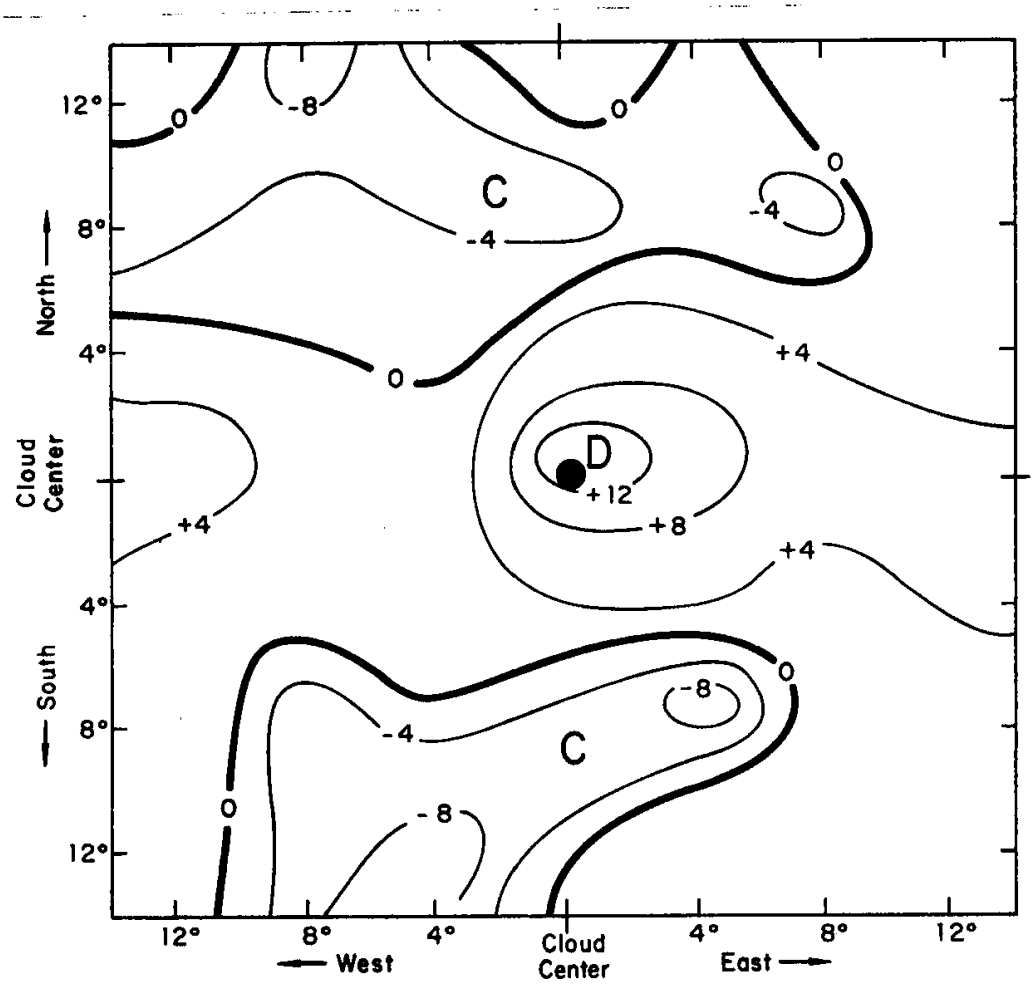

Fig. 29. $200 \mathrm{mb}$ divergence map for conservative clusters. Units are $10^{-6} \mathrm{sec}^{-1}$.

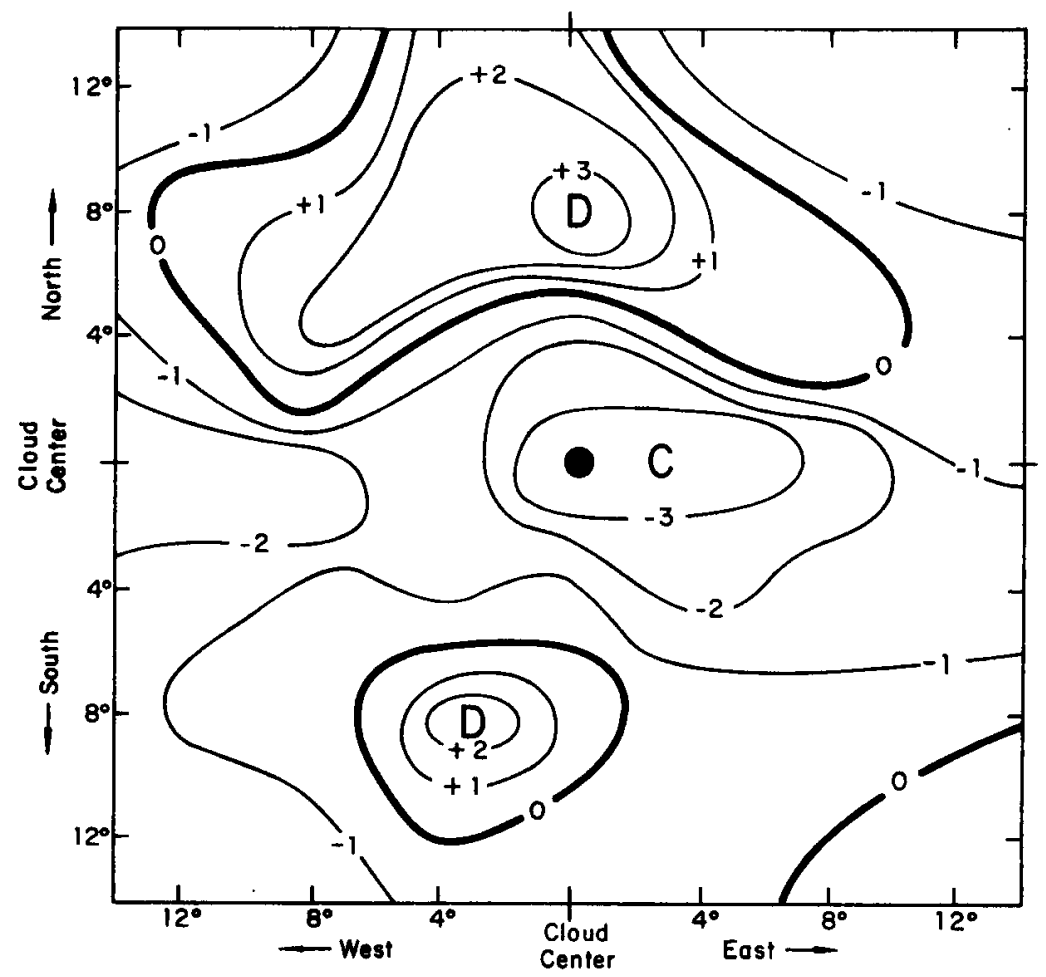

Fig. 30. Surface divergence map for conservative clusters. Units are $10^{-6} \mathrm{sec}^{-1}$. 


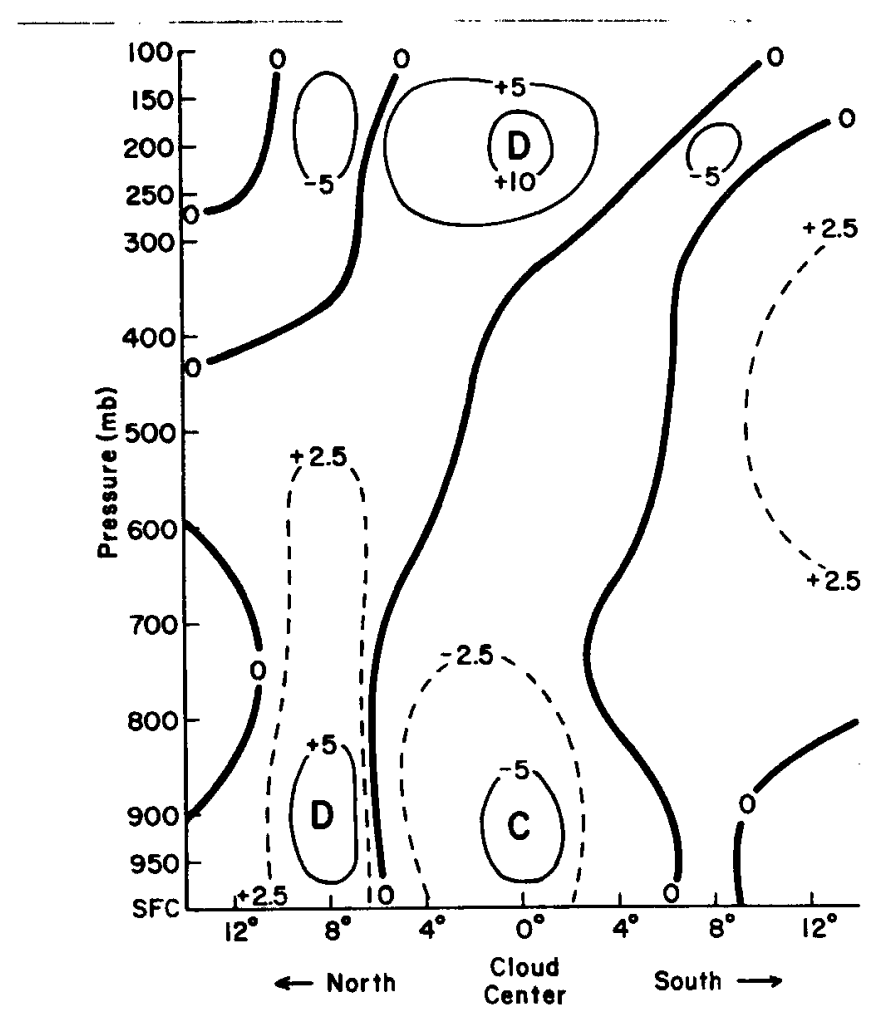

Fig. 31. Vertical north-south cross section of divergence for conservative clusters. Units are $10^{-6} \mathrm{sec}^{-1}$.

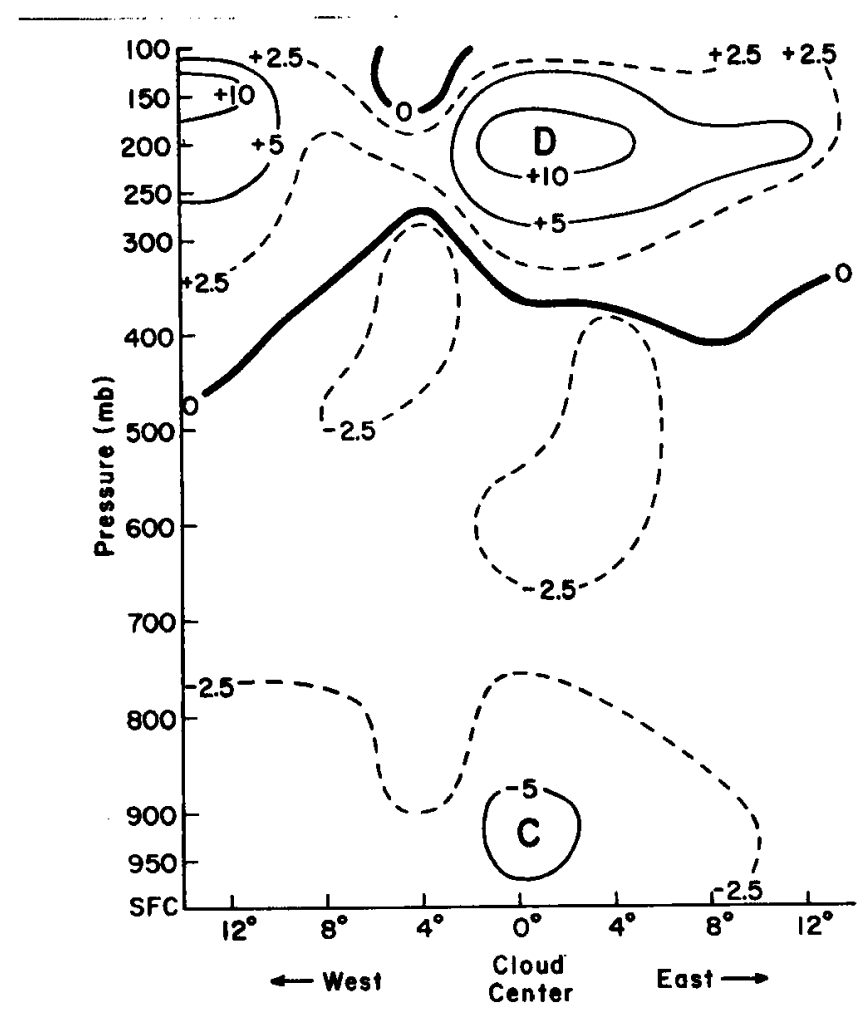

Fig. 32. Vertical east-west cross section of divergence for conservative clusters. Units are $10^{-6} \mathrm{sec}^{-1}$. 


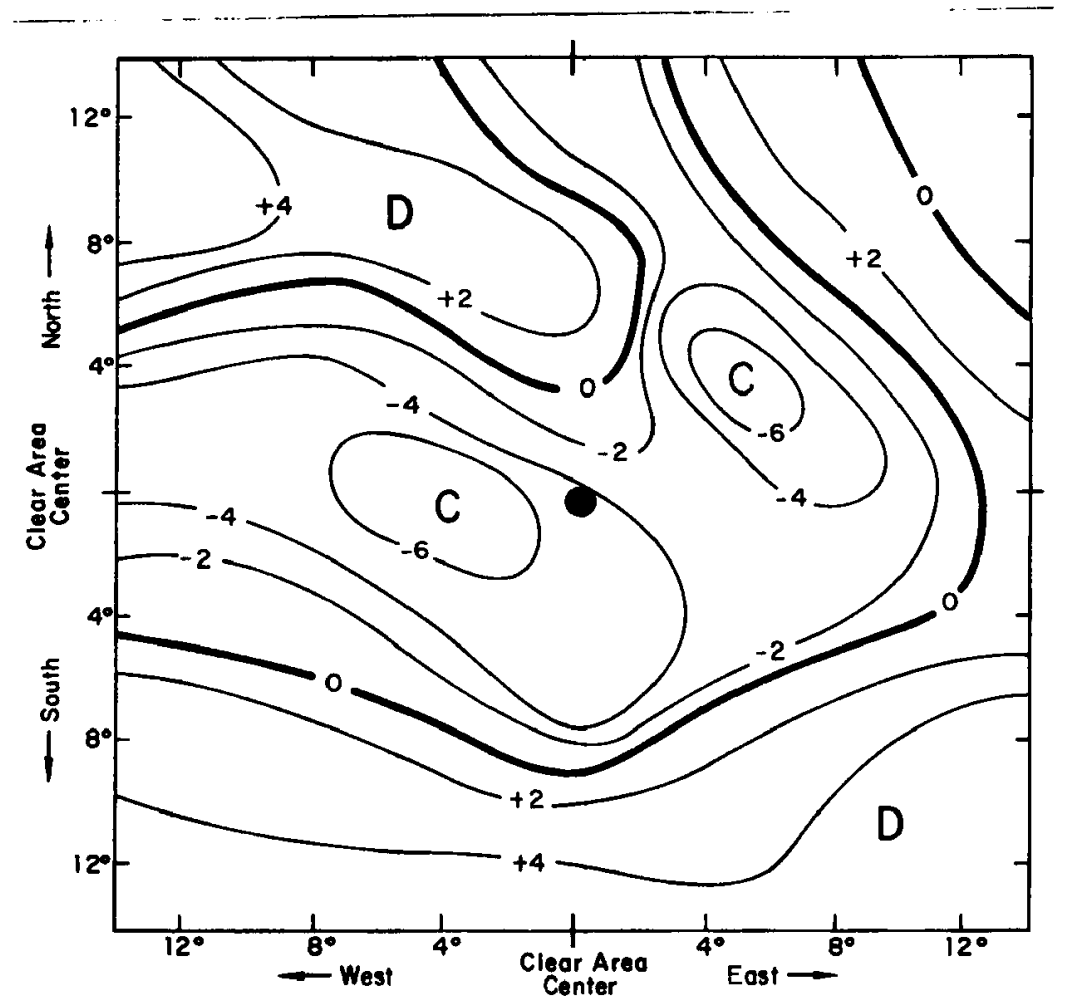

Fig. 33. $200 \mathrm{mb}$ divergence map for clear areas. Units are $10^{-6} \mathrm{sec}^{-1}$.

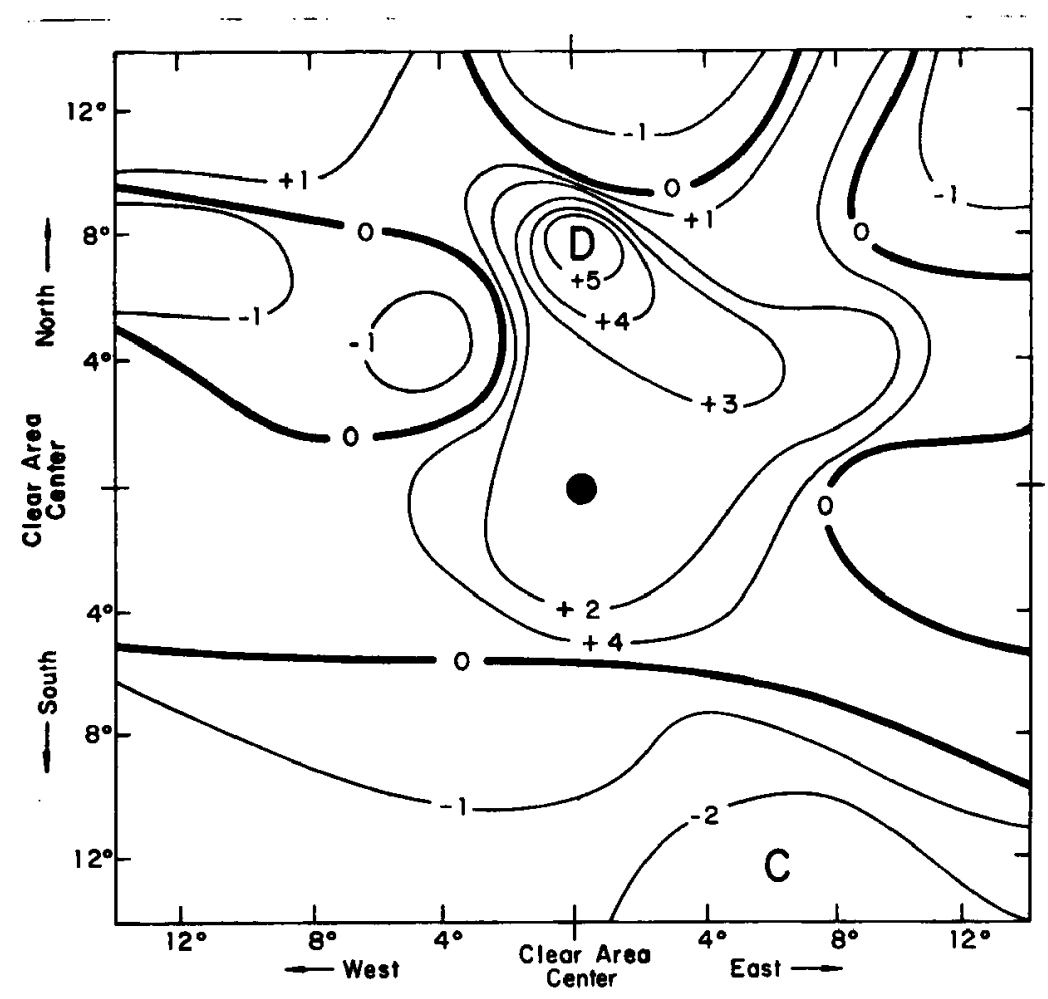

Fig. 34. Surface divergence map for clear areas. Units are $10^{-6} \mathrm{sec}^{-1}$. 


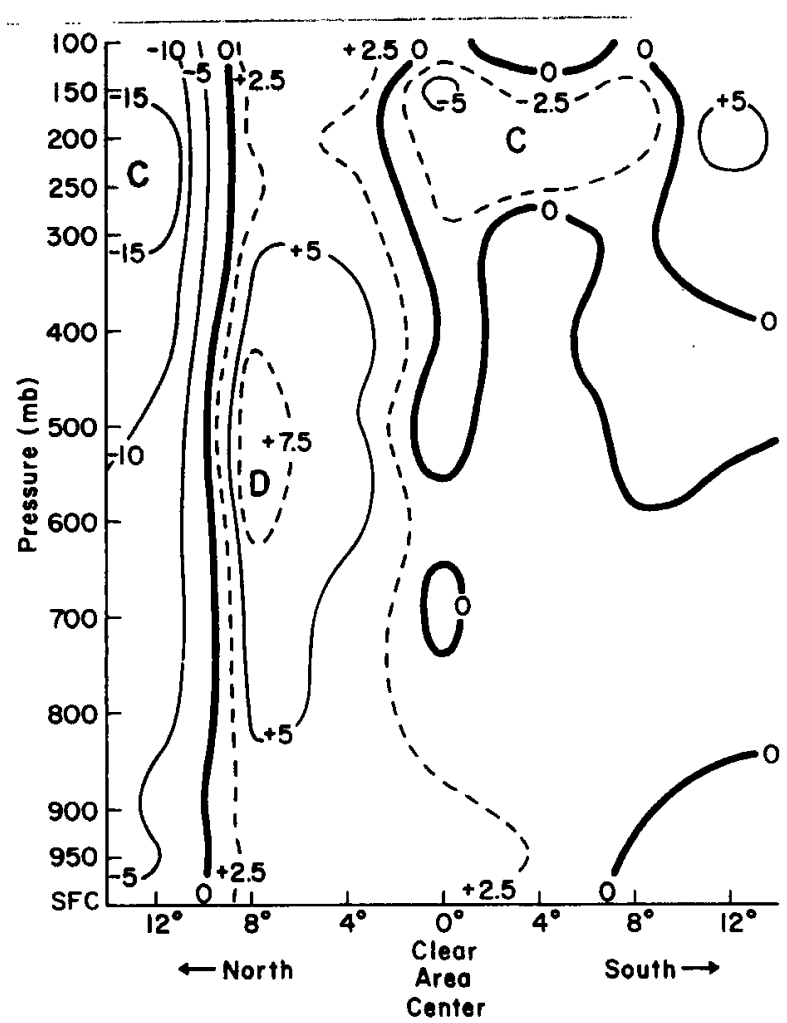

Fig. 35. Vertical north-south cross section of divergence for clear areas. Units are $10^{-6} \mathrm{sec}^{-1}$.

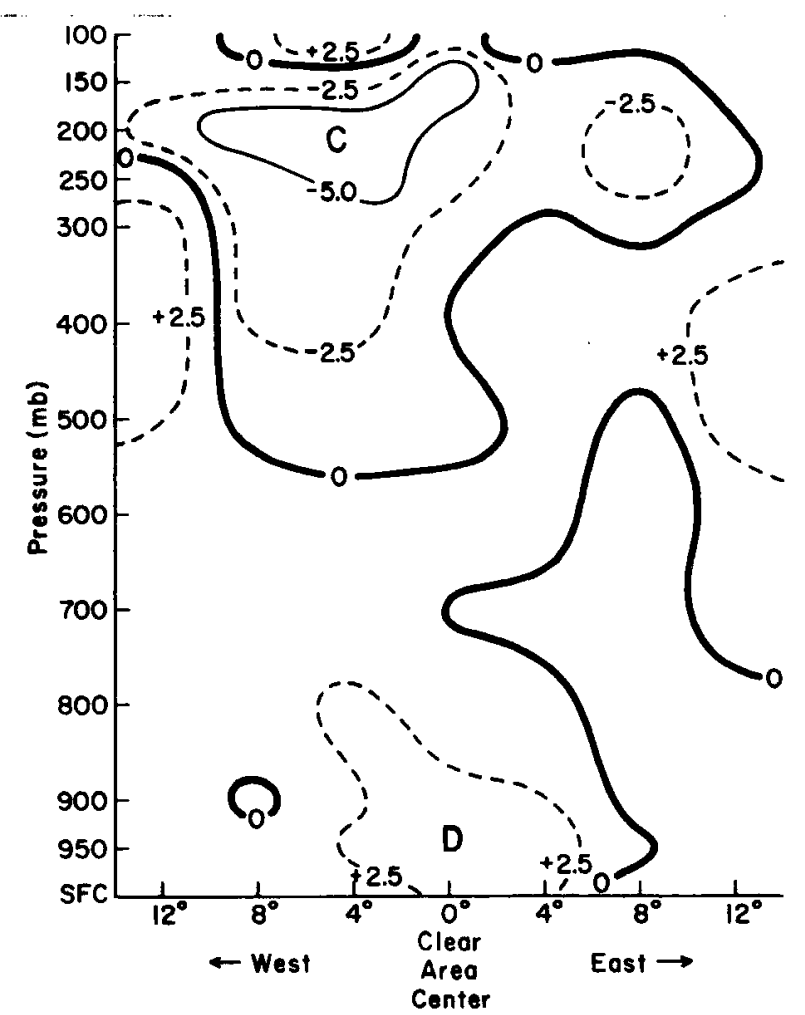

Fig. 36. Vertical east-west cross section of divergence for clear areas. Units are $10^{-6} \mathrm{sec}^{-1}$. 


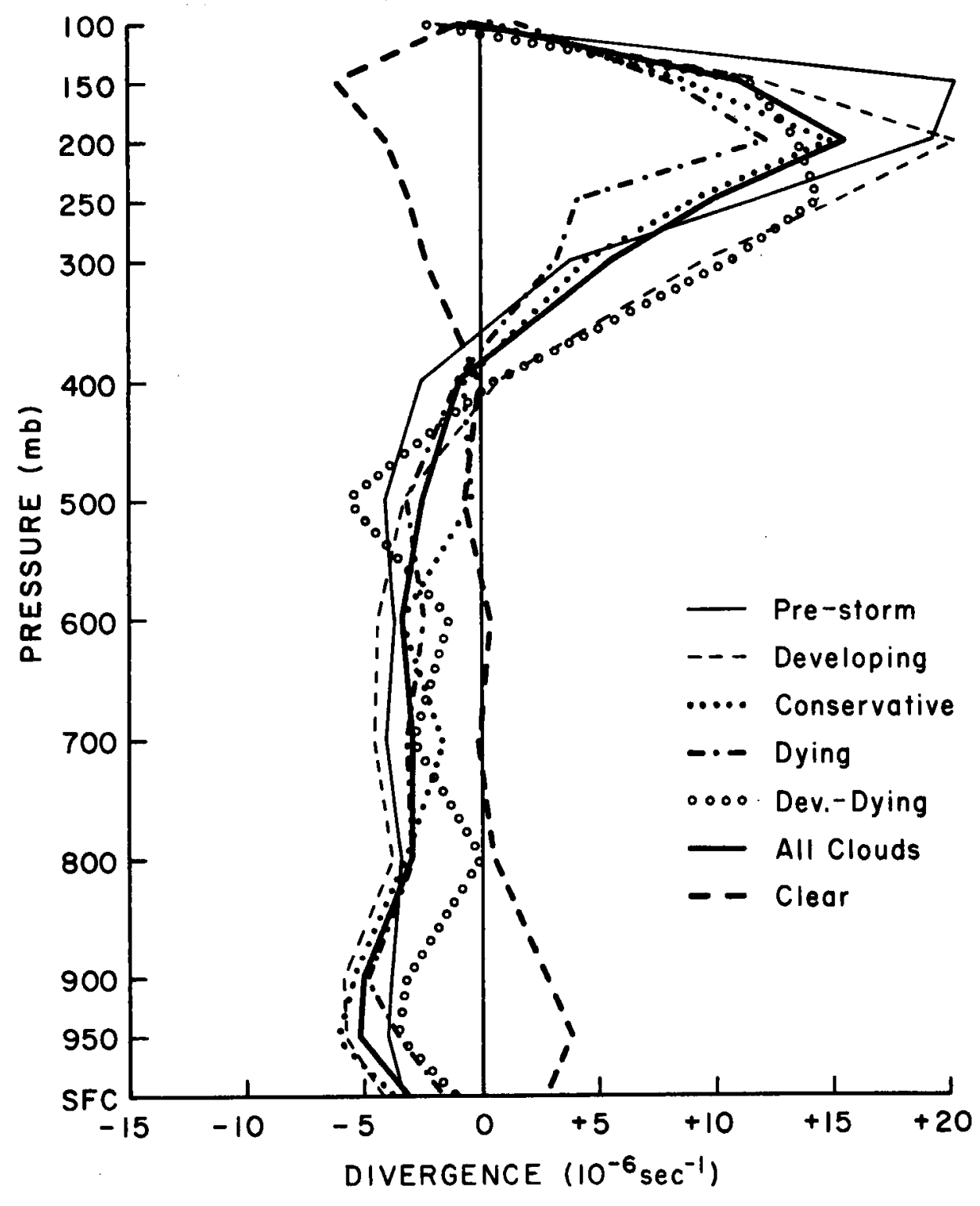

Fig. 37. Vertical profiles of $4^{\circ}$-square area-average divergence at cluster centers. 
This agrees very well with previous vertical divergence profiles determined from tropical storms [Gangopadhyaya and Riehl (1959), Riehl and Malkus (1961), and Yanai (1961)].

These vertical divergence profiles also show that the mass balance of a cloud cluster is achieved nicely by a two-layer model with inflow below $400 \mathrm{mb}$ and outflow strongly concentrated from 250 to $150 \mathrm{mb}$ (at 250 to $150 \mathrm{mb}$ cumulonimbi updrafts rapidly lose their buoyancy). Because the surface pressure tendencies following the conservative clusters showed very little change $(< \pm 2 \mathrm{mb}$ per day), a rigid balance of the vertically integrated divergence must take place. This requirement was met. It should be noted that the inflow is by no means confined to the lowest layers. Middle-level convergence is believed to result largely from entrainment into the cumuli, which are developed by boundary-layer frictional convergence.

These divergence profiles were obtained completely from the computer composites with no "massaging" of the data. It was indeed surprising that these kinematic-detemined divergence and vertical motion profiles (Fig. 47) should show such a remarkably close mass balance. This lended confidence to the other data computations.

It is thought that the effect of the low-level horizontal shears and positive relative vorticity in producing convergence in the planetary boundary layer are critically important to cluster dynamics. Charney (1958) and Charney and Eliassen (1964) have proposed conditional instability of the second kind (CISK) as an instability 
mechanism by which frictionally-forced convergence in the boundary layer in cooperation with the heating potential of cumulus convection combine to initiate development of tropical cyclones. This mechanism is viewed by the author as a plausible means of producing and maintaining tropical cloud clusters, some of which may later develop into tropical storms. Gray (1968) has previously shown a strong positive relationship between trade wind cyclonic wind shear and disturbances which intensify into tropical storms. To maintain the cluster, lowlevel mass convergence and cumulus convection must be continually active.

Mendenhall (1967) and Gray (op. cit.) have shown in statistical studies that significant Ekman or frictionally-induced wind veering does, in fact, exist in the sub-cloud layer (lowest $600-700 \mathrm{~m}$ ) over the tropical oceans. Fig. 38 graphically portrays this observed wind veering with height through the lowest two kilometers for NW Pacific atoll and ship stations. Average frictional veering of about $10^{\circ}$ exists in the lowest $600-700 \mathrm{~m}$ in this trade wind belt.

Due to Ekman-type reasoning, cyclonic wind shears will produce convergence in the planetary boundary layer and vertical motion at the top of this layer. The relationship between shear of a zonal trade current (i. e., positive relative vorticity resulting from northsouth horizontal shear) and convergence is illustrated in Fig. 39 for an idealized steady zonal trade flow with a barotropic boundary layer. 


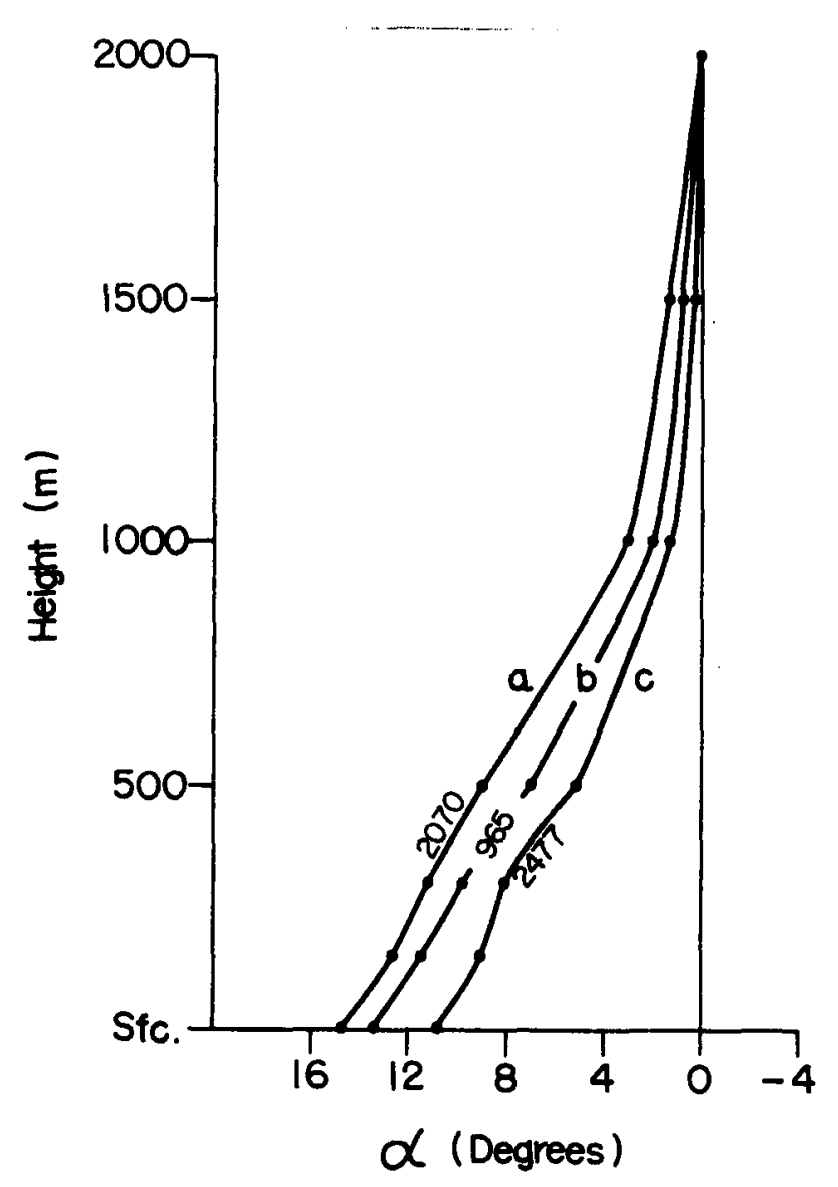

Fig. 38. Wind angle veering with height in the lowest two $\mathrm{km}$ is shown. Wind direction at two $\mathrm{km}$ is used as reference. Curve a represents veering of wind with height from surface vessels which were located at least $1^{\circ}$ latitude from any land. Curve b represents the frictional veering of wind with height as observed from atoll data in the NW Pacific; curve $c$ as observed from surface vessels located within $1^{\circ}$ latitude of land. Note the very small veering of wind with height in the second $\mathrm{km}$ layer. [after Gray (1968)] 


$$
w-S^{N}
$$

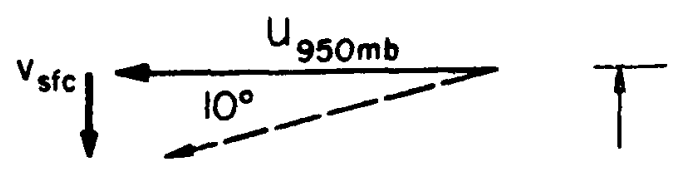

$\begin{aligned} & \text { Mean Con. } \\ & \text { (Sfc to } 950 \mathrm{mb})\end{aligned}=\frac{1}{2} \frac{\delta v_{\text {sc }}}{\delta y}$

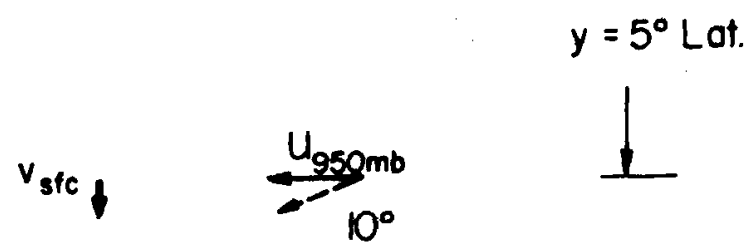

Fig. 39. Portrayal of how cyclonic shear in a zonal non-divergent trade wind current at $950 \mathrm{mb}$ can produce sub-cloud convergence if a frictional veering of $10^{\circ}$ were present. $\mathrm{V}_{\mathrm{SfC}}$ is the meridional surface wind. [after Gray (1968)]

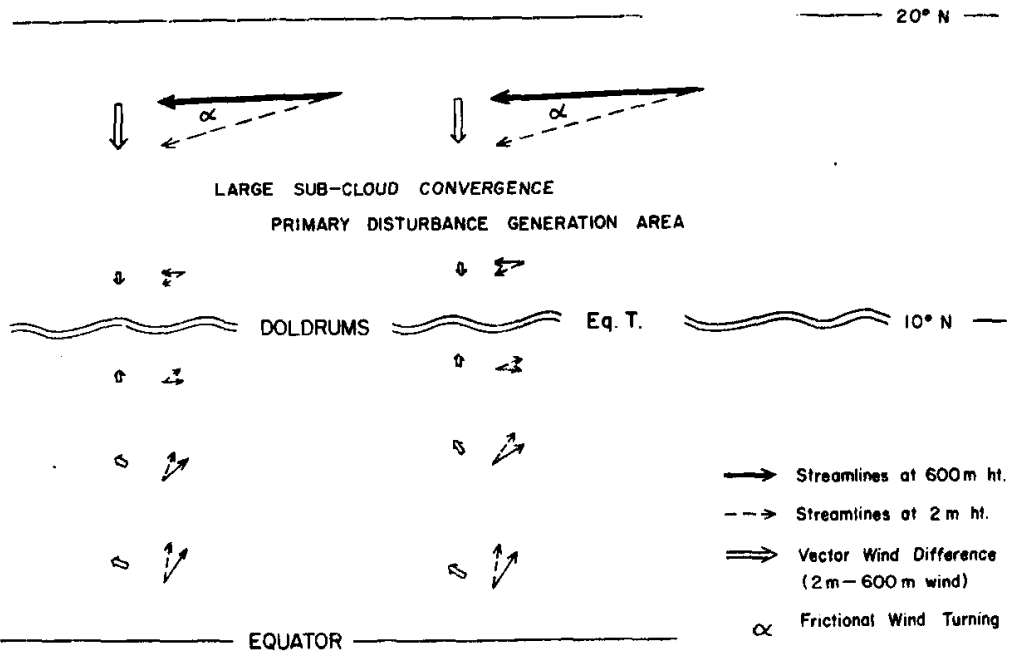

Fig. 40. Idealized portrayal of the difference in wind directions at the surface and at the top of the friction layer relative to a doldrum Equatorial Trough. Note that the wind south of the Equatorial Trough is in general weak and that the sharp cyclonic gradient of trade wind on the poleward side of the Equatorial Trough can lead to substantial lowlevel convergence by virtue of frictional veering. [after Gray (1968)] 
The following general specifications would hold for this conditon:

$$
\overline{\mathrm{C}} \sim-\frac{1}{2} \frac{\Delta \mathrm{V}_{\mathrm{sfC}}}{\Delta \mathrm{y}} \sim \frac{1}{2} \zeta_{\mathrm{r}(950)}
$$

and $\quad \mathrm{w}_{\mathrm{t}} \sim \frac{1}{2} \bar{\zeta}_{\mathrm{r}} \Delta \mathrm{z}$

where $\bar{C}=$ mean convergence in boundary layer (surface to $950 \mathrm{mb}$ )

$$
\begin{aligned}
& \zeta_{\mathrm{r}(950)}=\text { relative vorticity at } 950 \mathrm{mb} \text { due to north-south shear } \\
& \mathrm{w}_{\mathrm{t}}=\text { vertical velocity at top of boundary layer } \\
& \mathrm{V}_{\mathrm{sfc}}=\text { meridional surface wind } \\
& \bar{\zeta}_{\mathrm{r}}=\text { mean relative vorticity in boundary layer } \\
& \mathrm{z}=\text { depth of boundary layer } \sim 600 \mathrm{~m}
\end{aligned}
$$

Fig. 40 further portrays the direct relationship between shear and convergence as it exists in the cyclonic shearing trade current north of the Equatorial Trough. It is precisely in this region of the tropics that frictionally-induced boundary-layer mass and moisture convergence occur to produce and maintain the trade wind cluster.

The frictionless form of the vorticity equation on pressure surfaces, where the twisting term has been neglected,can be expressed as

$$
\mathrm{D}=-\frac{\mathrm{d} \zeta_{\mathrm{a}}}{\mathrm{dt}} / \zeta_{\mathrm{a}}=-\left(\frac{\partial \zeta_{\mathrm{a}}}{\partial \mathrm{t}}+\mathbb{V}_{2} \cdot \nabla \zeta_{\mathrm{a}}+\omega \frac{\partial \zeta_{\mathrm{a}}}{\partial \mathrm{p}}\right) / \zeta_{\mathrm{a}}
$$

in which $\mathrm{D}=$ divergence, $\zeta_{a}=$ absolute vorticity, and the other symbols as usually defined. It is significant that this equation is inadequate in explaining the observed convergence values especially in the lowest $100 \mathrm{mb}$ layer. As shown in Table 2, eq. (3) actually predicts a weak divergence below $900 \mathrm{mb}$ as opposed to the large observed 
Table $2.4^{\circ}$-square area-averaged divergęnce values calculated from eq. (3) and observed. Units are $10^{-6} \mathrm{sec}$.

D layer $(\mathrm{mb})$
[Calculated from eq. (3)]
D

[Observed]

$\begin{array}{rrr}\text { sfc }-950 & 0.9 & -4.9 \\ 950-900 & 0.2 & -5.8 \\ 900-800 & -2.0 & -4.4 \\ 800-700 & -2.5 & -2.6 \\ 700-600 & -0.8 & -2.6 \\ 600-500 & -1.0 & -1.9\end{array}$

convergence over the $4^{\circ}$-square central box for the conservative clusters. Above $900 \mathrm{mb}$ where gust-scale turbulent friction is insignificant, eq. (3) is more applicable but still falls short of describing the observed divergences by approximately $50 \%$.

These cloud clusters must not be thought of as wholly propagating centers of relative vorticity which can be generally handled with frictionless dynamics. The boundary layer and cumulus mixing are fundamental ingredients.

Above the planetary boundary layer where gust-scale friction is small, the horizontal wind shears do not directly contribute to convergence even though convergence is observed up to $400 \mathrm{mb}$ (see Fig. 37). The larger part of the convergence above the boundary layer results from buoyancy-induced entrainment into the cumuli, as portrayed in Fig. 41. The present lagrangian cumulus cloud models [Weinstein and Davis (1968) and Simpson and Wiggert (1969)] 


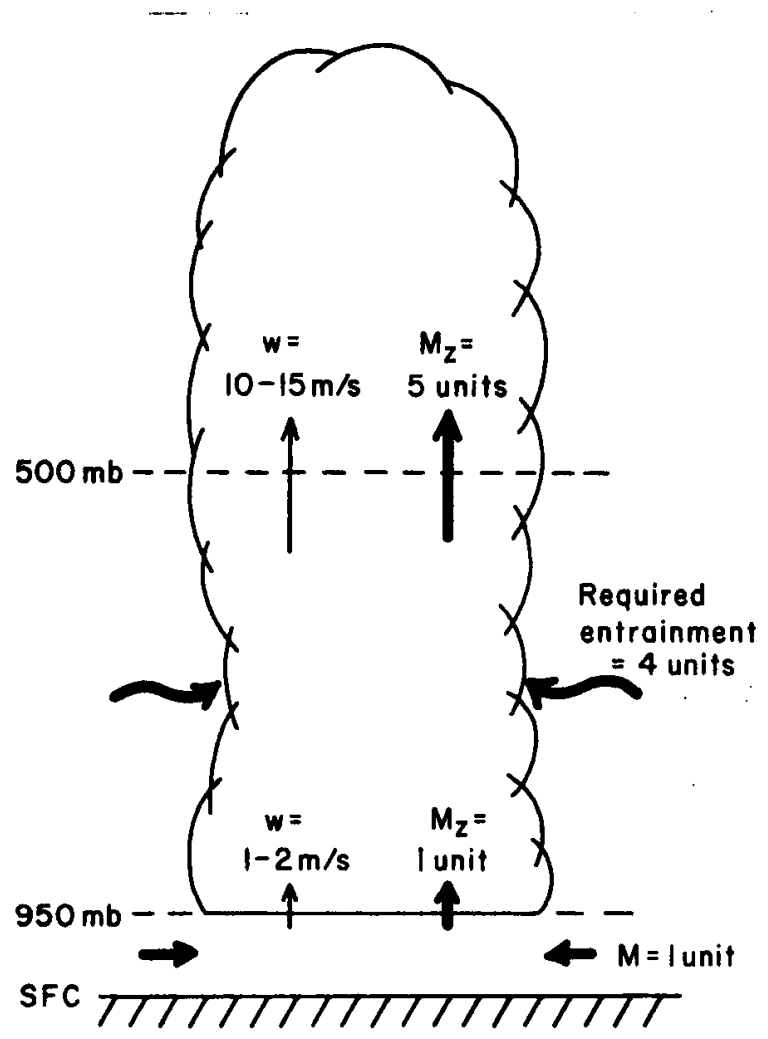

Fig. 41. Illustration of vertical mass fluxes $\left(M_{Z}\right)$ and resulting required lower and middle-level entrainment into the sides of the individual cumulonimbus.

prescribe such an entrainment. Cumulonimbus typically transport 3 to 7 times more mass upward through the 400 to $500 \mathrm{mb}$ surface than is supplied at the top of the boundary layer. Significant entrainment of environmental air into the sides of the cumulonimbus updrafts must continually be occurring. This entrainment requires a large convergence above the boundary layer. Without surface convergence to form the cumuli, a large fraction of the middlelevel convergence would not occur. The cloud cluster divergence profiles of Fig. 37 would then be analogous but opposite to the 


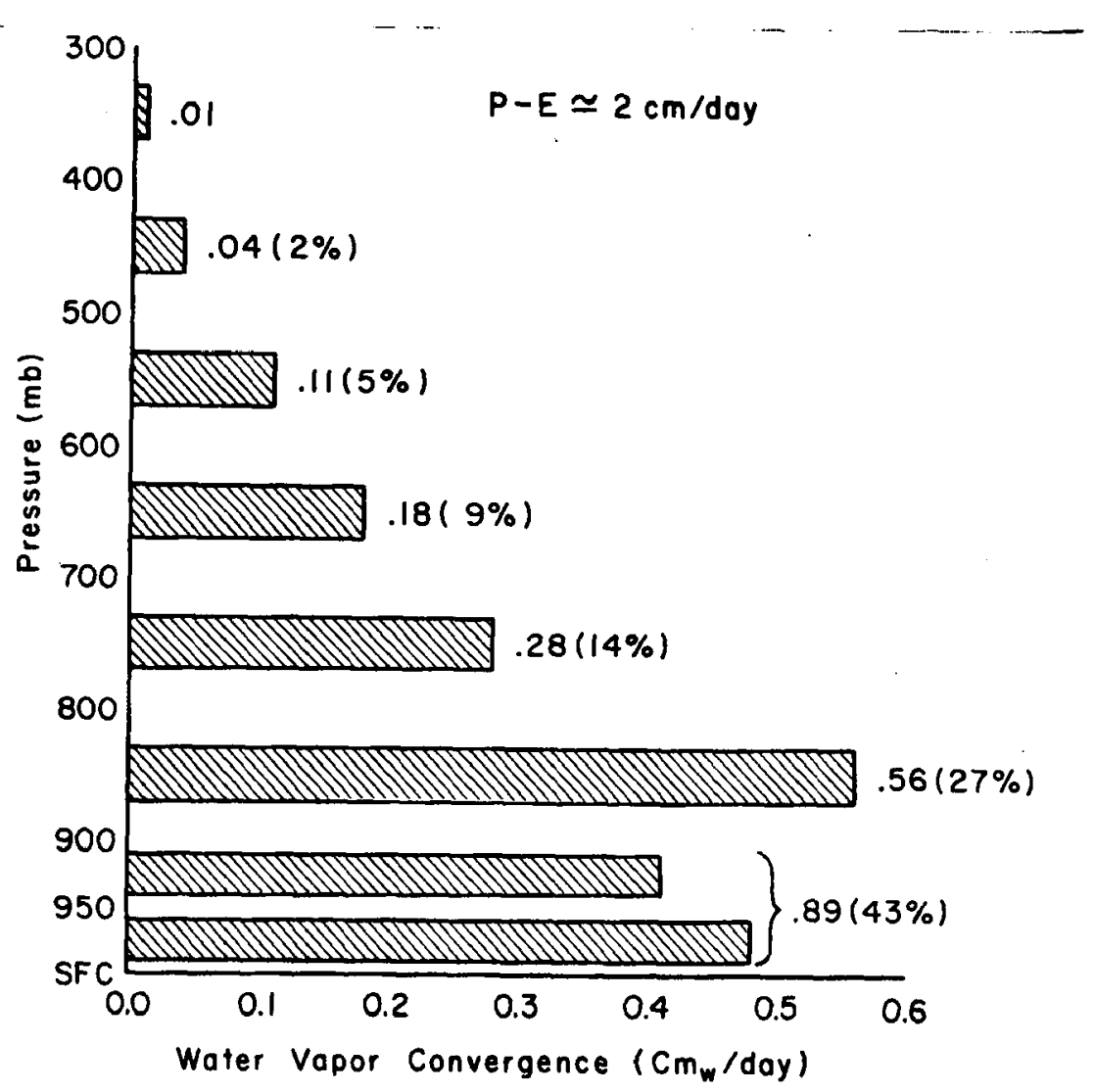

Fig. 42. $4^{\circ}$-square area-average moisture convergence at center of conservative clusters. Contributions of $100-\mathrm{mb}$ layers are given in $\mathrm{cm} /$ day and in \% of total.

clear area profile of upper-level convergence and surface outflow. No significant middle-level convergence is occurring in the clear areas.

Cumulus development is primarily a product of convergence in the planetary boundary layer, i. e., below 600-700 m. In the tropics, cloud bases typically exist at $600-700 \mathrm{~m}$, or $950-940 \mathrm{mb}$.

\section{Moisture Convergence}

A computation of moisture convergence for the conservative clusters (shown in Fig. 42) reveals that although this 
convergence is a maximum in the lowest $100 \mathrm{mb}$ layer, it is not confined to this layer. More than half the net moisture convergence into the cluster-centered $4^{\circ}$-square box occurs above $900 \mathrm{mb}$. Much of the above-the-boundary-layer moisture convergence is likewise induced by the cumulus entrainment-induced mass convergence.

A computation of $\mathrm{P}-\mathrm{E}$ was made from the equation

$$
P-E=-\frac{A}{g} \sum_{p}\left(\frac{\partial q}{\partial t} \Delta p\right)-\frac{\ell}{g} \sum_{p}\left(V_{n} q \Delta p\right)
$$

where

$$
\begin{aligned}
P & =\text { precipitation } \\
E & =\text { evaporation at the ground } \\
A & =\text { area of } 4^{\circ} \text {-square box } \\
g & =\text { acceleration of gravity } \\
q & =\text { specific humidity } \\
\ell & =\text { increment of boundary length } \\
V_{n} & =\text { wind component normal to boundary } \\
\Delta p & =\text { thickness of individual layers } \\
\frac{\partial}{\partial t} & =\text { change over } 24 \text { hours }
\end{aligned}
$$

The first term on the right represents the change in water vapor storage over 24 hours within the volume, and the second term is the advection of vapor into or out of the volume. The result is $P-E=2.0 \mathrm{~cm} /$ day, with the advection term contributing more than $90 \%$. If $\mathrm{E}$ is assumed to be $0.5 \mathrm{~cm} / \mathrm{day}$, then the resulting $4^{\circ}$-square 
area-averaged precipitation from a typical cloud cluster is 2.5 $\mathrm{cm} /$ day or $1 \mathrm{in} /$ day. Rainfall of this magnitude requires the presence of cumulonimbi, and indeed the bulk of the rainfall in this area comes from cumulonimbi which are maintained by synopticscale cyclonic wind shears.

Vertical Velocity

Vertical cross sections of kinematically-computed vertical velocities taken north-south and east-west are presented in Figs. 43 and 44 for the conservative clusters and in Figs. 45 and 46 for the clear areas. For the clusters, upward motion is a maximum at the cluster center and is confined to a narrow north-south extent. The clear areas exhibit a broad area of subsidence with maximum values north of the center.

Fig. 47 presents vertical velocity profiles at the $4^{\circ}$-square center of each cluster type. All cluster categories show maximum vertical motion at 400 to $300 \mathrm{mb}$. A typical area-averaged vertical velocity at this level is $170 \mathrm{mb} /$ day or $3 \mathrm{~cm} / \mathrm{sec}$. The upward motion becomes zero between 200 and $100 \mathrm{mb}$. It was unexpected that the kinematic vertical motion determination would give such consistent results. This is felt to be the result of the large statistical averaging process which smoothed out random errors. 


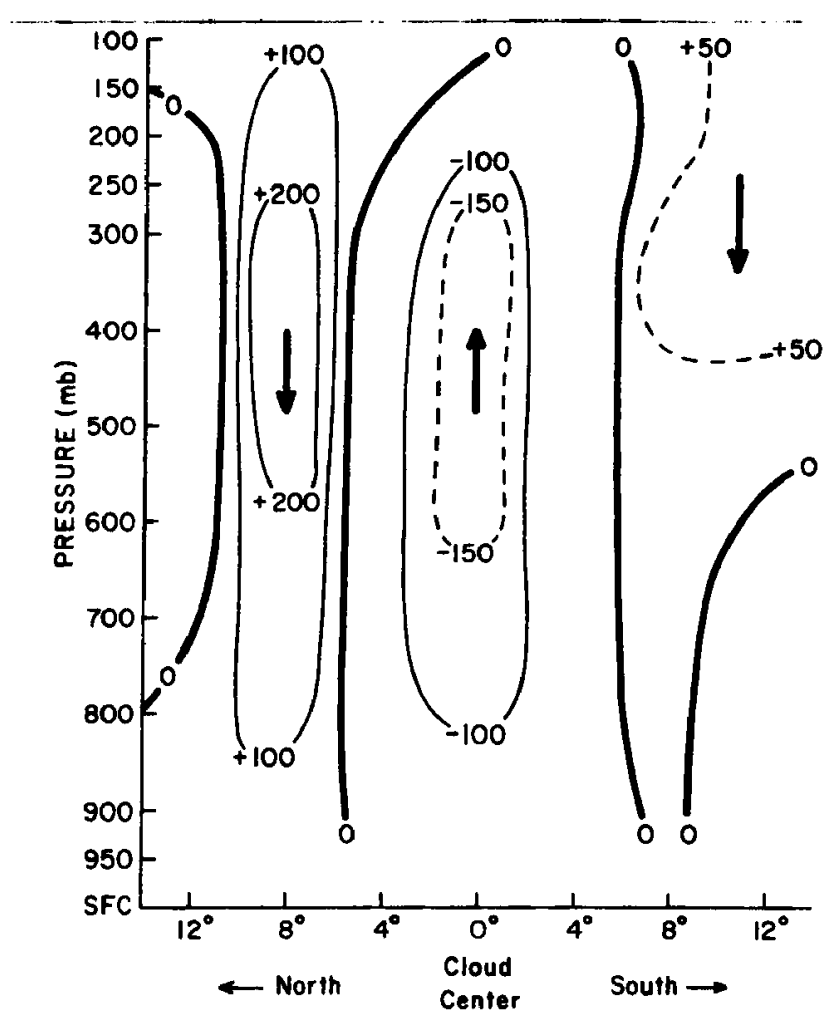

Fig. 43. Vertical north-south cross section of vertical velocity for conservative clusters. Units are mb/day.

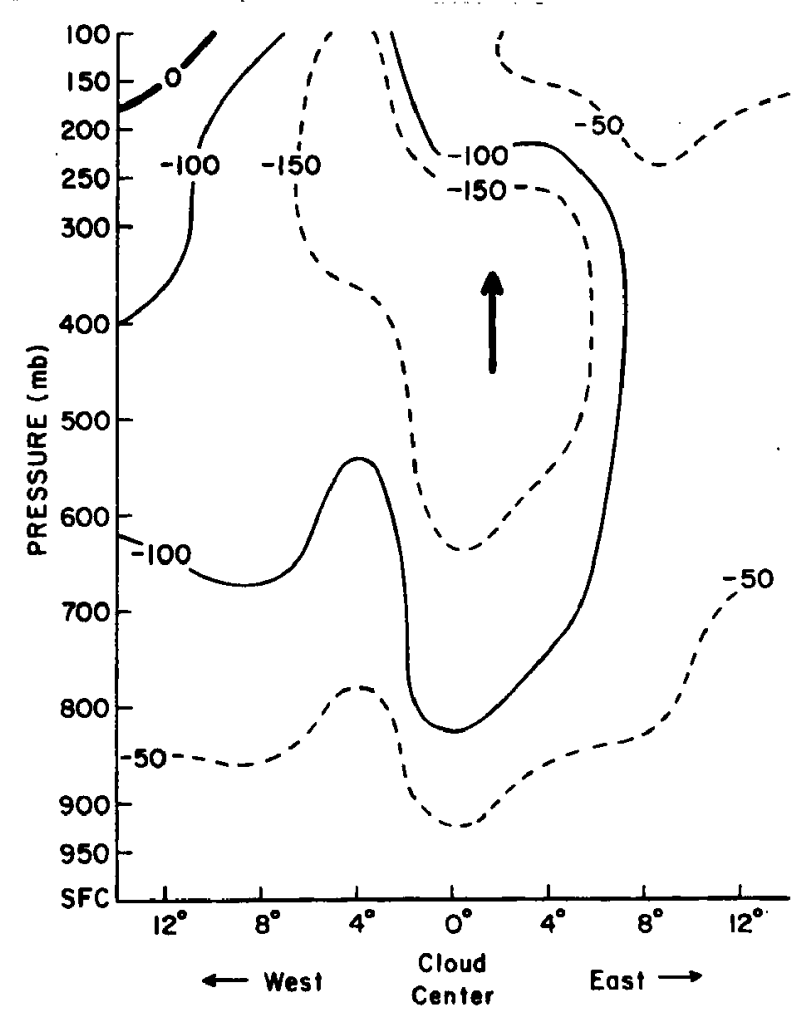

Fig. 44. Vertical east-west cross section of vertical velocity for conservative clusters. Units are mb/day. 


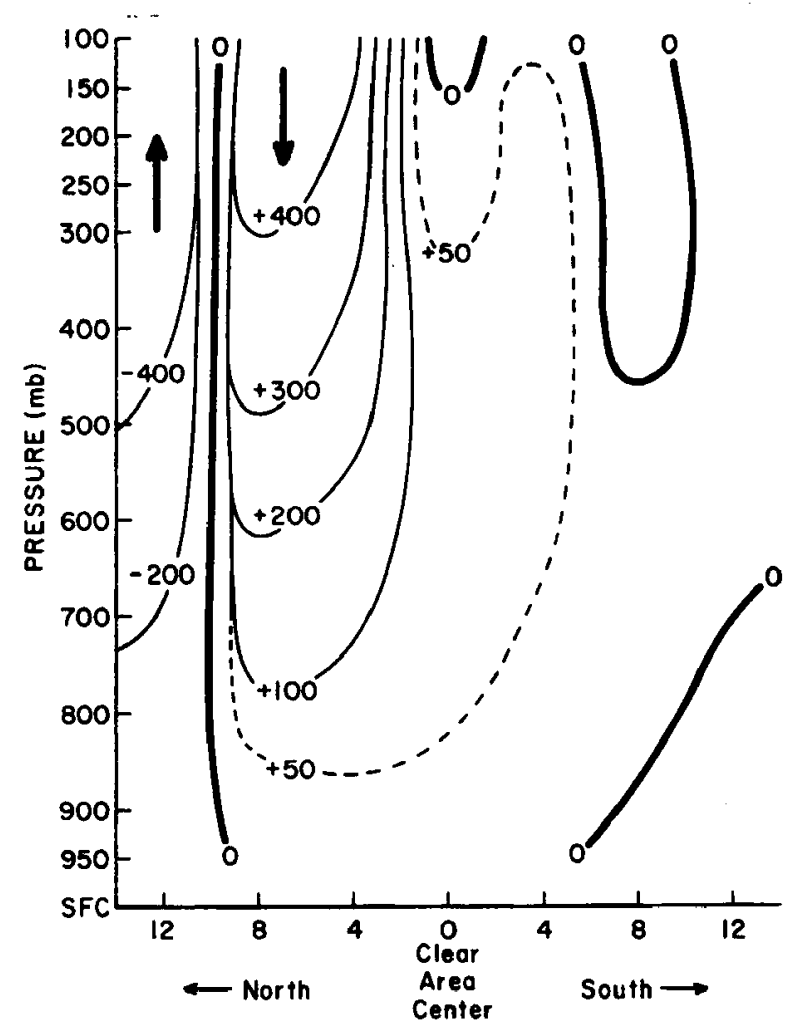

Fig. 45. Vertical north-south cross section of vertical velocity for clear areas. Units are mb/day.

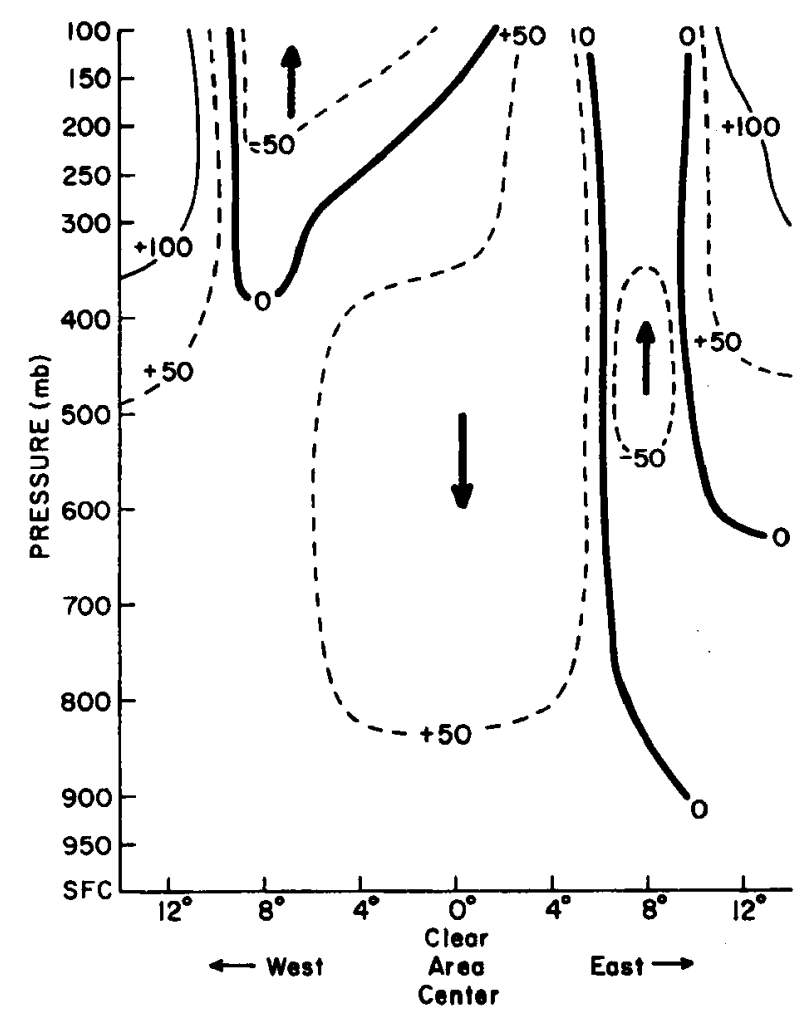

Fig. 46. Vertical east-west cross section of vertical velocity for clear areas. Units are mb/day. 


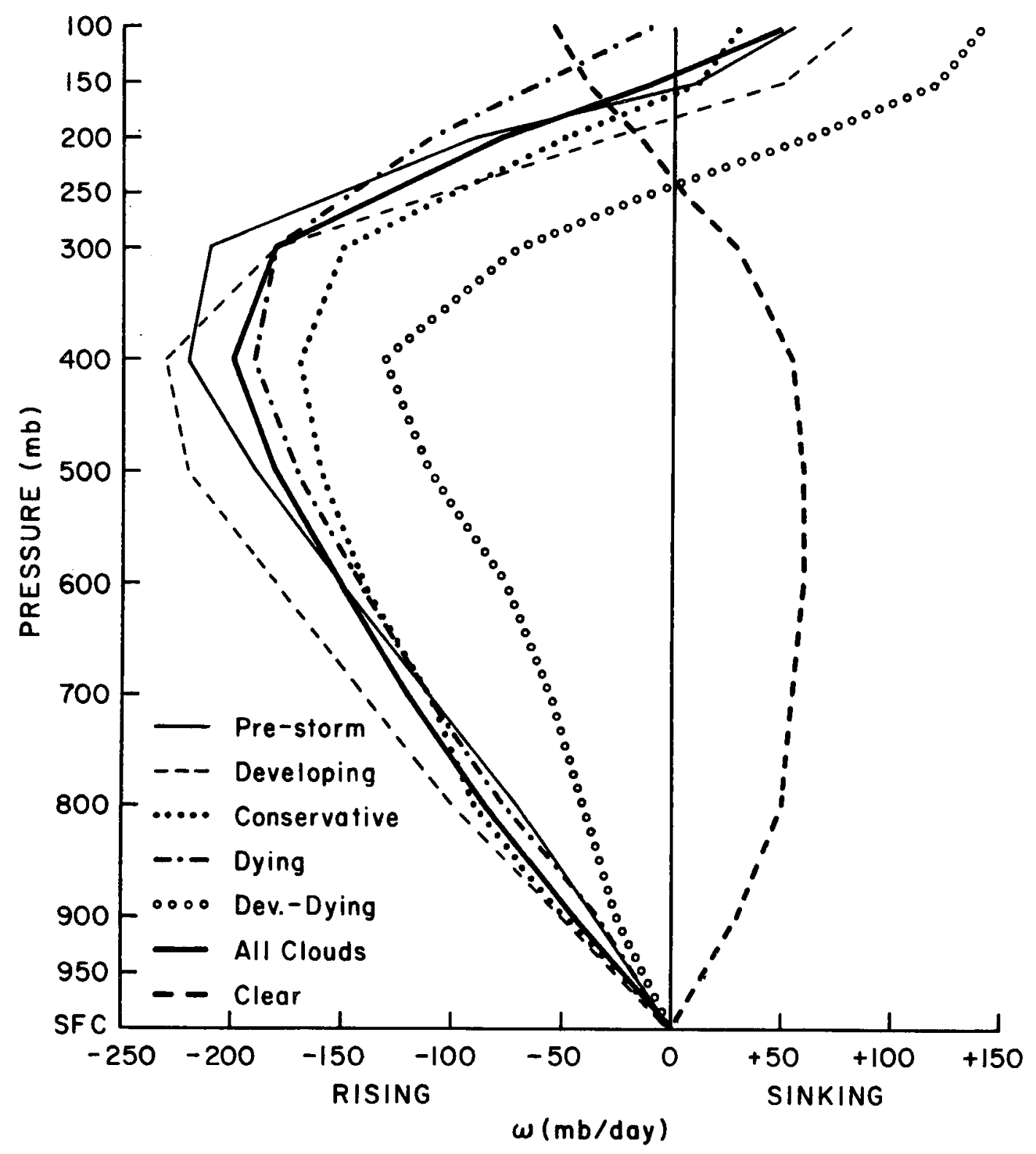

Fig. 47. Profiles of $4^{\circ}$-s quare area-average vertical velocity at cluster centers. 


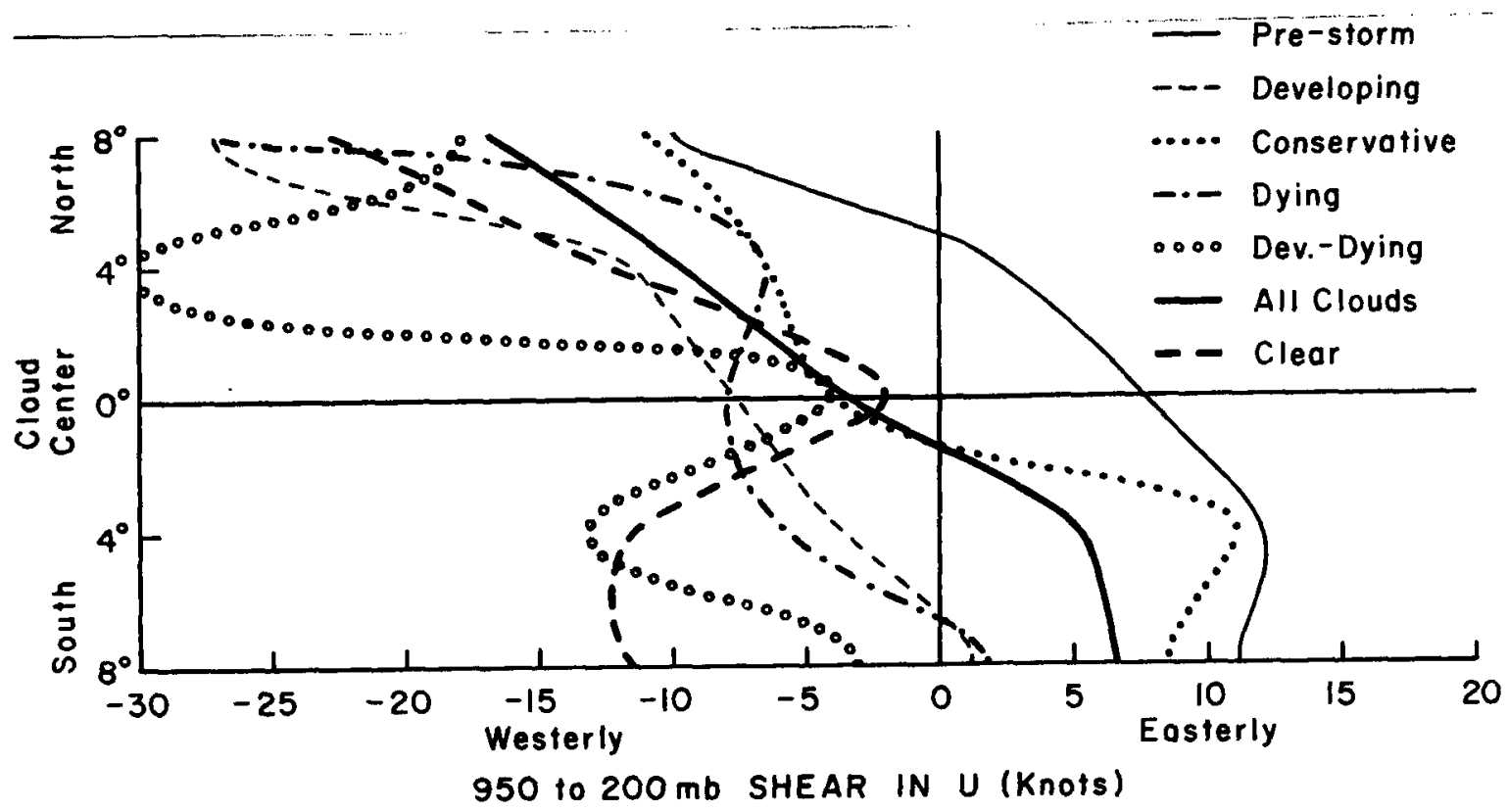

Fig. 48. Vertical shear of zonal wind $\left(u_{950}-u_{200}\right)$ at $4^{\circ}$ latitude intervals across cluster centers. Westerly shear denotes stronger west winds (or weaker east winds) aloft than near surface.

\section{Vertical Wind Shear}

Fig. 48 gives the 950 to $200 \mathrm{mb}$ shear in the $\mathrm{u}$ component. At the center of the conservative clusters this shear is westerly and only $4 \mathrm{kts}$. The small magnitude of this shear is thought to be important for cluster dynamics. A small vertical shear means a weak non-divergent ventilation influence [Gray (1968)]. Any sensible heat realized eithe $\mathrm{r}$ from condensation or from subsidence is not advected away from the cluster area but rather is allowed to accumulate. This is felt to be an important process in maintaining the conservative clusters and for tropical storm development.

Shears at the centers of all the trade wind cluster types are very small (within $\pm 8 \mathrm{kts}$.) by mid-latitude standards. It is 
curious that the pre-storm clusters are the only cluster type with an easterly vertical shear at their center, i. e., stronger easterlies aloft than near the surface (see also Fig. 15).

\section{Kinetic Energy Budget}

The kinetic energy equation can be expressed as

$$
\begin{aligned}
\int_{\mathrm{p}} \int_{\mathrm{A}} \frac{\partial \mathrm{KE}}{\partial \mathrm{t}} \delta \mathrm{A} \frac{\delta \mathrm{p}}{\mathrm{g}}= & -\int_{\mathrm{p}} \int_{l} \mathrm{~V}_{\mathrm{n}} \mathrm{KE} \delta \ell \frac{\delta \mathrm{p}}{\mathrm{g}}-\int_{\mathrm{p}} \int_{\mathrm{A}} \frac{\partial \omega \mathrm{KE}}{\partial \mathrm{p}} \delta \mathrm{A} \frac{\delta \mathrm{p}}{\mathrm{g}} \\
& -\int_{\mathrm{p}} \int_{\mathrm{A}} \mathbb{V}_{2} \cdot \nabla \mathrm{z} \delta \mathrm{A} \delta \mathrm{p}-\text { Dissipation }
\end{aligned}
$$

where $\mathrm{KE} \quad=$ kinetic energy $=\frac{1}{2} \mathrm{~V}^{2}$

$\frac{\partial}{\partial t}=$ change over 24 hours

$$
\begin{array}{ll}
\mathrm{A} & =\text { area } \\
\mathrm{p} & =\text { pressure } \\
\mathrm{g} & =\text { acceleration of gravity } \\
\ell & =\text { increment of boundary length } \\
\mathrm{V}_{\mathrm{n}} & =\text { wind component normal to boundary } \\
\omega & =\text { vertical velocity } \\
\mathbf{V}_{2} & =\text { horizontal wind vector } \\
\mathrm{z} & =\text { height of isobaric surface }
\end{array}
$$

The four terms on the right of eq. (5) represent, respectively, the horizontal advection, the vertical transport, the generation, and the dissipation (which cannot be calculated) of kinetic energy per unit volume. Eq. (5) can be written symbolically as 


$$
\frac{\partial K E}{\partial t} \text { (observed) }=\underbrace{-V_{n} K E-\frac{\partial \omega K E}{\partial p}-V_{n} \Delta z}_{\frac{\partial K E}{\partial t} \text { (calculated) }}+\operatorname{Residual~(6)~}
$$

The residual term can be viewed as a measure of the difference between the observed and the frictionless calculated kinetic energy tendency. The residual is a combination of frictional dissipation to heat and any other influences such as cumulus-scale mixing and possibly some data unrepresentativeness. The residual could not be directly assesised.

The terms of eq. (6) were computed at individual levels over the central $4^{\circ}$-square and are presented graphically in Fig. 49 for the conservative clusters (very representative of all cluster averages) and in Fig. 50 for the clear areas. For the clusters, the observed $\mathrm{KE}$ generation is found to be small at all levels, with a very slight positive generation (wind blowing down the height gradient) in the low levels and negative generation (wind blowing up the height gradient) in the upper levels. This result is due to the very small isobaric height gradients inside and outside of the clusters. The horizontal advection term shows a significant inflow of $\mathrm{KE}$ from the surface to $400 \mathrm{mb}$ and a very large outflow centered at $200 \mathrm{mb}$. The vertical transport term opposes and closely balances this horizontal advection. The vertical transport term is seen to 
decrease the KE of the low levels by transporting it upward where it makes a large positive contribution centered also at $200 \mathrm{mb}$. Neglecting the residual term, the calculated $\frac{\partial K E}{\partial t}$ shows an increase of $\mathrm{KE}$ in the low levels, very little change in the middle levels, and a significant decrease in the outflow region of the upper troposphere. The observed changes of $\mathrm{KE}$ over 24 hours, on the other hand, show near zero values everywhere except in the outflow region, where $\mathrm{KE}$ is decreasing.

The residual term represents the difference between the calculated and observed $\mathrm{KE}$ changes. In the low levels, the residual is negative, whereas in the upper-level outflow region, it is positive. This residual is largely attributed to the vertical $\mathrm{KE}$ transport by cumulus up- and downdrafts which is not properly represented in the $4^{\circ}$-square composites. Both up and down motions are occurring. The net vertical transports are thus larger than those indicated by the mean vertical motion itself. Gray (1967) has previously discussed this type of cumulus-induced sub-grid-scale residual influence.

The conclusion drawn from this kinetic energy budget is that the cloud clusters, in the net, are typically vertical transporters of $\mathrm{KE}$ with little internal generation or dissipation. $\mathrm{KE}$ is imported in the lower half of the troposphere, transported upward within the cumulonimbus clouds, and exported in the 


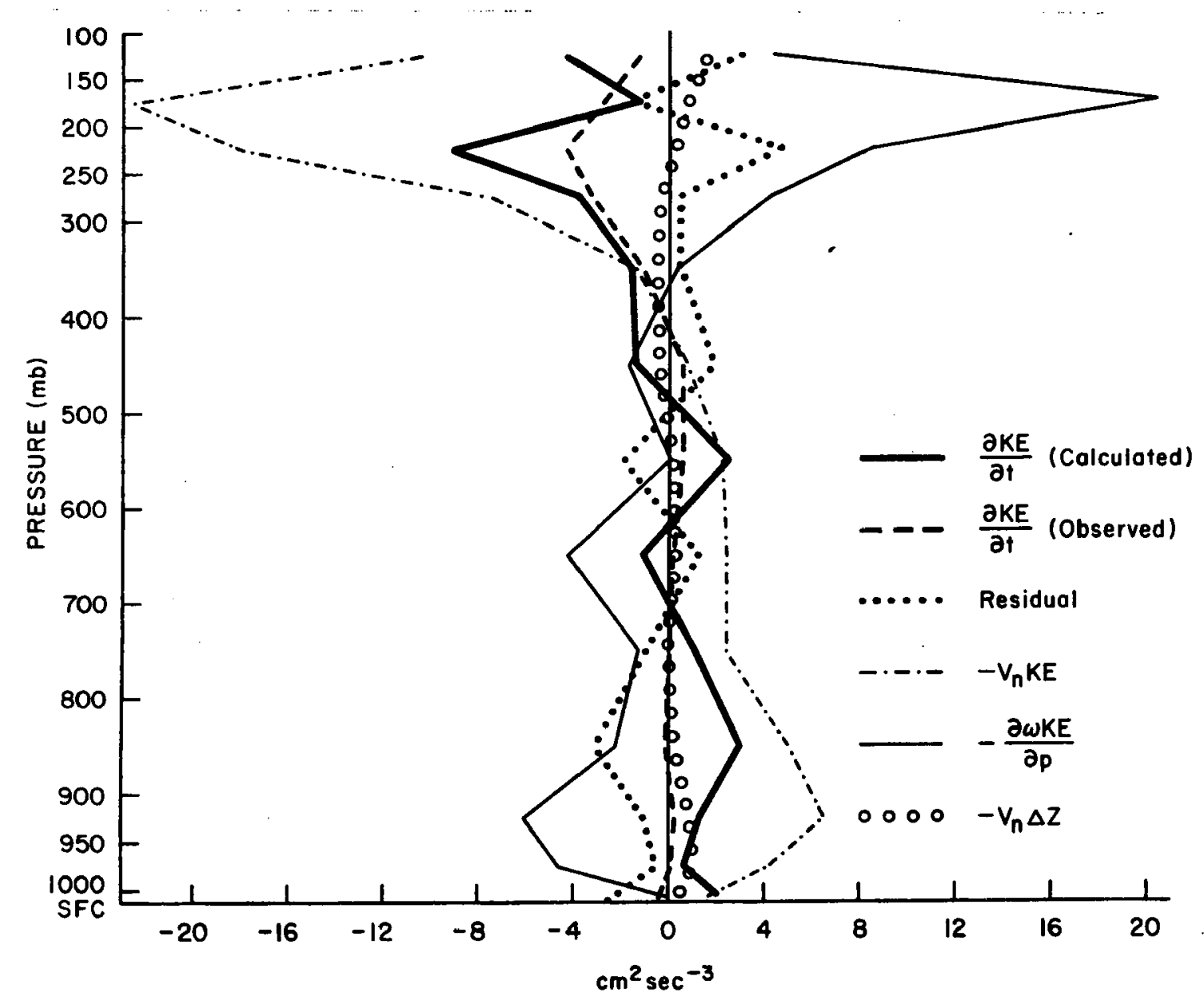

Fig. 49. Kinetic energy budget for conservative clusters: Vertical profiles of the terms of the kinetic energy equation. The computation was made over the $4^{\circ}$-square center box, and all values are per unit mass. 


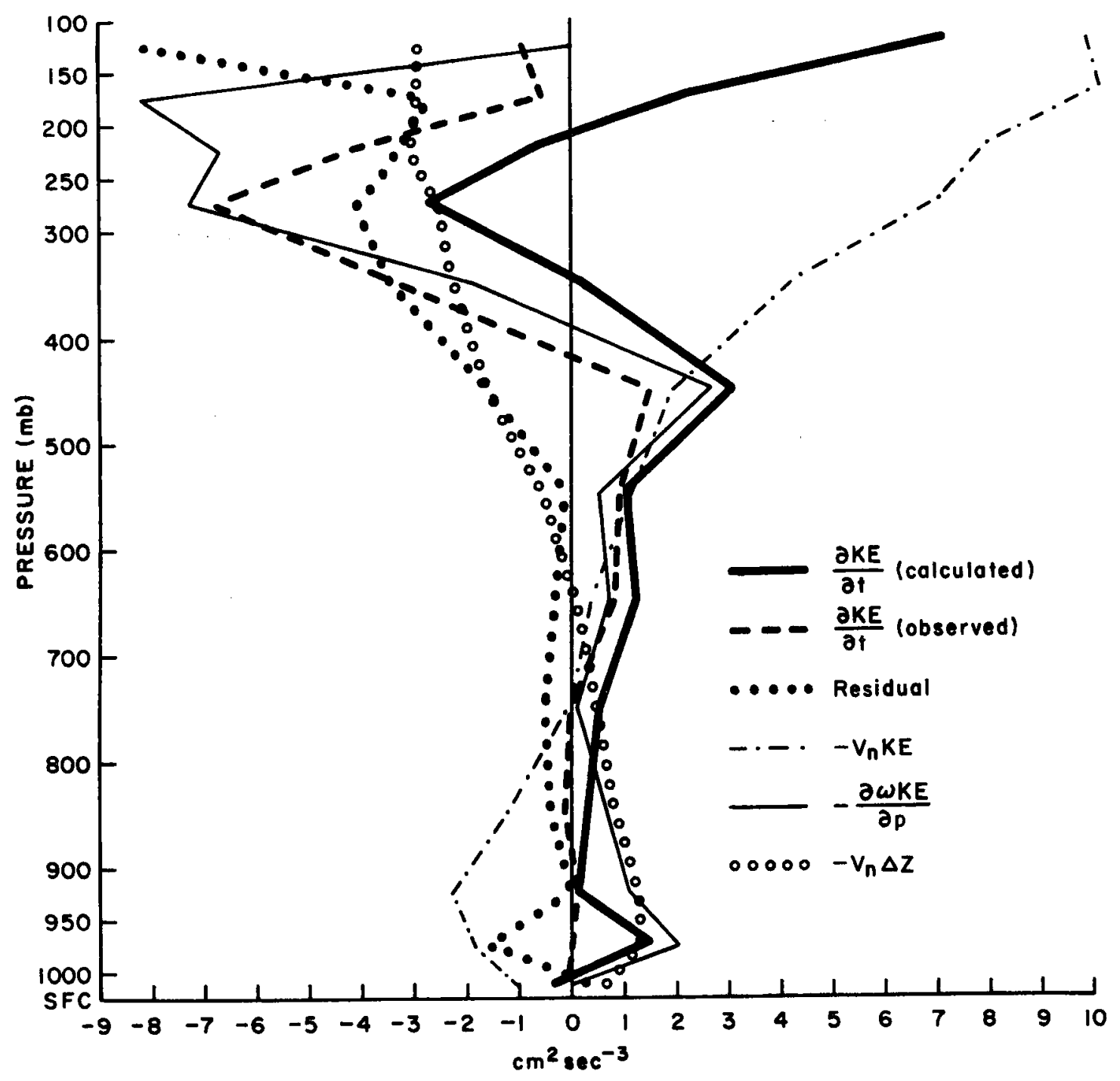

Fig. 50. Kinetic energy budget for clear areas: Vertical profiles of the terms of the kinetic energy equation. The computation was made over the $4^{\circ}$-square center box, and all values are per unit mass. 
upper troposphere outflow to the surroundings. The net effect is an almost neutral observed kinetic energy tendency.

The terms of the kinetic energy equation for the clear areas (Fig. 50) show basic differences from those for the clusters. There is a positive generation of $\mathrm{KE}$ in the low levels but a negative generation (wind blowing up the height gradient convergence into an anticyclone) in the high levels. The only positive contribution in the upper levels comes from the advection term, a result of the substantial inflow in the high troposphere. Low-level outflow advects $\mathrm{KE}$ out of the clear areas. The vertical transport term acts to remove $\mathrm{KE}$ from the upper levels and to carry it downward such that there is a positive contribution in the low levels. The advection and vertical transport terms are thus seen to act just oppositely in the clear and cluster areas. The observed and calculated $\frac{\partial K E}{\partial t}$ curves are similar in the lower half of the troposphere. No cumulus and no residual effect is thus present in this layer. A significant residual exists only in the upper troposphere.

The processes transporting kinetic energy act oppositely in clear areas than in cloud clusters. The advection and vertical transport terms dominate the kinetic energy budgets of both environments, but with much larger magnitudes in the cloud clusters. 


\section{Absolute Vorticity Budget}

The vorticity equation on pressure surfaces can be written as

$$
\begin{aligned}
\int_{\mathrm{p}} \int_{\mathrm{A}} \frac{\partial \zeta_{\mathrm{a}}}{\partial \mathrm{t}} \delta \mathrm{A} \frac{\delta \mathrm{p}}{\mathrm{g}}= & -\int_{\mathrm{p}} \int_{\ell} \mathrm{V}_{\mathrm{n}} \zeta_{\mathrm{a}} \delta \ell \frac{\delta \mathrm{p}}{\mathrm{g}}-\int_{\mathrm{p}} \int_{\mathrm{A}} \frac{\partial \omega \zeta_{\mathrm{a}}}{\partial \mathrm{p}} \delta \mathrm{A} \frac{\delta \mathrm{p}}{\mathrm{g}} \\
& -\int_{\mathrm{p}} \int_{\mathrm{A}} \mathrm{D} \zeta_{\mathrm{a}} \delta \mathrm{A} \frac{\delta \mathrm{p}}{\mathrm{g}}-\dot{\mathrm{T}}+\mathrm{F}
\end{aligned}
$$

where $\zeta_{\mathrm{a}}=$ absolute vorticity

$$
\begin{aligned}
& \frac{\partial}{\partial t}=\text { change over } 24 \text { hours } \\
& \mathrm{p} \quad=\text { pressure } \\
& \mathrm{g} \quad=\text { acceleration of gravity } \\
& \ell \quad=\text { increment of boundary length } \\
& V_{n}=\text { wind component normal to boundary } \\
& \omega \quad=\text { vertical velocity } \\
& D \quad=\text { divergence } \\
& T \quad=\text { twisting term } \\
& F \quad=\text { friction term }
\end{aligned}
$$

This equation has also been evaluated for the central $4^{\circ}$-square of the conservative clusters and for the clear areas. The first three terms on the right are, respectively, the advection term, the vertical transport term, and the divergence term. Eq. (7) can be simplified and written symbolically as

$$
\frac{\partial \zeta_{a}}{\partial t} \text { (observed) }=\underbrace{-V_{n} \zeta_{a}-\frac{\partial \omega \zeta_{a}}{\partial p}-D \zeta_{a}}_{\frac{\partial \zeta_{a}}{\partial t} \text { (calculated) }}+\text { Residual }
$$




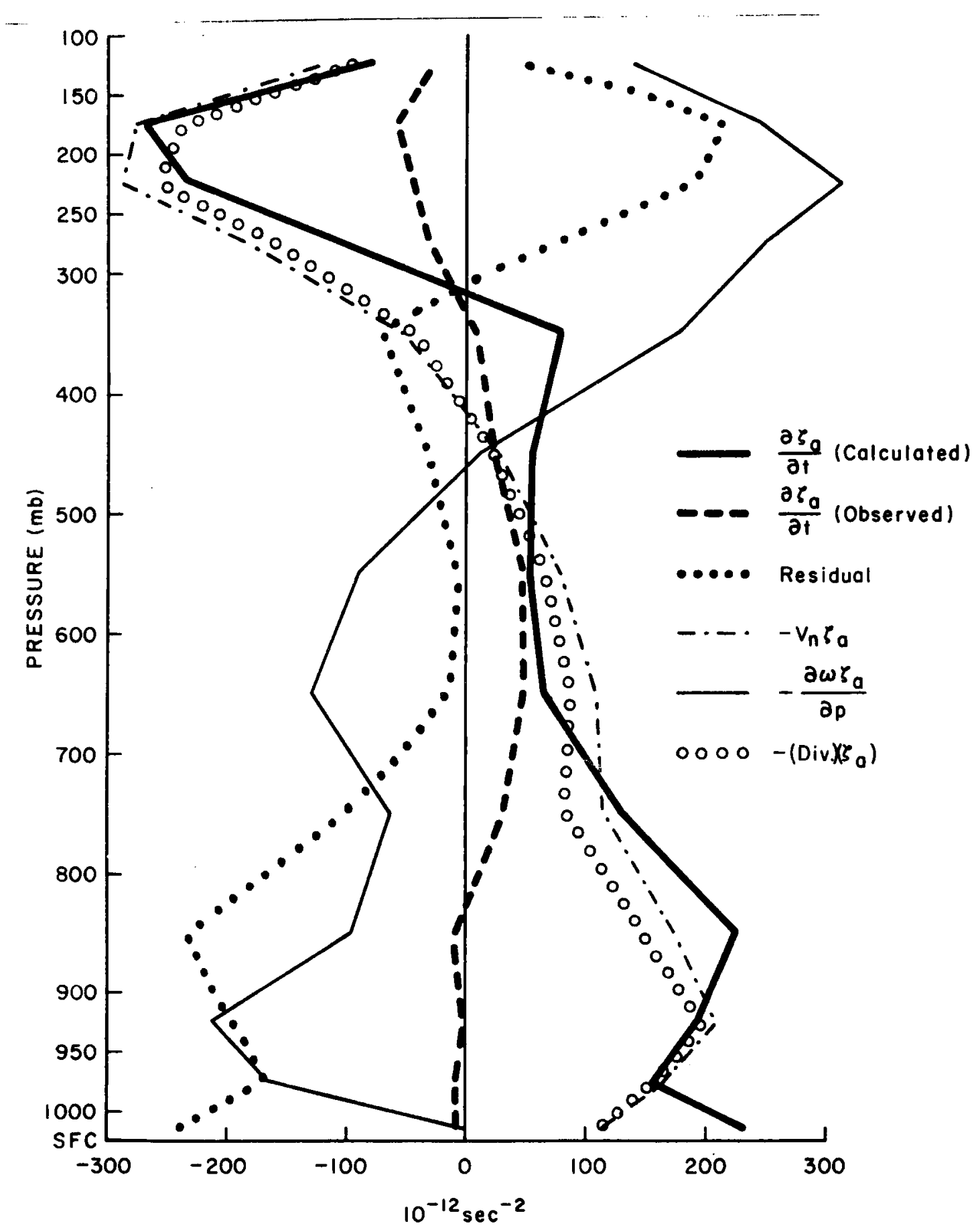

Fig. 51. Absolute vorticity budget for conservative clusters: Vertical profiles of the terms of the vorticity equation. The computation was made over the $4^{\circ}$-square center box, and all values are per unit mass. 


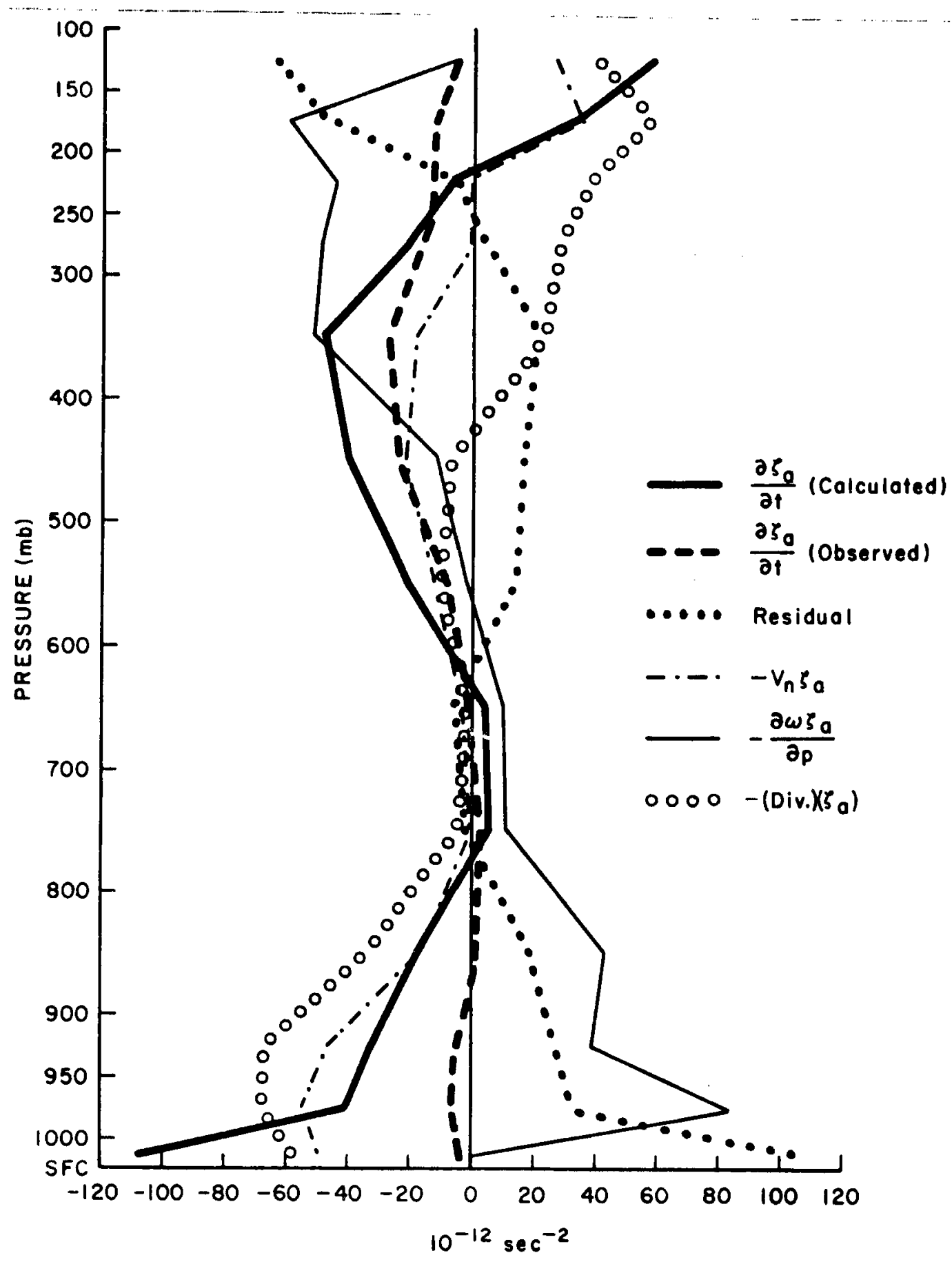

Fig. 52. Absolute vorticity budget for clear areas: Vertical profiles of the terms of the vorticity equation. The computation was made over the $4^{\circ}$-square center box, and all values are per unit mass. 
Here, the residual includes the twisting term and the friction or sub-synoptic-influence term. The terms of eq. (8) are presented graphically in Fig. 51 for the conservative clusters and in Fig. 52 for the clear areas.

For the clusters, the advection and divergence terms act similarly to increase vorticity in the lower half of the troposphere and to decrease vorticity in the upper half. The vertical transport takes vorticity out of the lower layers and into the upper layers. The sum of these three terms yields calculated $\frac{\partial \zeta a}{\partial t}$ values which are positive below $300 \mathrm{mb}$ and negative above this level. The observed change is very much less, however, so that a large negative residual must exist in the low levels and a large positive residual in the high levels. Similar to the KE residual, the vorticity residual might also be largely explained by cumulus up- and downdrafts vertically rearranging the momentum. The characteristic difference of vertical wind shears north and south of the clusters (see Fig. 48) and the presence of cumulus clouds prescribe such a relationship. This influence of the cumulus, of course, could not be measured. Finally, an integration of the observed $\frac{\partial \zeta a}{\partial t}$ values over all layers for the clusters reveals only a slight increase in vorticity over 24 hours.

Compared with the clusters, the clear areas (Fig. 52) are revealed to be much weaker systems, with all terms having smaller magnitudes. The divergence, advection, and vertical transport 
terms act to import vorticity in the upper levels, carry it downward, and export it near the surface. The integrated observed vorticity change over 24 hours shows a small net decrease. The residual influence is observed to be much less with the clear areas than with the clusters.

\section{$\underline{\text { Contrast with }} \underline{\text { Clear }} \underline{\text { Areas }}$}

Although both cloud clusters and clear areas are deeply embedded in the trade current (see Figs. 16 and 17), vital dynamic differences exist between the two environments. The data for the clear areas show a striking departure from any of the cloud areas. In the clear areas, low-level shears are markedly anticyclonic, and relative vorticities are negative throughout the troposphere. The divergence profile reveals low-level divergence, upper-level convergence, and a deep middle layer of non-divergence. Subsidence throughout most of the troposphere suppresses cumulus development. Horizontal and vertical transports of kinetic energy and absolute vorticity are also weak.

\section{Thermodynamic Properties}

Temperature and Moisture

Soundings for the conservative clusters and for the clear areas are presented in Fig. 53. The clear area sounding is representative of the clear environment between well-defined cloud clusters. Whereas there is little difference in the dry-bulb temperature curves (both have lapse rates slightly steeper than moist adiabatic), it is 
immediately noticeable that there are large moisture differences between the two environments. For constrast, the level at which the relative humidity has fallen off to $50 \%$ is at $450 \mathrm{mb}$ for the clusters and $840 \mathrm{mb}$ for the clear areas.

This moisture difference is also evident in the vertical profiles of $\theta_{e}$ shown in Fig. 54. Since $\theta_{e} \sim \frac{1}{c_{p}}\left(g z+c_{p} T+L q\right)$, and since only small temperature and isobaric height differences exist between the two environments, the large difference in $\theta_{\mathrm{e}}$ is attributable only to the difference in water vapor. The drier clear environment is undoubtedly a product of broad-scale subsidence, as shown in the vertical motion cross sections of Figs. 45 and 46.

\section{$\underline{\text { Stability }}$}

The $\theta_{\mathrm{e}}$ profiles indicate that the clear areas possess a much larger Cumulus Potential Buoyancy, defined as $\theta_{\mathrm{e}}$ (sfc) $-\theta_{\mathrm{e}}$ (minimum), than do the cloud areas. Thus, if a parcel could be raised to the level of free convection, the unentrained parcel would have more buoyancy and would accelerate upward more rapidly in the clear than in the cloud environment. However, the absence of boundary-layer convergence eliminates the initial lifting mechanism to allow the parcel to attain buoyancy. A dynamic constraint exists, therefore, to cumulus development in clear areas. In addition, a strong thermodynamic constraint also exists. This is dry-air entrainment (see Fig. 53), 


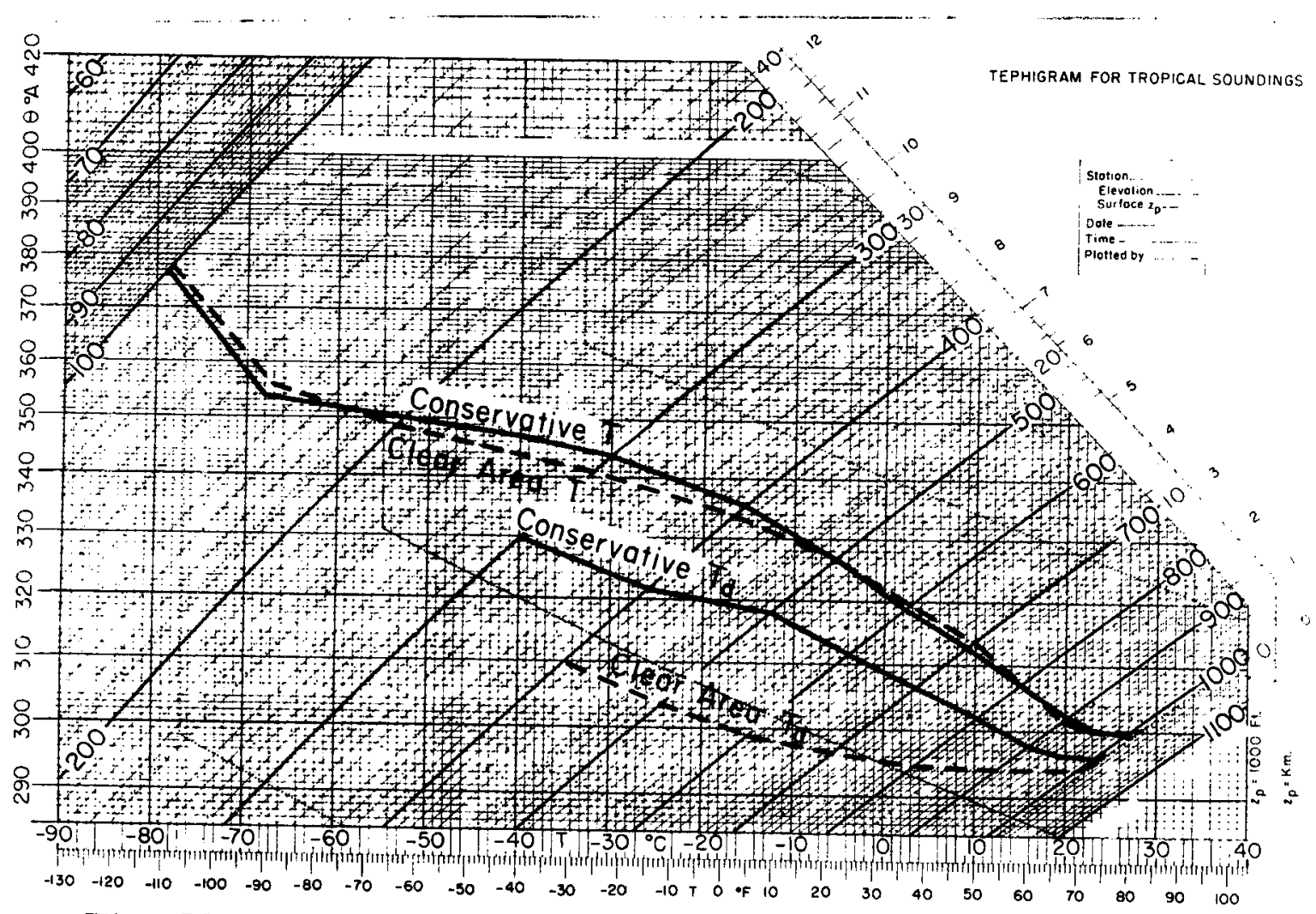

Fig. 53. Mean soundings ( $\mathrm{T}$ and $\mathrm{Td}$ ) at centers of cloud clusters (solid) and clear areas (dashed).

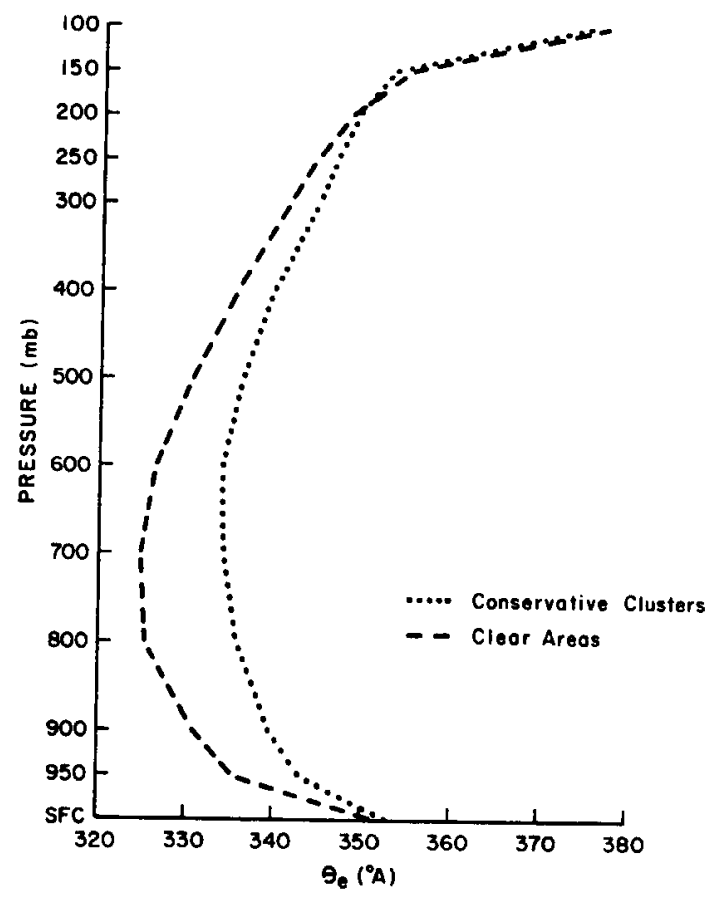

Fig. 54. Vertical profiles of $\theta_{e}$ at centers of cloud clusters (dotted) and clear areas (dashed). 
causing rapid erosion of cumulus towers. In the cluster areas, on the other hand, the entrainment constraint is much less.

Stability in the cluster regions is also affected by cumulus downdrafts. Zipser (1969) has observed that these spreading downdrafts strongly suppress cumulus buoyancy for a few hours. This may offer a partial explanation to the frequently observed pulsating nature of these cloud clusters.

\section{Temperature and Thickness Considerations}

Fig. 55 compares the heights of isobaric surfaces in the cloud environment with the heights of the same surfaces in the clear environment. The isobaric heights in the low levels of cloud clusters are lower than the same isobaric heights in the clear areas. Conversely, the high-level cloud cluster isobaric heights are higher than those in the clear areas. For example, the height of the $1000 \mathrm{mb}$ surface is 24 meters lower in the cloud areas than in the clear areas, whereas the $200 \mathrm{mb}$ surface is 16 meters higher. Although these height differences are not great, there is an increased thickness between pressure surfaces in the cloud areas. As long as the profile of Fig. 55 slopes upward from left to right, there is greater thickness between successive pressure surfaces in the cloud areas than in the clear areas. Except for the 700 to $500 \mathrm{mb}$ layer, this is true.

The question of whether these trade wind clusters are warm or cold core arises. The temperature data show that the lower layers 


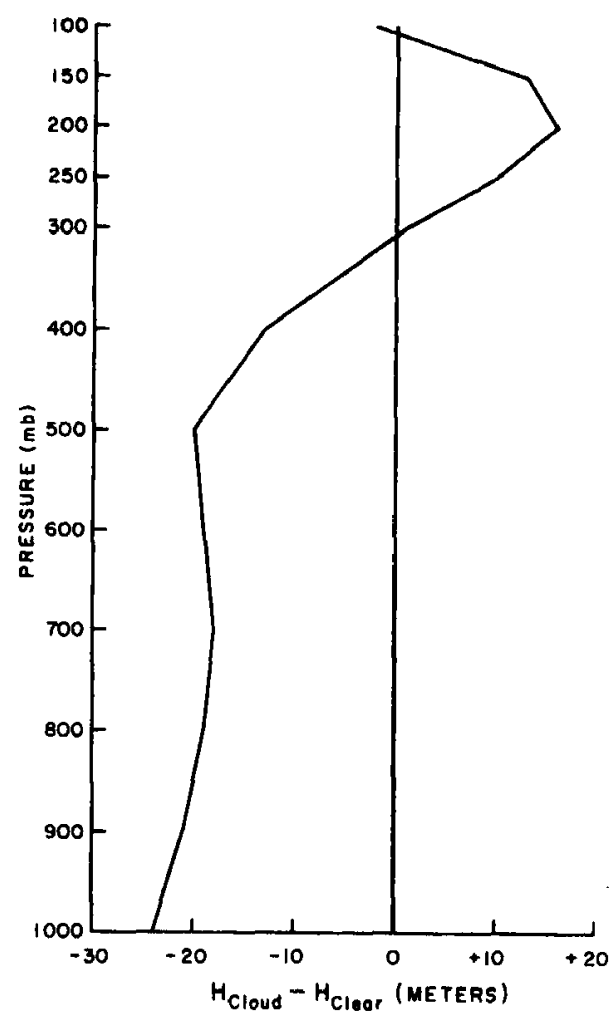

Fig. 55. Height difference of corresponding isobaric surfaces between center of cloud clusters and center of clear areas.

are slightly colder and the upper layers are warmer than the surroundings. The integrated effect is a slight tropospheric cooling. But from the hydrostatic viewpoint, heat added to upper layers produces a greater thickness change than if added below. Hence, even though clusters have weak cold cores, the heat is distributed in the vertical so as to produce a net tropospheric thickness increase over that observed in the clear areas. In this sense, the clusters may be considered as warm core.

The data 12 and 24 hours before and after the $00 \mathrm{Z}$ observation time show that the surface pressure changes were all less than 2 to 3 
$\mathrm{mb} /$ day despite an ave rage rainfall of $2 \frac{1}{2} \mathrm{~cm} /$ day. It is obvious that the condensation heat from the rainfall $\left(1500 \mathrm{cal} / \mathrm{cm}^{2}-\right.$ day) is not being directly realized in sensible heat increase.

\section{Comparison of Cluster Categories}

Vertical soundings of both dry-bulb and dew-point temperatures were constructed from the composited data for each cloud category. Though not shown here, these soundings were all nearly identical with that shown for the conservative clusters in Fig. 53. There were very little temperature or moisture differences among categories. Although the dynamic characteristics (i.e., cyclonic wind shears) point to differences in the amount of convection, there were no significant static stability differences between clusters. 


\section{SUMMARY DISCUSSION}

The results obtained in this study were all based on analyses of composited data. Some critics argue that composited data are of little value because the averaging process smooths over any nonrecurrent peaks in the original data so that in the final analysis, the most interesting and significant characteristics are lost. Compositing does reduce extremes, but those features which do stand out after compositing are of great interest and can be viewed with confidence. In the present study, the most interesting and significant characteristics are the persistent features which are not destroyed by compositing.

The data have shown that the typical tropical cloud cluster of the Pacific lies in the north-south cyclonic shearing trade flow just north of the Equatorial Trough. Mass continuity is maintained by a two-level model with deep tropospheric inflow and high-level outflow centered at $200 \mathrm{mb}$. Clusters undoubtedly make a major contribution to the general circulation in that there are so many of them and they are such large vertical transporters of mass and momentum. The cluster's large condensation heat release does not go directly into sensible warming but rather into potential energy gain which is realized as heat at a later time and place in compensating subsidence. 
In this sense the energy input of the cluster into the general circulation may be viewed not as a direct but rather as a delayed action influence.

Clusters are associated with a low-level vorticity field characterized much more by shear than by curvature. This lowlevel shear and resulting Ekman-induced convergence is critical in maintaining the cumulus convection. These observations support the contention that CISK is the probable mechanism for producing and maintaining these clusters. An entraining cumulus cloud model is required to understand fully the deep tropospheric convergence into the cluster.

Because of their hypothesized large importance in the general circulation, the precise dynamics of disturbances in the trade winds have been under much recent discussion. The 1969 BOMEX project and future programs, including the planned GARP Tropical Cloud Cluster Experiment, will investigate individual clusters in more detail. Hopefully, individual case studies based on much denser data samples will be possible. However, until observational techniques are advanced further or until these costly GARP programs are implemented, data compositing as accomplished in this study will be a most applicable and necessary method of specifying cluster characteristics. This compositing technique can be used for other studies and in planning future cluster experiments. The approach of this study - using large statistical summaries of satellite and 
conventional radiosonde data in combination - is readily applicable to studies in other regions of the world where, because of typically existing coarse conventional networks, conventional data compositing with satellite pictures as a guide is the only reasonable method of approach. We need many more statistical studies like this which combine satellite and conventional data. 


\section{ACKNOWLEDGEMENTS}

To Professor William M. Gray who proposed this research topic and whose instruction and guidance throughout made this study possible; to Gladys Odle, Janice Lauck, and Marilyn Setnicka for their help in analyzing the data and drafting the figures; to Mr. Ed Buzzell for programming assistance; and to Marsha, my wife, for her willing participation in typing the manuscript.

This research has been sponsored by the National Environmental Satellite Center in Suitland, Maryland with much assistance in data collection by the Naval Weather Research Facility. 


\section{APPENDIX}

\section{Error Analysis}

The results achieved in this statistical analysis are based on mean values derived from composited data. Compositing relative to the cluster centers was necessary because of the coarse data network and the sub-grid-scale size of the clusters. Whenever mean values are used, the sample size and the degree to which the data tend to spread about the mean are important in specifying the representativeness of the mean. Table A1 shows the number of observations in each of the nine central $4^{\circ}$-square boxes for the conservative clusters and for the clear areas. These values represent but a sample size (N) drawn from the near-infinite population of meteorological variables (temperature, relative humidity, $u$ and $v$ wind components, etc.). The values of $\mathrm{N}$ are all large.

Table A1. Number of upper air observations in each of the nine central $4^{\circ}$-square boxes for the conservative clusters and for the clear areas.

Conservative Clusters

\begin{tabular}{|c|c|c|}
\hline 64 & 61 & 70 \\
\hline 117 & 115 & 83 \\
\hline 55 & 44 & 54 \\
\hline
\end{tabular}

Clear Areas

\begin{tabular}{|l|l|l|}
\hline 44 & 45 & 50 \\
\hline 59 & 59 & 52 \\
\hline 62 & 46 & 48 \\
\hline
\end{tabular}


Standard deviations of all the data parameters used in this study were computed for the conservative clusters and for the clear areas. Standard deviations of temperature, relative humidity, and $\mathrm{u}$ and $\mathrm{v}$ wind components at all levels are presented in Fig. A1 for one of the conservative cluster boxes having 83 observations. This sample is representative of all the computed standard deviations.

For the conservative clusters, the standard deviations of divergence and relative vorticity were computed at each pressure level and are presented in Fig. A2. Sixty-eight per cent of the observations should fall within the envelopes surrounding the mean profiles of divergence and relative vorticity. The standard deviations range from $\pm .8\left(\times 10^{-6} \mathrm{sec}^{-1}\right)$ at the surface to \pm 2.5 at $150 \mathrm{mb}$ for divergence, and from \pm .9 at the surface to \pm 3.2 at $150 \mathrm{mb}$ for relative vorticity. The surprisingly small deviations are a result of the large number of observations within each $4^{\circ}$-square box.

To perform this calculation, it was necessary to assume that the samples for different boxes were independent. Because the samples consist of composited data, this is, in general, a good assumption. As discussed by Speigel (1961), the standard deviations for the differences or sums of two independent samples drawn from infinite populations can be expressed by

$$
\sqrt{\frac{\sigma_{1}^{2}}{N_{1}}+\frac{\sigma_{2}^{2}}{N_{2}}}
$$




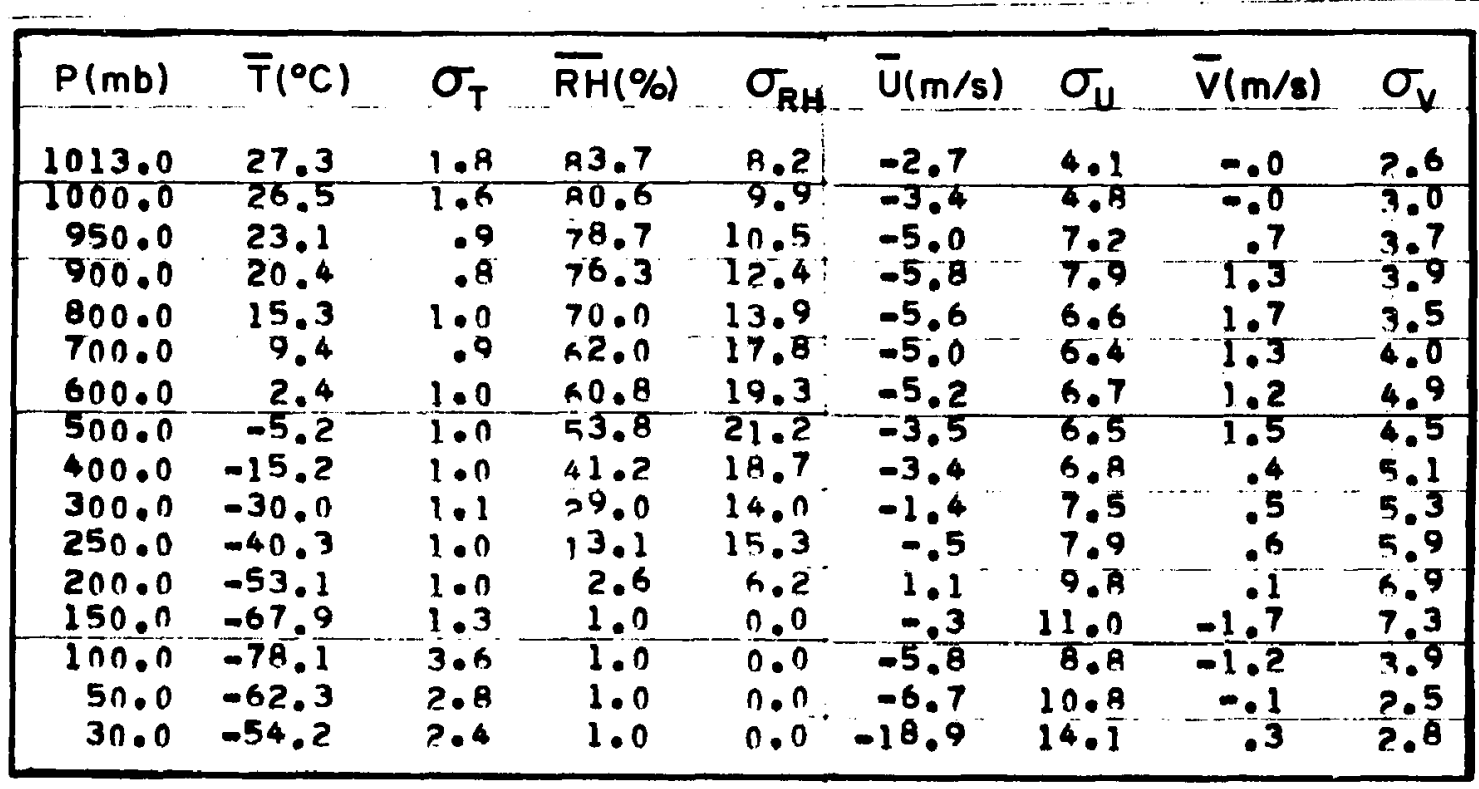

Fig. A1. Representative sample of $4^{\circ}$-square area-averaged means and their standard deviations. $\mathrm{N}=83$ for this sample.

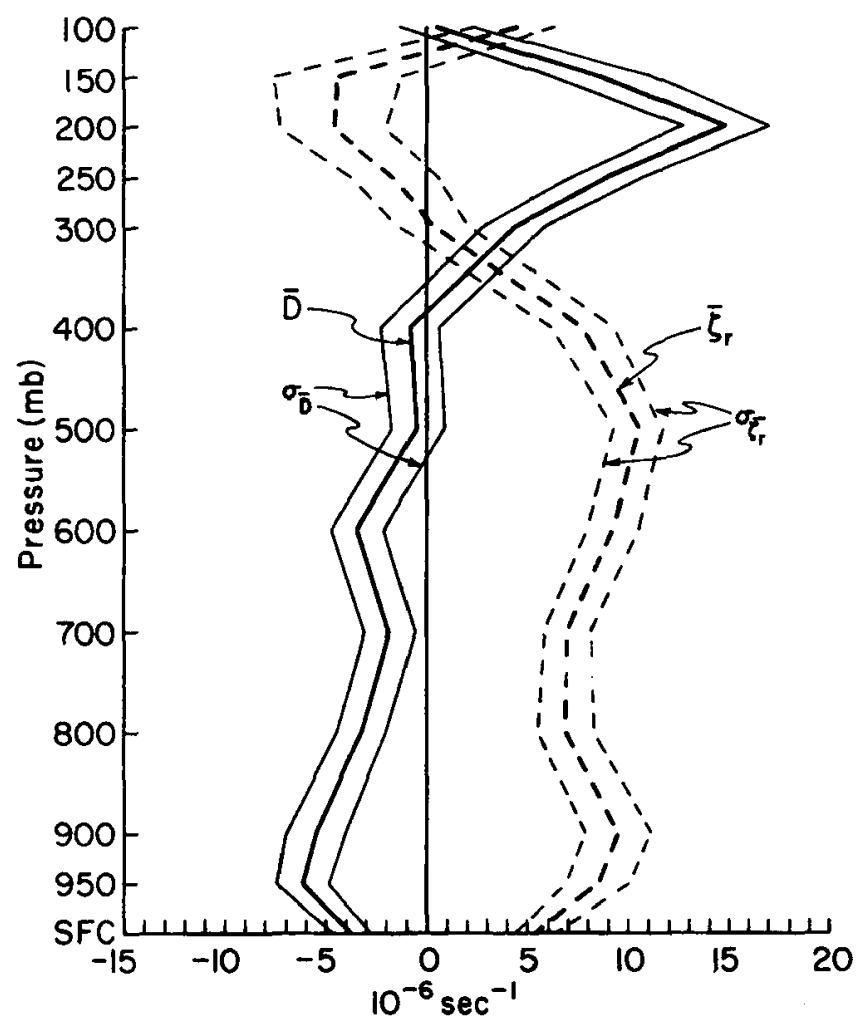

Fig. A2. Vertical profiles of mean divergence and mean relative vorticity and the envelopes of \pm 1 standard deviation for the conservative clusters. $68 \%$ of the observations should be included within these envelopes. 
where $\sigma_{1}, \mathrm{~N}_{1}$ and $\sigma_{2}, \mathrm{~N}_{2}$ are the respective standard deviations and sizes of the two samples. In the particular case of computing the deviations for the profiles of divergence or relative vorticity, the above equation is adapted such that

$$
\sqrt{\frac{\sigma_{\mathrm{n}}^{2}}{\mathrm{~N}_{\mathrm{n}}}+\frac{\sigma_{\mathrm{s}}^{2}}{\mathrm{~N}_{\mathrm{s}}}+\frac{\sigma_{\mathrm{e}}^{2}}{\mathrm{~N}_{\mathrm{e}}}+\frac{\sigma_{\mathrm{w}}^{2}}{\mathrm{~N}_{\mathrm{w}}}}
$$

where the subscripts $n, s, e, w$, denote, respectively, the samples north, south, east, and west of the $4^{\circ}$-square center box for which the divergence or relative vorticity computation is being made.

These small deviations about the mean relative vorticity and divergence profiles lend further confidence to the quantitative reasoning based on the mean vorticity and divergence profiles of Figs. 27 and 37 . 


\section{REFERENCES}

Bohan, W. A., 1968: Tropical Pacific cioud patterns, ESSA digital product, 1967 (WAB 196). $16 \mathrm{~mm}$ \%imis prepared by the Walter A. Bohan Company, Park Ridge, Kiinois.

Chang, C.-P., 1970: Westward propagating cloud patterns in the tropical Pacific as seen from time-composite satellite photographs. J. Atmos. Sci., 27, $133-138$.

Chang, C.-P., V. F. Morris, and J. M. Wallace, 1970: A statistical study of easterly waves in tre western Pacific: JulyDecember 1964. J. Atmos. Sci., 27, 195-20i.

Charney, J. G., 1958: On the formation of tropical depressions. Paper presented at the First Tecinnical Conference on Hurricanes and Tropical Meteorology, Miami, Florida.

Charney, J. G. and A. Eliassen, 1964: On the growth of the hurricane depression. J. Atmos. Sci., 21, 68-75.

Elsberry, R., 1966: On the mechanics and thermodynamics of a low-levei wave on the easteriies. Atmos. Sci. Paper No. 101, Coiorado State Univ., 31 pp.

Fett, R. W., 196̈4: Tiros photograpins and mosiac sequerces of iropical cyciones in the western Pacific during 1962. Meteoroiogical Satellite Lab. Rept. No. 32, U. S. Weather Bureau, National Weather Satelitie Center, Washington, D. C.

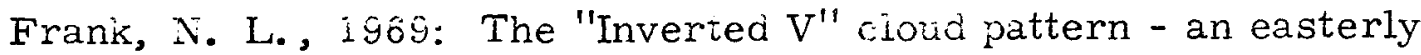
wave? Mor. Wea. Rev., 97, 130-i40.

Frank, N. L., 1970: Atlantic ropical systems of 1969. Mon. Wea. Rev., 98, 307-314.

Frank, N. L., a....... Ni. Johnsor, i969: Vo ical clour systems

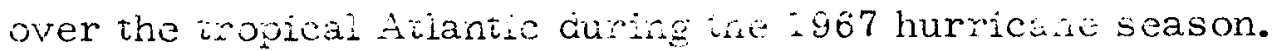
Vicn. Wea. Rev., 97, 124-i2..

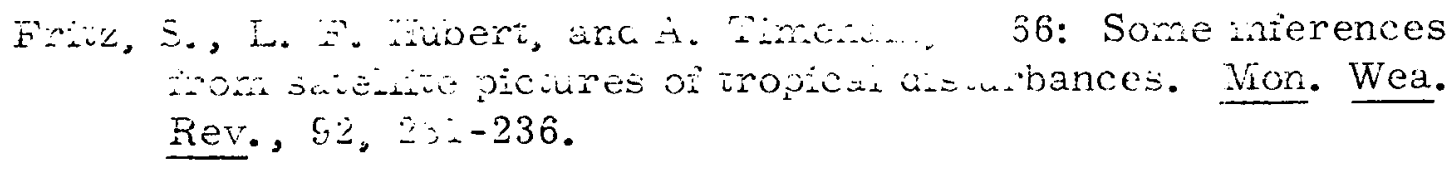


Fujita, T., K. Watanabe, and T. Izawa, 1969: Formation and structure of equatorial anticyclones caused by large-scale cross-equatorial flows determined by ATS-1 photographs. J. Appl. Meteor. , 8, 649-667.

Gangopadhyaya, M., and H. Riehl, 1959: Exchange of heat, moisture, and momentum between hurricane Ella (1958) and its environment. NHRP Report No. 29, $12 \mathrm{pp}$.

GARP report on the first session of the study group on tropical disturbances (Madison, Wis., 21 October - 8 November 1968), Joint GARP Organization Committee, WMO.

Gray, W. M., 1967: The mutual variation of wind, shear, and baroclinicity in the cumulus convective atmosphere of the hurricane. Mon. Wea. Rev. , 95, 55-73.

Gray, W. M., 1968: Global view of the origin of tropical disturbances and storms. Mon. Wea. Rev., 96, 669-700.

Hayden, C. M., 1969: Objective dimensions of Pacific cloud clusters. Paper presented at the 50th Annual Meeting of the American Geophysical Union, Washington, D. C.

Malkus, J. S., and H. RiehI, 1964: Cloud Structure and Distributions over the Tropical Pacific Ocean. Berkeley and

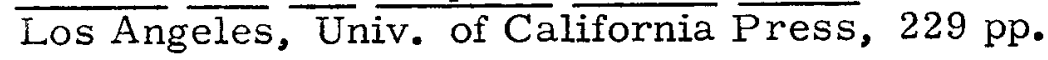

Mendenhall, B., 1967: A statistical study of frictional wind veering in the planetary boundary layer. Atmos. Sci. Paper No. 116, Colorado State Univ. , 57 pp.

Oliver, V. J., and R. K. Anderson, 1969: Circulation in the tropics as revealed by satellite data. Buli. Amer. Meteor. Soc., $50,702-707$.

Paimer, C. E., 1952: Tropical Meteorology. Quart. J. Roy. Meteor. Soc., 78, 126-164.

Riehi, Fi., 1945: Waves in the easterlies and the polar front in the iropics. Depi. oi Meteorology, Univ. of Chicago, Misc. Rept. 17, 79 pp.

Ṙen. ‥, 1954: Tropicai Meteorology. New York, McGraw-Hill, 392 pp. 
Rieh1, H., and J. S. Malkus, 1958: On the heat balance in the equatorial trough zone. Geophysica, 6, 503-538.

Riehl, H., and J. S. Malkus, 1961: Some aspects of hurricane Daisy, 1958. Tellus, 13, 181-213.

Sadler, J. C., 1962: Utilization of meteorological satellite cloud data in tropical meteorology. Proceedings of the First International Symposium on Rocket and Satellite Meteorology, Washington, D. C.

Sadler, J. C., 1966: The easterly wave - the biggest hoax in tropical meteorology. Paper presented at the seminar at the National Center for Atmospheric Research, Boulder, Colorado, August 8-12.

Simpson, J., M. Garstang, E. J. Zipser, and G. A. Dean, 1967: A study of a non-deepening tropical disturbance. J. Appl. Meteor., 6, 237-254.

Simpson, J., and V. Wiggert, 1969: Models of precipitating cumulus towers. Mon. Wea. Rev., 97, 471-489.

Simpson, R. H., N. Frank, D. Shideler, and H. M. Johnson, 1968: Atlantic tropical disturbances, 1967. Mon. Wea. Rev., 96, $251-259$.

Simpson, R. H., N. Frank, D. Shideler, H. M. Johnson, 1969: Atlantic tropical disturbances of 1968. Mon. Wea. Rev., $97,240-255$.

Spiegel, M. R., 1961: Theory and Problems of Statistics. New York, Schaum Pubiishing Co., 359 pp.

Wallace, J. M., and C. -P. Chang, 1969: Spectrum analysis of large-scale wave disturbances in the tropical lower troposphere. J. Atmos. Sci., 26, 1010-1025.

Weinstein, A. ..., and L. G. Davis, 1968: A parameterized numerical model of cumulus convection. Rept. No. 11 to NSF, Pennsylvania State Univ., $44 \mathrm{pp}$.

Yanai, M., 196i: $\therefore$ detailed analysis of typhoon formation. J. Met. Soc. japan, Ser. II, 39, 187-214. 
Yanai, M., 1963: A preliminary survey of large-scale disturbances over the tropical Pacific region. Proceedings of the III Technical Conference on Hurricanes and Tropical Meteorology, Mexico City.

Zipser, E. J., 1969: The role of organized unsaturated convective downdrafts in the structure and rapid decay of an equatorial disturbance. J. Appl. Meteor., 8, 799-814. 
Author: Kiwax T. Williams

A STATISTKAL ANALYSIS OF SATELLITEORSBRT BHADE WINT CLOLP CLUSTER

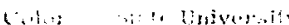

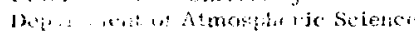

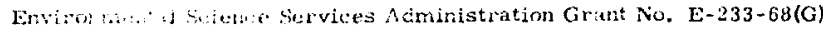

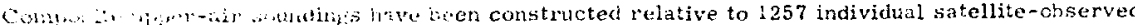

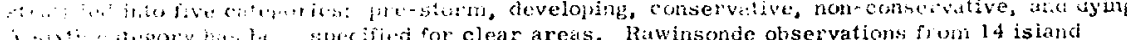

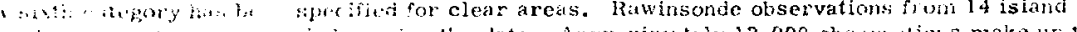

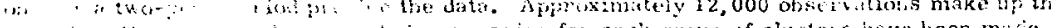

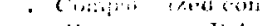

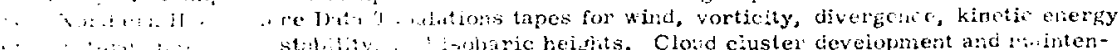

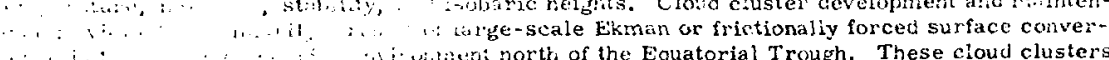
i. $\quad \therefore$ cistculy tracic wave only if the latt. $r$ is primarily interpreted

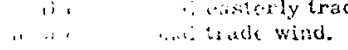

Author: Knox T. Williams

A STATISTICAL ANALYSIS OF SATELLITEOBSETTED TRADE WIND CLOT D CLLSTER

531.515 .51

IN THE WESTERN NORTH PACIFIC

Subject Headings:

Tropical Cloud Cluster

Tropical Disturbances

Colorudo State University

Dejartment of Atmospheric Science

Environmental Science Services Administration Grant No, E-233-68(G)

Composite upper-air soundings have been constructed relative to 1257 individual satellite-observed mesuscale trade wind cloud i:Lusters in the westem tropical North Pacific. Clusters have been stritified into five categories: pre-storm, developing, conservative, non-conservative, and tying A sixti: category has been specified for clear areas. Rawinsonde observations from 14 island stitisns for a tu's-year period provide the data. Apgroximately 12,000 observations make up the duta sample. Computerized compisited summaries for each group of clusters have been made from Nurthern Hemisphere Data Tabulations tapes for wind, vorticity, divergence, kinetic energy, ance is gerice in the cyclenic shearing envirominent north of the

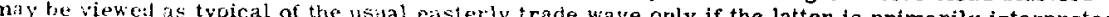
as a shearing phenomena of the zonal trade wind.

\section{Autnor: knox T, Williams}

A STATISTICAL ANALYSIS OF SATELLITEOBSERVED TRADE WIND CLOLD CILOTTERS

Coloracio State Cniversity

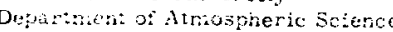

Environmentai Scierice Services Administration Grant No. E-233-68(G)

Composite upper-air soundings have been constructed relative to 1257 individual satellite-observed mesoscale trade wind cloud clusters in the western tropical Nortin Pacific. Clusters have been siratifec into five categories: pre-storm, developing, conservative, non-conservative, and dying. A sixth category has been specified for clear areas. Rawinsonde observations from 14 island data from sorthern temishere Dats Thuted summaries for each group of clusters have been made temperature, moisture, stability ans isobaric heights Cl vor cluster development and menergy. ance is vië ad as primarily a resuit of large-scale Eikman or frictionally forced surface convergerce ir. the cyclonic shearing ervirorment north of ti:c Equatorial Trough, These cloud clusters may be viewed as iypicai of the usurui easteriy trace wave only if the latter is primarily interpreted a stearing pheromena of the zonai trade wind.
Subject Headings: Tropical Disturbances Tropical Circulation

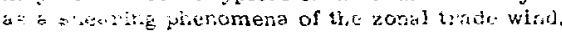

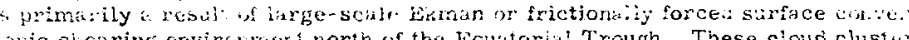

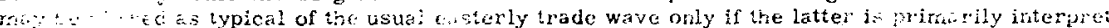

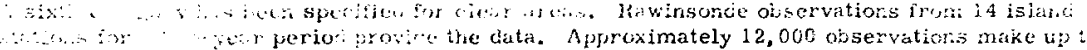

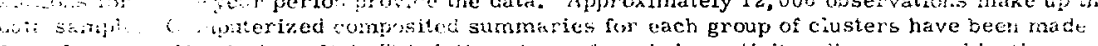

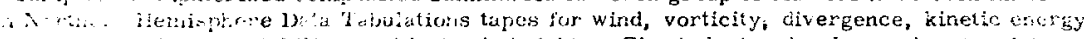

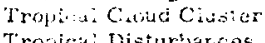

$$
\begin{aligned}
& \text { Tropled Disturbarces }
\end{aligned}
$$$$
\text { i. }
$$$$
\text { (n) }
$$ 